\title{
AN EXAMINATION OF THE APPLICABILITY OF SOCIAL COGNITIVE CAREER THEORY FOR AFRICAN AMERICAN COLLEGE STUDENTS
}

\author{
A Dissertation \\ Presented to \\ The Graduate Faculty of the University of Akron \\ In Partial Fulfillment \\ of the Requirements for the Degree \\ Doctor of Philosophy
}

Josephine Dickinson, M.A.

August, 2007 


\title{
AN EXAMINATION OF THE APPLICABILITY OF SOCIAL COGNITIVE CAREER THEORY FOR AFRICAN AMERICAN COLLEGE STUDENTS
}

\author{
Josephine Dickinson, M.A.
}

\section{Dissertation}

Approved:

Advisor

Dr. David M. Tokar

Committee Member

Dr. Linda Mezydlo Subich

Committee Member

Dr. Susan I. Hardin

Committee Member

Dr. John E. Queener

Committee Member

Dr. Sandra L. Perosa
Accepted:

Department Chair

Dr. Paul E. Levy

Dean of the College

Dr. Ronald F. Levant

Dean of the Graduate School

Dr. George R. Newkome

Date 


\begin{abstract}
Lent, Brown, and Hackett's (1994) social cognitive career theory (SCCT) is a theoretical model of career development that delineates how person, contextual, and sociocognitive factors affect the formation of vocational interests, career choice goals, career choice actions, and academic/career performance attainments. Although considerable research support has been demonstrated for several key paths in SCCT, several other areas of SCCT have been under-researched or have received mixed empirical support. The purpose of the present study was to address several limitations of the extant literature. Specifically, the present study examined (a) the applicability of SCCT with an African American sample, (b) the validity of SCCT across Holland's (1997) six vocational domains, (c) the role of specific learning experiences in the formation of corresponding self-efficacy and outcome expectations, and (d) the moderating role of perceptions of racism in the relationship between vocational interests and corresponding choice goals.

Results of path analyses based on a sample of 208 African American college students revealed strong support for all of the hypothesized relations involving corresponding learning experiences, self-efficacy beliefs, outcome expectations, vocational interests and choice goals for each of the six Holland themes. Furthermore, although the nature of some of the observed relations (i.e., direct vs. indirect) was not always supportive of my hypotheses, overall, the results indicated that SCCT is a valid
\end{abstract}


model to use with African Americans. In addition, the results revealed strong support for the applicability of SCCT to Holland's (1997) RIASEC themes. Regarding the role of specific learning experiences in self-efficacy and outcome expectations, results revealed partial support for both my hypothesis that verbal persuasion would contribute most strongly and SCCT's prediction that performance accomplishments would account for the majority of the unique variance. These findings suggest that for African American college students, the role that learning experiences play in the formation of their selfefficacy beliefs and outcome expectations is domain-specific. Finally, results of moderated regressions and follow-up analyses tended not to support the hypothesis that perceptions of racism would moderate the relationship between vocational interests and choice goals. The results revealed that perceptions of racism significantly moderated the interests-goals relation in only one model--the Realistic model for men--and, contrary to prediction, a greater perception of racism actually strengthened the Realistic interestschoice goals relationship. 


\title{
TABLE OF CONTENTS
}

\begin{abstract}
Page

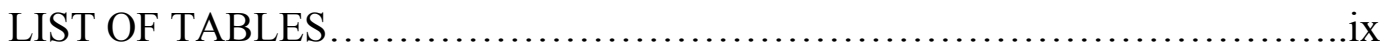

LIST OF FIGURES............................................................

CHAPTER
\end{abstract}

I. STATEMENT OF THE PROBLEM..........................................

Social Cognitive Career Theory .........................................

Research on SCCT ....................................................

Limitations of Extant SCCT Research................................. 4

Paucity of SCCT Research with African Americans..................4

Focus on Math and Science.......................................6

The Paucity of Research on the Role of Experiential Sources of Self-efficacy and Outcome Beliefs............................. 7

The Dearth of Research Examining the Role of Proximal Contextual Factors in SCCT ....................................10

Summary of Limitations.......................................11

Purpose of the Present Research..........................................12

II. LITERATURE REVIEW ....................................................

Social Cognitive Career Theory .......................................... 14

Description of Social Cognitive Career Theory ......................14

Model of Interest Development..................................14 
Model of Career Choice......................................... 18

Model of Performance............................................20

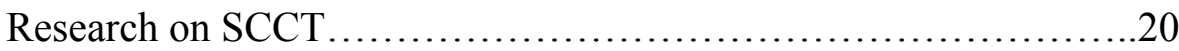

Research Primarily Examining SCCT's Interest Model..............21

Summary of the Extant Research Primarily Focusing on

SCCT's Interest Model............................................... 32

Research Primarily Examining SCCT's Choice Model................33

Summary of the Research Examining SCCT's Choice Model..........54

Research Primarily Examining SCCT's Performance Model..........55

Summary of the Research Examining SCCT's Interest, Choice and Performance Models........................................59

Limitations of SCCT Research.......................................60

Paucity of Research Examining SCCT with African Americans......60

Focus on Math and Science-Related Activities......................62

Paucity of Research on the Experiential Sources of Self-Efficacy and Outcome Beliefs............................................63

The Dearth of Research Examining the Role of Proximal Contextual Factors in SCCT.......................................69

Summary of Limitations..........................................73

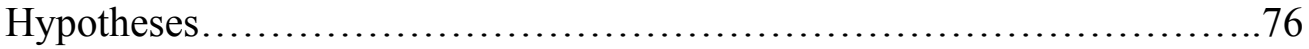

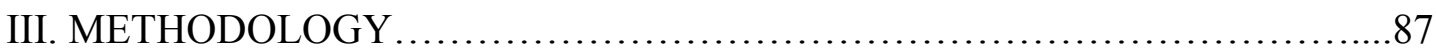

Participants and Procedure ................................................... 87

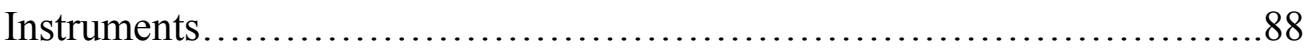

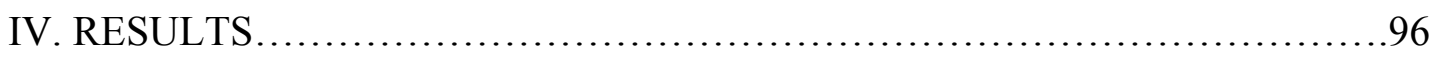

Descriptive Statistics and Internal Consistency Estimates of the Measures...96 
Correlations

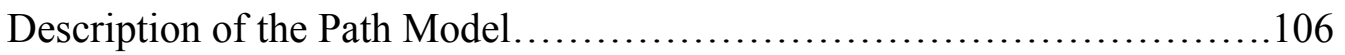

Structural Invariance by Gender...................................107

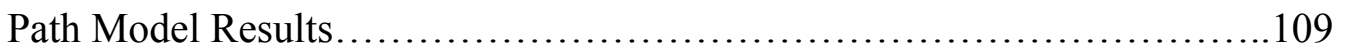

Results of the Regression Analyses Predicting Self-Efficacy and Outcome

Expectations from Learning Experiences.............................. 119

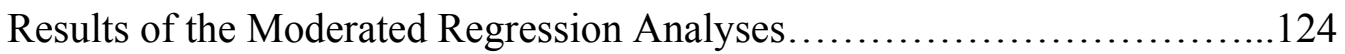

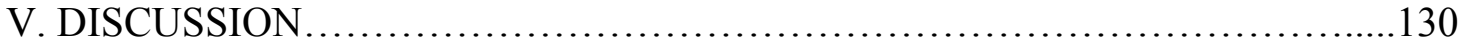

Major Findings of the Present Study .................................131

The Applicability of SCCT for African Americans using Holland's RIASEC Themes..........................................131

The Role of Learning Experiences in SCCT.......................135

The Moderating Role of Racism..............................138

Implications for Counseling..................................... 141

Limitations and Implications for Future Research.......................143

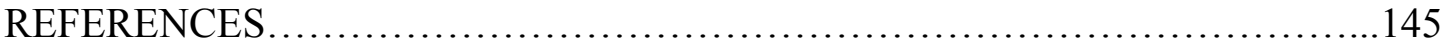

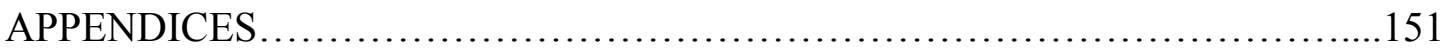

APPENDIX A. DEMOGRAHIC QUESTIONNAIRE....................... 152

APPENDIX B. LEARNING EXPERIENCES QUESTIONNAIRE...............154

APPENDIX C. SELF-EFFICACY MEASURE........................... 162

APPENDIX D. OUTCOME EXPECTATIONS MEASURE $\ldots \ldots \ldots \ldots \ldots \ldots \ldots \ldots . . . . .166$

APPENDIX E. VOCATIONAL INTERESTS MEASURE.................... 170

APPENDIX F. CHOICE GOALS MEASURE $\ldots \ldots \ldots \ldots \ldots \ldots \ldots \ldots \ldots \ldots \ldots \ldots . \ldots \ldots \ldots$ 
APPENDIX G. SCHEDULE OF RACIST EVENTS

APPENDIX H. TABLE 20. CORRELATIONS AMONG PERFORMANCE ACCOMPLISHMENTS, VICARIOUS LEARNING, VERBAL PERSUASION, EMOTIONAL AROUSAL, AND SELF-EFFICACY FOR ALL SIX RIASEC

THEMES

APPENDIX I. TABLE 21. CORRELATIONS AMONG PERFORMANCE ACCOMPLISHMENTS, VICARIOUS LEARNING, VERBAL PERSUASION, EMOTIONAL AROUSAL, AND OUTCOME EXPECTATIONS FOR ALL SIX

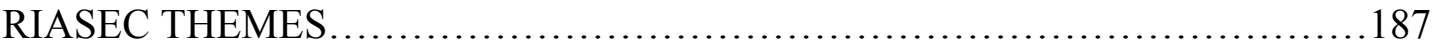

APPENDIX J. IRB APPROVAL LETTERS.......................................192 


\section{LIST OF TABLES}

Table

Page

1. Descriptive Statistics and Internal Consistency Estimates for the LEQ, the Measure of Self-Efficacy, the OOE, the Measure of Interests, the Measure of Choice Goals, and the SRE.

2. Correlations Among Realistic Sociocognitive Variables, Realistic Interests, and Realistic Choice Goals

3. Correlations Among Investigative Sociocognitive Variables, Investigative Interests, and Investigative Choice Goals.

4. Correlations Among Artistic Sociocognitive Variables, Artistic Interests, and Artistic Choice Goals

5. Correlations Among Social Sociocognitive Variables, Social Interests, and Social Choice Goals

6. Correlations Among Enterprising Sociocognitive Variables, Enterprising Interests, and Enterprising Choice Goals.

7. Correlations Among Conventional Sociocognitive Variables, Conventional Interests, and Conventional Choice Goals.

8. Tests of Structural Invariance for RIASEC Path Models

9. Standardized Path Coefficients and Fit Statistics for the Six RIASEC Models

10. Summary of the Total Effects, Broken Down by Total Indirect Effects and Direct Effects for Hypothesized Paths for the Realistic Model for Women.

11. Summary of the Total Effects, Broken Down by Total Indirect Effects and Direct Effects for Hypothesized Paths for the Realistic Model for Men.

12. Summary of the Total Effects, Broken Down by Total Indirect Effects and Direct Effects for Hypothesized Paths for the Investigative Model. 
13. Summary of the Total Effects, Broken Down by Total Indirect Effects and Direct Effects for Hypothesized Paths for the Artistic Model.

14. Summary of the Total Effects, Broken Down by Total Indirect Effects and Direct Effects for Hypothesized Paths for the Social Model

15. Summary of the Total Effects, Broken Down by Total Indirect Effects and Direct Effects for Hypothesized Paths for the Enterprising Model.

16. Summary of the Total Effects, Broken Down by Total Indirect Effects and Direct Effects for Hypothesized Paths for the Conventional Model.

17. Simultaneous Regression Analyses Predicting Self-Efficacy from Learning Experiences

18. Simultaneous Regression Analyses Predicting Outcome Expectations from Learning Experiences.

19. Summary of Moderated Regression Analyses.

20. Correlations Among Performance Accomplishments, Vicarious Learning, Verbal Persuasion, Emotional Arousal, and Self-Efficacy for all Six RIASEC Themes

21. Correlations Among Performance Accomplishments, Vicarious Learning, Verbal Persuasion, Emotional Arousal, and Outcome Expectations for all Six RIASEC themes. 


\section{LIST OF FIGURES}

$\begin{array}{lll}\text { Figure } & \text { Page }\end{array}$

1. Social Cognitive Career Theory .............................................

2. SCCT Structural Model for the Path Analyses................................... 107 


\section{CHAPTER I}

\section{STATEMENT OF THE PROBLEM}

\section{Social Cognitive Career Theory}

Social Cognitive Career Theory (SCCT; Lent, Brown, \& Hackett, 1994) represents a comprehensive theoretical model for understanding the complex relationships among person, contextual, and sociocognitive factors and their relationships to vocational interests, career choice goals, choice actions, and performance attainments. As depicted in Figure 1, SCCT posits that person inputs (e.g., race/ethnicity) and background contextual affordances (e.g., gender role socialization) contribute to occupationally relevant self-efficacy beliefs and outcome expectations by influencing occupationally relevant learning experiences (i.e., personal performance accomplishments, vicarious learning, verbal persuasion, and physiological states). Self-efficacy beliefs and outcome expectations then contribute to the formation of vocational interests, which subsequently influence vocational choice goals, choice actions, and performance attainments. In addition, proximal contextual factors (e.g., opportunity structure, perceived barriers) are posited to influence the development of career choice goals and choice actions. Several additional assumptions of SCCT are central to the present study. Lent et al. (1994) 
posited that of the four learning experiences, personal performance accomplishments would account for more variance in self-efficacy and outcome expectations than

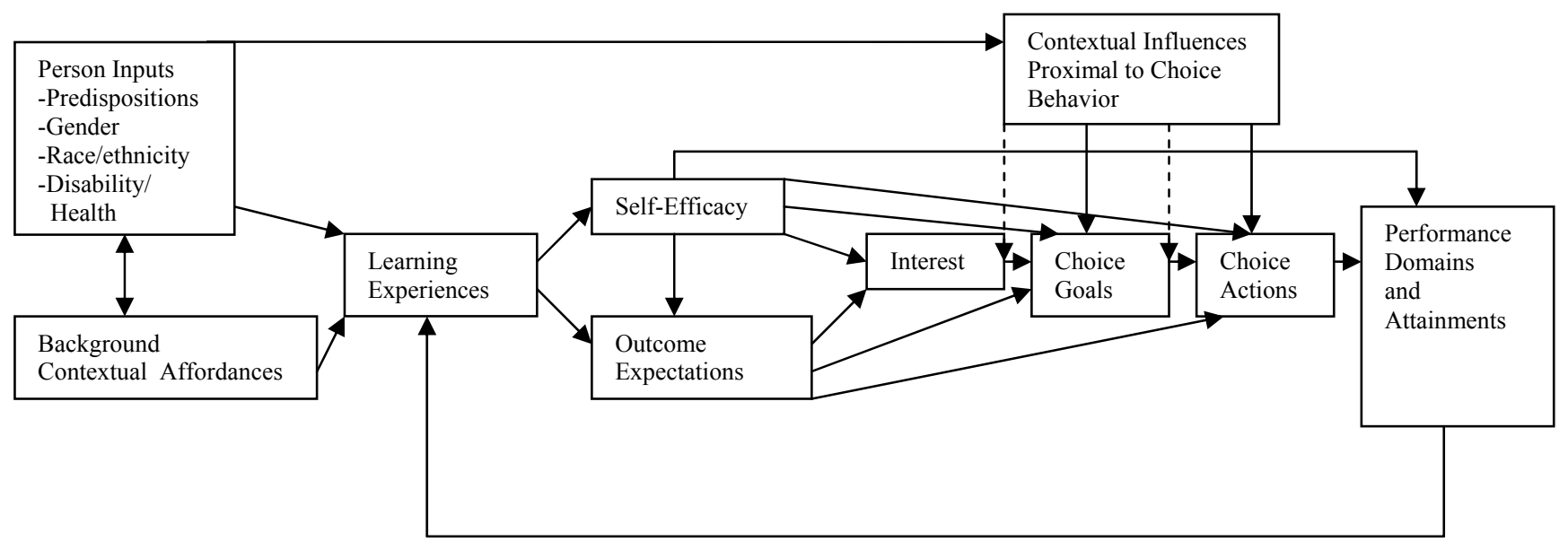

Figure 1. Model of person, contextual, and experiential factors affecting career-related choice behavior. Copyright by R.W. Lent, S.D. Brown, and G. Hackett. Reprinted by permission.

vicarious learning, verbal persuasion, and physiological states. Lent et al. (1994) also posited that, in addition to their direct effect on choice goals and choice actions, proximal contextual factors may moderate the relationships between interests and choice goals and between choice goals and choice actions. For example, the relationship between interests and choice goals should be stronger when perceived barriers (e.g., discrimination) are relatively low and perceived opportunities and supports are relatively high. 


\section{Research on SCCT}

SCCT has generated a large amount of research testing various aspects of the model. Given SCCT's complexity and comprehensiveness, all of the published research reviewed herein has examined only a portion of the model (e.g., various paths involving precursors of vocational interests). When analyses have been performed to compare the fit of the obtained data to the corresponding portion of the model tested, results generally have indicated good overall model-data fits (e.g., Gainor \& Lent, 1998; Lent, et al., 2003; Lent, et al., 2005; Schaub \& Tokar, 2005), with a few notable exceptions (e.g., Fouad \& Smith, 1996). When researchers have turned their focus to specific paths posited in SCCT, the most consistent empirical support has been demonstrated for the positive relation of self-efficacy to outcome expectations and for positive relations of both selfefficacy and outcome expectations to corresponding vocational interests (e.g., Bishop \& Bieschke, 1998; Fouad \& Smith, 1996; Gainor \& Lent, 1998; Lapan, Shaughnessy, \& Boggs, 1996; Lent, Brown, Nota, \& Soresi, 2003; Lent, et al., 2003; Lent, et al., 2005; Lopez, Lent, Brown, \& Gore, 1997; Schaub \& Tokar, 2005; Turner, Steward, \& Lapan, 2004).

Consistent, albeit less, support has also been found for other posited SCCT paths, including the positive relations of vocational interests to choice goals and choice behaviors (e.g., Gainor \& Lent, 1998; Fouad \& Smith, 1996; Lapan, Shaughnessy, \& Boggs, 1996; Lent, Brown, Nota, \& Soresi, 2003; Lent, et al., 2003; Lent, et al., 2005; Lopez, Lent, Brown, \& Gore, 1997) and positive relations between proximal contextual factors and choice goals (e.g., Lent, Brown Nota, \& Soresi, 2003; Lent, et al., 2005). 


\section{Limitations of Extant SCCT Research}

Although considerable research support has been demonstrated for several key paths in SCCT, several other important paths of the model either have received mixed empirical support or have received limited research attention. For example, relatively little research has examined SCCT's hypotheses regarding the role of learning experiences and contextual affordances/barriers (particularly the potential moderating role of proximal contextual factors in the interests-choice goals/actions relations). Further, most of the SCCT research has focused exclusively on math-science career domains and has been conducted using primarily White samples. In an effort to extend the empirical research base on SCCT, the primary purpose of this dissertation is to further current understanding of the role of learning experiences and proximal contextual affordances/barriers in SCCT using an African American college student sample and measuring SCCT constructs for each of Holland's (1997) RIASEC themes. In the sections that follow, I will discuss in greater detail the aforementioned limitations of the extant SCCT research and how this dissertation will improve upon each.

\section{Paucity of SCCT Research with African Americans}

Lent et al. (1994) stated that SCCT may be a particularly good framework for studying the career development of racial/ethnic minority groups, given that factors potentially important to racial/ethnic minorities' career development, such as the experience of racism and discrimination, can be accounted for in the model. Further, because SCCT takes into consideration the interactional role of the person (including sex and race/ethnicity) and the environment (e.g., structural barriers and supports) in shaping career relevant behavior, the model allows for a more complex examination of career 
development than other theories. Thus, SCCT could be an ideal framework for more comprehensively examining the career development process of racial/ethnic minorities.

Despite suggestions that SCCT holds promise for understanding minority career development, there has been a relative paucity of research on SCCT using African Americans, and the evidence to date has revealed mixed support. For example, Fouad and Smith (1996) tested a portion of SCCT by examining the relationships among selfefficacy for math and science, outcome expectations for math and science, interest in math and science, intentions to take math/science classes, and intentions to pursue math and science-related careers in a sample of 380 ethnically diverse middle school students. Results of this study revealed a less than adequate model-data fit for their sample of African Americans (the adjusted goodness-of-fit index [AGFI] was .88), which differed markedly from the model-data fits found for Caucasians (AGFI $=.97)$ and Hispanics $(\mathrm{AGFI}=.96)$.

Gainor and Lent (1998) examined the relationships among several constructs in SCCT's career choice model using a sample of 164 African-American college students. Consistent with SCCT, the authors hypothesized that of the four learning experiences, personal performance accomplishments would comprise the largest amount of variance in and produce unique paths to self-efficacy and outcome expectations. However, contrary to the authors' hypotheses, performance accomplishments did not comprise the largest amount of variance in self-efficacy and only verbal persuasion produced a significant unique path to outcome expectations.

In addition, the few studies (e.g., Fouad \& Smith, 1996; Gainor \& Lent, 1998; Lent et al., 2005) that included African Americans as part of the sample only examined SCCT 
relationships for the domains of math and science, leaving the application of SCCT with other career-related domains with African Americans unknown. Given that African Americans remain underrepresented in the SCCT literature, results of research on the applicability of SCCT for African Americans have been mixed, and studies that have included African Americans have only examined SCCT constructs for the domains of math and science, it is vital that additional research examine the applicability of SCCT for African Americans. One focus of the present research, then, is to examine the applicability of SCCT with a sample comprised of African Americans.

\section{Focus on Math and Science}

A review of the literature revealed that only two published studies (Lent et al., 2003; Schaub \& Tokar, 2005) examined SCCT constructs using model testing procedures for domains other than math and science. Smith and Fouad (1999) asserted that, "it is particularly critical to examine domain areas other than math and science if the social cognitive career model is to be applied generally across occupational areas" (p. 462). One possible framework for examining domains other than math and science is Holland's (1997) RIASEC typology. Holland's theory of vocational choice is based on the personality/interest pattern of the individual and the work environment. This model has been conceptualized in terms of RIASEC, an acronym for the interest types and occupational categories of Realistic, Investigative, Artistic, Social, Enterprising, and Conventional. A combination of these six interest types describes an individual's vocational interest pattern in an attempt to match the individual's interests and personality with the predominant interest/personality of a given work environment (Spokane, 1996). Betz, Harmon, and Borgen (1996) asserted that, "given the centrality of 
the RIASEC typology to our conceptualization of vocational interests, testing of the social cognitive theory using the RIASEC types is an obvious, needed step" (p. 90).

Lending credence to the idea that Holland's (1997) RIASEC themes may be useful for examining SCCT for domains other than math and science, Lent et al. (2003) and Schaub and Tokar (2005) both found strong support for many of SCCT's hypothesized paths using measures of SCCT constructs for Holland's RIASEC types. For example, both studies found that, across most Holland themes, self-efficacy had a direct positive relationship with outcome expectations; self-efficacy and outcome expectations had direct positive relationships with interests; and self-efficacy had an indirect relationship (via outcome expectations) to interests.

Although preliminary evidence supports the investigation of SCCT using Holland's RIASEC types, additional research on SCCT needs to be conducted using the RIASEC typology to provide additional evidence of SCCT's utility across a broad range of important occupational areas. Thus, another purpose of the present study is to test several hypothesized paths between SCCT constructs for each of Holland's RIASEC themes.

The Paucity of Research on the Role of Experiential Sources of Self-efficacy and Outcome Beliefs

According to Lent et al. (1994), the most important mechanisms in SCCT are the sociocognitive factors of self-efficacy and outcome expectations. Learning experiences are considered to be the precursors to these sociocognitive mechanisms, and, as such, help shape the formation of an individual's self-efficacy beliefs and outcome expectations. Despite their hypothesized importance, a review of the published literature revealed that only three studies included a measure of learning experiences in their 
examination of SCCT (i.e., Gainor \& Lent, 1998; Lopez, et al., 1997; Schaub \& Tokar, 2005), and only one (Schaub \& Tokar, 2005) examined learning experiences for domains other than math and science.

Results of Gainor and Lent (1998) and Lopez et al. (1997), both of which measured SCCT constructs for math/science domains, provided mixed support for Lent et al.'s (1994) proposition that learning experiences contribute to the formation of self-efficacy beliefs and outcome expectations. Specifically, Lopez et al. (1997) found that selfefficacy was uniquely predicted by personal performance accomplishments and social persuasion, whereas Gainor and Lent (1998) found that self-efficacy was uniquely predicted by social persuasion and physiological arousal. In addition, Gainor and Lent (1998) found that only verbal persuasion uniquely predicted outcome expectations. Finally, both studies failed to support SCCT's hypothesis that personal performance accomplishments would be the strongest unique predictor (among learning experiences) of self-efficacy and outcome expectations.

Recall that Gainor and Lent (1998) examined SCCT constructs with a sample of African American college students. While their study provides some initial support for the applicability of SCCT for African Americans, some of their results-particularly those bearing on the role of learning experiences in self-efficacy and outcome expectationswere not consistent with prediction (as previously mentioned), leaving unclear how career relevant learning experiences inform corresponding self-efficacy beliefs and outcome expectations for African Americans.

Further, both of the aforementioned studies (Gainor \& Lent, 1998; Lopez et al., 1997) only examined SCCT constructs for the domains of math and science. Thus, it is 
unclear how learning experiences relate to self-efficacy and outcome expectations for career domains other than math and science.

In a study that did examine SCCT constructs for domains other than math and science (i.e., RIASEC themes), Schaub and Tokar (2005) found strong positive relationships of learning experiences to self-efficacy and outcome expectations, with the relationship of learning experiences to outcome expectations being largely mediated by self-efficacy. These results support several key hypotheses proposed by Lent et al. (1994). However, Schaub and Tokar's (2005) findings are somewhat limited by the fact that they measured learning experiences globally, and, as such, the unique contribution of each individual learning experience to corresponding self-efficacy and outcome expectations is unknown. In addition, their sample consisted of upper-middle class, European-American students. Thus, the applicability of SCCT (including hypothesized paths involving learning experiences) for other groups (such as African Americans) with domains other than math and science is also not known.

Examining the individual role of each learning experience in the formation of selfefficacy and outcome expectations may be of particular importance for African Americans given that African Americans may have different and/or more difficult learning experiences (Hackett \& Byars, 1996) than White individuals. In a conceptual article, Hackett and Byars (1996) specifically detailed how each of the four learning experiences may uniquely affect African Americans' educational and vocational selfefficacy beliefs and outcome expectations. For example, the authors surmised that given African Americans' perceptions of racism in the academic and work environment, they may experience heightened and negative physiological states (e.g., anxiety, distrust), 
which may make it difficult for them to develop high self-efficacy and positive outcome expectations for particular academic and occupational activities.

Overall, it is unclear from the extant empirical research exactly how each of the learning experiences contributes to self-efficacy and outcome expectations in SCCT for domains other than math and science with African American students. As such, future tests of SCCT with African Americans should examine each of the four learning experiences across a range of career-related activities in order to explore more fully their relations to corresponding self-efficacy beliefs and outcome expectations.

The Dearth of Research Examining the Role of Proximal Contextual Factors in SCCT

Proximal contextual influences are conceptualized in SCCT as those environmental factors (e.g., barriers and supports) that are important during active phases of vocational or educational decision making. Recall that, according to SCCT, proximal contextual influences may moderate the relation between interests and choice goals, moderate the relation between choice goals and actions, and/or have a direct relationship with choice goals and/or choice actions. Of particular importance to the present study is the posited moderating role of proximal contextual influences in the relationship between career/educational interests and choice goals. Lent et al. (1994) hypothesized that the presence of more barriers and less supports would hinder an individual from translating his/her interests into choice goals. The inverse was also hypothesized; that is, the presence of more supports and fewer barriers would facilitate the translation of one's interests into choice goals.

To date, only one empirical study has examined the proposed moderating role of proximal contextual affordances in SCCT. Lent et al. (2001) compared the correlations 
of interests to choice goals among mostly White college students in high- and low-barrier and high- and low- support environments. The results indicated that the moderator hypothesis was only partially supported. Specifically, interests were related more strongly to choice goals in the low-barrier environment, but not in the high-support environment.

The proposed moderating role of proximal contextual affordances may be of particular importance to African Americans given that research (e.g., Luzzo, 2001) has demonstrated that African Americans experience more academic barriers and less academic support, which may make it particularly difficult for them to translate their interests into goals. In addition, research (e.g., Landrine \& Klonoff, 1996) has demonstrated that African Americans perceive a high rate of racism throughout the course of their lives. Thus, one such barrier that may make it difficult for African Americans to translate their interests into goals is the perception of racism in the environment. Further understanding of how racism affects the nature of the relationship between interests and choice goals is important for the development of interventions aimed at enhancing African Americans' career development. As such, the present study will examine how one proximal contextual factor (i.e., perceptions of racism) affects the translation of interests into choice goals with an African American sample.

\section{Summary of Limitations}

A review of the literature revealed at least three major limitations of the research on SCCT. First, there is little research on the applicability of SCCT for African Americans, despite the assertion that SCCT may be an ideal model for examining the career-relevant behavior of African Americans. Second, a large portion of the research has examined 
SCCT constructs for the domains of math and science, leaving the applicability of SCCT for domains other than math and science in question. Third, the role of two important SCCT constructs, learning experiences and proximal contextual affordances/barriers, has not been adequately examined. Thus, it is unclear how each learning experience relates to self-efficacy and outcome expectations and how perceptions of racism affect the relationship between vocational interests and choice goals.

Purpose of the Present Research

The purpose of this study is to further scholars' knowledge of the applicability and potential utility of SCCT by addressing the limitations of extant SCCT research mentioned above. First, the present study will use a sample of African-American college students to test how applicable certain SCCT relationships are for this particular underrepresented group. Second, the applicability of SCCT across a range of careerrelated activities will be examined by testing the relations of learning experiences, selfefficacy, outcome expectations, vocational interests, and choice goals across Holland's (1997) six RIASEC types. Third, the present study will examine how each of the four learning experiences relates to self-efficacy and outcome expectations. Finally, the posited moderating role of racism will be examined in the relationship between interests and choice goals. 


\section{CHAPTER II}

\section{LITERATURE REVIEW}

The purpose of this chapter is to (a) describe Lent et al.'s SCCT and the corresponding model, (b) review extant SCCT research, (c) discuss limitations of SCCT research, and (d) develop hypotheses for the current research.

I begin by examining Lent et al.'s (1994) SCCT, focusing on how the theory led to the development of the SCCT model. A comprehensive review of the empirical and theoretical writings which SCCT generated follows the discussion of the theory. Finally, I discuss limitations of the extant SCCT research and present hypotheses for the current research. 


\section{Social Cognitive Career Theory}

The following section will provide a description of Social Cognitive Career Theory (SCCT; Lent, Brown, \& Hackett, 1994). The focus will be on describing each of the three SCCT models proposed by Lent et al. (1994) - the model of interest development, the model of career choice, and the model of performance- as well as defining and describing the relevant constructs within each of the three models.

\section{Description of Social Cognitive Career Theory}

Lent et al. (1994) proposed a conceptual framework for understanding the development of academic and career-related interests, academic and career-relevant choices, and the achievement of performance outcomes. Based on Bandura's (1986) social cognitive theory, SCCT emphasizes the importance of the core sociocognitive mechanisms of self-efficacy and outcome expectations to build three "interlocking" models that integrate numerous career-related variables, including person inputs, learning experiences, interests, academic/vocational goal-setting, and performance attainments. The resulting SCCT model (see Figure 1) outlines the manner in which person inputs, background contextual variables, self-efficacy beliefs, and outcome expectations affect vocational interests, choice goals, choice actions, and performance attainments.

What follows is a description of the three models within SCCT: (1) the model of interest development, (2) the model of career choice, and (3) the model of performance.

\section{Model of interest development}

This first model, as described by Lent et al. (1994), illustrates the precursors of sociocognitive variables, the prominent role of sociocognitive determinants of academic and vocational interests, and how such academic and vocational interests lead to 
involvement in relevant academic and career-related activities, which in turn lead to gaining the necessary skills to pursue one's interests. Vocational and academic interests in this model are defined as patterns of what appeals or does not appeal to individuals in regards to academic and career-related activities and vocations. Sociocognitive mechanisms in this model include self-efficacy beliefs (defined as individuals' perceptions of their ability to perform the behaviors necessary to achieve desired performances) and outcome expectations (defined as individuals' beliefs about the possible results of engaging in certain behavior).

In SCCT, there are two precursor constructs, person inputs and background contextual factors, which give rise to the sociocognitive mechanisms of self-efficacy, outcome expectations, and choice goals. Person inputs are conceptualized as individual difference variables and include such constructs as race, ethnicity, gender, and inherited traits. Background contextual factors are conceptualized as those factors that comprise the opportunity structure of an individual's experience. Background contextual factors may include differential experiences with exposure to role models, familial support for wanting to pursue particular activities, and gender role socialization processes. Person inputs and background contextual affordances indirectly affect the formation of interests through their effect on learning experiences and, subsequently, through self-efficacy beliefs and outcome expectations. Thus, person inputs and background contextual factors give rise to learning experiences as the next step in the SCCT interest model.

Learning experiences in SCCT are conceptualized using Bandura's (1986) four sources of self-efficacy information: personal performance accomplishments (e.g., successfully passing a test), vicarious learning (e.g., observing a peer pass a test), social 
persuasion (e.g., a teacher telling a student that he or she has the academic ability to pass a test), and physiological states (e.g., a student perceiving his or her test anxiety as a motivator to do well). As stated above, learning experiences are posited to indirectly affect the development of interests through their effect on the development of selfefficacy beliefs and outcome expectations. Therefore, relevant positive learning experiences (e.g., watching someone succeed at a given behavior) are posited to increase an individual's beliefs that they are effective in certain activities and that desired outcomes would result from their activity in those activities. Similarly, negative learning experiences are posited to decrease an individual's beliefs that they are effective in certain activities and that their effort will result in desired outcomes. In addition, Lent et al. (1994) posited that personal performance accomplishments would account for more variance in self-efficacy and outcome expectations than vicarious learning, verbal persuasion, and physiological states. Thus, the next step in the SCCT interest model is the role of self-efficacy and outcome expectations, two of the three major sociocognitive variables in SCCT.

The sociocognitive variables of self-efficacy and outcome expectations are the central mechanisms by which interests are formed. Self-efficacy beliefs refer to individuals' perceptions of their ability to perform the behaviors necessary to attain desired performances (Bandura, 1986). In SCCT, self-efficacy beliefs are posited to have a direct effect on vocational interests, choice goal, choice actions, and performance attainments. Specifically, interests are developed, goals are formed, and actions are executed for activities in which individuals perceive themselves to be effective. In SCCT, self-efficacy development is conceptualized as a dynamic process, which may be 
strengthened or weakened depending on one's learning experiences from performance attainments.

Outcome expectations also play a central role in the development of interests and related skills. According to SCCT, outcome expectations are defined as beliefs about the possible results of engaging in certain behaviors. As mentioned previously, the development of such beliefs is determined by outcomes of one's past actions, through observing the experiences of significant others, and by "attending to third-person (e.g., written) accounts of reinforcement contingencies" (p. 103). Further, outcome expectations are determined, in part, by self-efficacy beliefs because individuals are likely to assume positive results from activities in which they view themselves to be efficacious. Lent et al. (1994) posited that interests, goals, and actions are directly affected by outcome expectations.

According to SCCT, once interests have been formed through a combination of selfefficacy beliefs and outcome expectations (influenced by person inputs and contextual factors), an individual will move to establishing goals (the third sociocognitive variable in SCCT) for further activity in a particular academic or vocational domain. The establishment of goals is thought to help an individual self-regulate his or her behavior by working within an organized framework that will guide and sustain the particular behaviors necessary to take action. Self-efficacy beliefs, outcome expectations, and vocational interests directly affect goals. Goals may be changed as a result of the effect of new or additional learning experiences on self-efficacy beliefs and outcome expectations. 
The interest model in SCCT highlights the role of person inputs, background contextual factors, self-efficacy, and outcome expectations in the formation of interests. The next model, the choice model, adds on to the interest model by highlighting factors contributing to career and academic choice goals and choice actions. Model of career choice

According to Lent et al. (1994), the model of career choice is conceptualized as a "developmental extension" of the interest formation model (p. 94). Thus, this model includes the sociocognitive mechanisms and causal paths of the interest model and extends to include choice goal representations, choice actions, and performance attainments. In SCCT, choice goals are conceptualized as intentions to pursue a course of action. Choice actions are the actual activities engaged in to execute the choice. Performance attainments are those outcomes one experiences as a result of pursuing a particular action. One property of performance attainments is that they create a feedback loop by which individuals will reevaluate their self-efficacy, outcome expectations, interests, and goals depending on the outcomes of a particular action.

In extending the interest model to the choice model, interests are posited to have a direct effect on choice goals, which, in turn, have a direct effect on choice actions. Choice actions, then, have a direct effect on performance attainments. Thus, a person is more likely to formulate goals based on his or her particular set of interests; if the goals one sets are clear and attainable, then an individual will likely engage in activities that bring the goals to fruition. Finally, depending on the type of performance one has (e.g., passing or failing a class), an individual will re-evaluate the process and make necessary modifications. 
Choice goals and actions may also be affected by proximal contextual affordances. In contrast to the background contextual affordances described above, proximal contextual affordances are those influences that affect interests, choice goals, and choice actions at important choice points (e.g., wanting to pursue a degree in art, but not being able to because of a lack of financial support). According to SCCT, proximal contextual affordances may either moderate the relationships between interests and choice goals and between choice goals and choice actions or they may have a direct effect on choice goals and/or choice actions.

In terms of the moderating role of proximal contextual affordances, Lent et al. (1994) posited that the relationships between interests and goals and between goals and actions would be stronger for those individuals whose environments provide them with necessary supports and few barriers. In contrast, interests-goals and goals-actions relationships will be weaker for those individuals whose environments provide them with little support and a multitude of barriers. In addition, proximal contextual affordances may directly affect choice goals and/or choice actions.

Overall, the choice model highlights the role of interests in the development of choice goals, choice actions, and performance attainments, as well as the role of proximal contextual factors in affecting the relationships between interests and choice goals and between choice goals and choice actions. The final SCCT model is the performance model, which extends the interest and choice models by explicitly focusing on the role of performance attainments. 


\section{Model of performance}

According to SCCT, performance is defined as one's level of achievement and the degree to which one's choice actions are stable over the course of time. In SCCT, the performance model starts with self-efficacy beliefs. Self-efficacy is posited to have a direct effect on performance attainments in such that high self-efficacy helps individuals organize and execute their skills. Self-efficacy also is posited to have an indirect effect on performance attainments through interests, choice goals, and choice actions. Outcome expectations are seen as primarily having an indirect effect on performance attainments through choice goals and choice actions. Performance attainments then link back to learning experiences to inform future choices and behavior.

\section{Research on SCCT}

Lent et al.'s (1994) SCCT posits a complex, causal model by which academic and vocational interests, choice goals, choice actions, and performance attainments are all influenced by a variety of person inputs, contextual affordances, learning experiences, and sociocognitive factors. Thus, the extant research has generally examined specific aspects of the model and used structural equation modeling and path analysis to examine the causal relations among the multiple SCCT constructs. The extant research has examined the validity of certain propositions posited by Lent et al. (1994). In this next section, I will review those research studies on SCCT that utilized structural equation modeling or path analysis to examine the extent to which aspects of SCCT fit the data. In accordance with the organizational schema presented above, the research will be organized according to the three SCCT models. 


\section{Research primarily examining SCCT's interest model}

Fouad and Smith (1996) tested a portion of SCCT by examining the relationships among self-efficacy for math and science, outcome expectations for math and science, interest in math and science, intentions to take math/science classes, and intentions to pursue math and science-related careers in a sample of 380 ethnically diverse middle school students. For this study, intentions were substituted for choice goals given the developmental status of the sample. Specifically, the authors hypothesized that selfefficacy and outcome expectations would directly and indirectly affect interests, selfefficacy would directly affect intentions, and outcome expectations would directly affect intentions. Also included in this model as person inputs were the variables of age and gender. The authors hypothesized that person inputs would have a direct relationship with self-efficacy and outcome expectations such that boys and older students would have higher self-efficacy in math and science and expect more positive outcomes from taking math and science courses. Finally, given the ethnically diverse sample, the authors also examined the degree of model-data fit for each of the three ethnic groups included in the total sample (Caucasian, African-American, and Hispanic).

The measures used for this study were primarily developed by the first author and included scales for math and science self-efficacy, math and science outcome expectations and intentions, and math and science interest. The math and science selfefficacy instrument was used to assess students' confidence in completing twelve tasks that middle school students might encounter (e.g., "determine the amount of sales tax on clothes I want to buy"). The math and science outcome expectations instrument consisted of seven items assessing students' perceived outcomes for math and science- 
related activities. The math and science intentions instrument consisted of six items assessing intent to choose math and science-related activities and goals (e.g., science classes). Finally, the math and science interest instrument, based on Holland's (1985) Investigative theme, consisted of twenty items developed to assess interest in math and science activities.

Using structural equation modeling procedures, Fouad and Smith (1996) found small, yet significant effects of person inputs (i.e., gender and age) on interests in math and science. Most notable, male students had lower interests in math and science than female students, but higher outcome expectations. In addition, there was a significant, direct path from age to interests (in a negative direction), indicating a longitudinal decline in interest in math and science for this middle-school population. Fouad and Smith found strong positive and direct paths from self-efficacy to outcome expectations, from self-efficacy to intentions, and from outcome expectations to intentions. Self-efficacy was found to have a direct positive and indirect positive (via outcome expectations) relation to interests. Although not specifically hypothesized, the results indicated that self-efficacy was indirectly (via outcome expectations and interests) related to intentions, and outcome expectations were also indirectly (via interests) related to intentions. Finally, the authors reported that the model fit the data well for each of the three ethnic groups (i.e., Caucasian Americans, Hispanic Americans, and African Americans). However, examination of the fit statistics indicated that the model did not fit the data as well for African Americans (the adjusted goodness-of-fit index [AGFI] was .88) as for Caucasians $(\mathrm{AGFI}=.97)$ and Hispanics $(\mathrm{AGFI}=.96)$. 
Fouad and Smith's (1996) findings generally support the paths posited by Lent et al. (1994). Several potential limitations should be noted, however. First, the role of learning experiences was not examined. Lent et al. (1994) posited that person inputs have an indirect effect (via learning experiences) on self-efficacy and outcome expectations. They further posited that person inputs have an indirect (via learning experiences, selfefficacy, and outcome expectations) relationship with interests. Fouad and Smith (1996) modeled person inputs to have a direct effect on self-efficacy and outcome expectations, as well as on interests. Thus, given that learning experiences were not accounted for as an intervening variable, it is unclear how the person inputs of age and gender affect math and science self-efficacy, outcome expectations and interests. Second, although the authors stated that, "the model appears to be robust for the three major ethnic groups represented in the study" (p. 344), examination of the fit statistics revealed that the model did not fit each of the three ethnic groups equally well. In fact, there was a marked difference in the model-data fit for the African American sample, in comparison to the Caucasian sample (AGFI of .88 and .97, respectively). Byrne (1989) and Loehlin (1987) suggested that AGFI values above .90 indicate an acceptable model-data fit. The marginal model-data fit for African Americans indicates that further examination of SCCT with an African American sample is needed. Finally, Fouad and Smith only examined SCCT for math and science domains; thus, the applicability of SCCT for other domains remains unclear. Future studies of SCCT may consider including domains other than math and science.

Bishop and Bieschke (1998) were interested in predicting interest in research using SCCT. The authors wanted to test whether the SCCT model of vocational interest 
development applied to interest in research among 184 counseling psychology doctoral students. Specifically, Bishop and Bieschke (1998) tested the following SCCT propositions: (a) the effect of research self-efficacy and research outcome expectations on research interest, (b) the effect of research self-efficacy on research outcome expectations, and (c) the indirect effect (via research self-efficacy and research outcome expectations) of person inputs and environmental influences (i.e., background contextual affordances) on research interests. The authors also tested two paths that were not posited by Lent et al. (1994), that is, the direct effects of person inputs and environmental influences on research interest.

To assess the above constructs, Bishop and Bieschke (1998) used five different measures. Person inputs tested included age, gender, and personality types, measured by the Vocational Preference Inventory-Form B (VPI-B; Holland, 1985). This instrument consists of seven items for each of Holland's personality types. Individuals are asked to indicate their interest in occupational titles that represent each of the six personality types. Given that the research indicates that counseling psychology graduate students fall predominantly into three personality types, the authors only used scores for Investigative, Social, and Artistic personality types. Environmental influences (i.e., background contextual affordances) included year in program and the research training environment, which was measured with the 45-item Research Training Environment Scale (RTES; Gelso, et al., 1991). Research self-efficacy was measured with the Research SelfEfficacy Scale (RSES; Greeley, et al., 1989), a 51-item scale designed to measure an individual's perceived ability to perform research-related tasks. Research outcome expectations were assessed using the Research Outcome Expectations Questionnaire 
(ROEQ; Bieschke \& Bishop, 1994), a 20-item measure designed to assess an individual's perception of the positive and negative outcomes of participating in research activities. Finally, interest in research activities was assessed using the 16-item Interest in Research Questionnaire (IRQ; Bishop \& Bieschke, 1994).

Results of the path analysis indicated that the research training environment, Investigative personality type, and year in program directly predicted research selfefficacy. Investigative personality type, research training environment, and research selfefficacy positively and directly predicted research outcome expectations. Interest in research was predicted directly by research outcome expectations, research self-efficacy, Investigative personality type, age, and Artistic personality type (with the latter path yielding a negative beta weight). There also was an indirect effect of Investigative personality type on interest in research, with the relationship being partially mediated by research self-efficacy and outcome expectations. Finally, an indirect effect was found for research self-efficacy on interest in research, with the relationship being partially mediated by research outcome expectations.

In summary, Bishop and Bieschke's (1998) study supports numerous paths predicted by SCCT. Overall, the entire model accounted for $62 \%$ of the variance in research interests. However, several potential limitations may be noted. First, the role of learning experiences was not examined. The present authors noted that a small amount of the variance in predicting research self-efficacy was accounted for in this study (21\%) and, as such, they suggested that other variables might contribute to research self-efficacy. Specifically, Bishop and Bieschke suggested that other sources of self-efficacy expectations, such as the four sources of self-efficacy information (e.g., vicarious 
learning) posited by Bandura (1977), might better explain the formation of research selfefficacy beliefs. Given that Bandura's four sources of self-efficacy information are conceptualized as learning experiences in SCCT, further examination of their role in the model is warranted. Second, the sample consisted primarily of Caucasian individuals. Of the 184 people included in the sample, $81 \%$ were Caucasian $(\underline{n}=149)$, while only $3 \%$ $(\underline{\mathrm{n}}=5)$ were African Americans, for example. Thus, the lack of substantial ethnic minority representation in the sample limits the ability to gauge the applicability of SCCT for such populations. Future studies might consider including samples of racial and/or ethnic minority individuals in order to understand how SCCT applies to various groups. Finally, it is hardly surprising that Investigative personality type (measured as Investigative interests) predicted research interests, given that the two constructs overlap and even share item content. As such, knowing that Investigative interests predict research interests does not assist in scholars' further understanding of the relationship between person inputs (e.g., predispositions) and interests in SCCT.

More recently, Turner, Steward, and Lapan (2004) investigated the effects of background contextual factors and person inputs on the math self-efficacy, math outcome expectations, and math/science interests of 318 sixth graders. Specifically, they used SCCT as a framework for examining the relationship of background contextual factors (i.e., mother support, father support, and family structure [single-parent versus two-parent household]) to math and science self-efficacy and math and science outcome expectations, and the relationship of a person input (i.e., career gender typing, defined as girls and boys believing that math and science careers are more appropriate for boys than for girls) to math/science self-efficacy, math/science outcome expectations, and to choice 
of a math/science career. The authors hypothesized that (a) the person input and background contextual factors would have direct relationships with math self-efficacy and math outcome expectations, (b) math self-efficacy would have a direct relationship with math outcome expectations, and (c) math self-efficacy and math outcome expectations both would have a direct relationship with math and science career interests.

To assess the hypothesized relationships among the aforementioned variables, two measures were used, the Science Scale of the Revised Unisex American College Testing Interest Inventory (UNIACT; Lamb \& Prediger, 1995) and the Fennema-Sherman Mathematics Attitudes Scale (FSMA; Fennema \& Sherman, 1976). The former measure is a 15 -item scale measuring math and science career interests that corresponds to Holland's (1997) Investigative Occupational theme. The latter scale consists of nine separate 12-item subscales that measure nine different mathematics attitudes. For this study, only five of the nine scales were used: the Mother Scale, which consists of four items assessing perception of mother support for studying math; the Father Scale, which consists of four items assessing the perception of father support for studying math; the Mathematics as a Male Domain Scale, which consists of three negatively scored items assessing perceptions of career gender typing (e.g., "studying math is just as good for girls as for boys" and "studying for math is just as good for boys as for girls"); the Math Confidence Scale, a 5-item scale measuring math self-efficacy; and the Usefulness of Mathematics Scale, a 4-item scale measuring math outcome expectations.

Using structural equation modeling procedures, Turner et al. (2004) tested two separate models, one including the background contextual factors, the sociocognitive variables, and interests, and the other including the person inputs, the sociocognitive 
variables, and interests. With regard to the background contextual factors model, there were positive direct relationships of father and mother support to math self-efficacy, and a positive direct relationship of mother support to math outcome expectations. In the person input model, there were direct negative relationships of career gender typing to math self-efficacy and math outcome expectations. In addition, for both models, there were positive direct relationships between math self-efficacy and math outcome expectations, between math self-efficacy and math and science career interests, and between math outcome expectations and math and science career interests.

The results indicated that sixth graders' math self-efficacy positively affects their math outcome expectations and that their math self-efficacy and math outcome expectations each contributed to their interest in math and science. In addition, some of the contextual factors (e.g., mother support) were found to positively affect the sample's math self-efficacy and math outcome expectations, and the person input (i.e., career gender typing) was found to negatively affect the sample's math self-efficacy and math outcome expectations. However, as with previously mentioned studies (e.g., Fouad \& Smith, 1996), the role of learning experiences was not examined. While it is certainly not feasible or called for that researchers examine every construct of the SCCT model in their individual studies, there does appear to be a general trend in the literature of not examining the role of learning experiences in SCCT. This trend is particularly troubling when theorized precursors to learning experiences are included and related to theorized effects of learning experiences. Tests of such models leave unclear how person inputs and background contextual factors affect sociocognitive mechanisms, for example. Further, only math and science domains were examined, thus leaving it unclear how 
applicable SCCT is to other domains. Finally, the sample used in this study was comprised of $74 \%$ Caucasian Americans. As such, the applicability of SCCT to samples comprised of other races/ethnicities is unknown.

Finally, a recent study by Schaub and Tokar (2005) examined the direct and indirect effects of personality (a person input) on interest formation, and the SCCT proposition that self-efficacy and outcome expectations derive from corresponding and relevant learning experiences, in a sample of 327 university students. They were also interested in testing the relationships among SCCT variables for each of Holland's (1997) RIASEC themes. The authors hypothesized that (a) personality would have an indirect relationship (via learning experiences, self-efficacy, and outcome expectations) with vocational interests, (b) personality would have an additional (i.e., beyond the indirect effect) direct relationship with vocational interests, and (c) career relevant learning experiences (defined as performance accomplishments, vicarious learning, social persuasion, and physiological/emotional arousal) would have a positive relationship with self-efficacy and outcome expectations for each of the six Holland themes.

Schaub and Tokar (2005) used five instruments to assess personality, learning experiences, self-efficacy, outcome expectations, and interests. The NEO Five-Factor Inventory (Form S) (NEO-FFI-S; Costa \& McCrae, 1992), a 60-item self-report measure, was used to assess the Big Five dimensions of normal personality (i.e., Neuroticism, Extraversion, Openness, Agreeableness, and Conscientiousness). The Learning Experiences Questionnaire (LEQ; Schaub, 2004) was developed by the first author to assess the four sources of self-efficacy information as posited by Bandura (1986) for each of Holland's (1997) RIASEC themes. The Skills Confidence Inventory (SCI; Betz et al., 
1996), a 60-item measure of self-efficacy, was used to assess individuals' confidence in performing tasks related to Holland's (1997) RIASEC themes. The Occupational Outcome Expectations measure (OOE; Gore \& Leuwerke, 2000) was used to measure outcome expectations for each of Holland's (1997) RIASEC types. Finally, the General Occupational Themes (GOTs) of the Strong Interest Inventory (SII; Harmon et al., 1994) were used to measure RIASEC vocational interests.

Using path analysis, the authors tested seven paths for each of six models, one corresponding to each of Holland's RIASEC themes. The paths tested corresponded to SCCT's hypothesized relations involving personality (a person input), learning experiences, self-efficacy, outcome expectations, and interests. An additional path testing the direct effect of personality on interests was included in five of the six models. For five of the models, personality was represented by one or more of the Big Five, based on previous RIASEC interest-personality links (e.g., Larson, et al., 2002). (Realistic was not included because research has not consistently linked Big Five personality constructs to Realistic interests.) Thus, the personality construct of openness was included in the Investigative and Artistic models; extraversion was included in the Enterprising model; conscientiousness in the Conventional model; and both extraversion and agreeableness in the Social model.

Results indicated that personality had a significant and positive direct effect on interests for openness predicting Artistic interests, agreeableness predicting Social interests, and extraversion predicting Enterprising interests. In addition, results indicated that the relation of personality to interests was partially mediated through learning experiences and the sociocognitive mechanisms that derive from learning experiences in 
five of the six personality-interest relations tested. (The relation between openness and Investigative interests was non-significant.)

Regarding the relationships of learning experiences with self-efficacy and outcome expectations, results revealed that, for all six of the models, learning experiences were a positive and significant predictor of self-efficacy and outcome expectations. Results also revealed that the influence of learning experiences on outcome expectations was partially mediated by self-efficacy for the Social model and fully mediated by self-efficacy for the Investigative, Artistic, Enterprising, and Conventional models.

Other relationships posited by SCCT but not directly related to this study's hypotheses also were examined. Consistent with SCCT, results revealed that self-efficacy was a positive predictor of outcome expectations for the Social, Investigative, Artistic, Enterprising, and Conventional models. The effect of self-efficacy on interests was partially mediated by outcome expectations for the Investigative, Artistic, Social, and Conventional models, and fully mediated for the Enterprising model. Finally, personality was a significant positive predictor of learning experiences for the Artistic, Social, Enterprising, and Conventional models.

Overall, Schaub and Tokar's (2005) results demonstrate strong support for Lent et al.'s (1994) interest formation model, as well as for the relationships of personality to interests and of learning experiences to self-efficacy and outcome expectations. One potential limitation of their study is the lack of a representative sample. Their sample was composed of mostly White, upper-middle class students from a private university. Thus, it is difficult to ascertain the applicability of SCCT, particularly for Holland's (1997) RIASEC themes, for racial/ethnic minority and lower middle-class students. 
Nevertheless, Schaub and Tokar's findings suggest that it may be fruitful to continue examining how learning experiences contribute to the sociocognitive mechanisms in SCCT and how applicable SCCT is to Holland's RIASEC occupational constructs. Summary of the extant research primarily focusing on SCCT's interest model

SCCT's interest model purports that the sociocognitive mechanisms of self-efficacy and outcome expectations give rise to one's vocational and/or academic interests. In addition, person inputs, background contextual factors, and learning experiences also affect the formation of interests through their relations with self-efficacy and outcome expectations.

Overall, the four studies reviewed in this section provide strong support for Lent et al.'s (1994) proposed interest model in SCCT. Results of the studies supported the proposed relationships between the sociocognitive mechanisms and interests, as well as the effects of person inputs, background contextual factors, and learning experiences on the development of self-efficacy, outcome expectations, and interests. Several limitations may be noted from this review, however. First, although considerable support has been demonstrated for SCCT's propositions involving the role of self-efficacy and outcome expectations in interest formation, the posited role of person inputs, background contextual factors, and, in particular, learning experiences has received limited empirical scrutiny and support. In addition, only one of the studies reviewed here (i.e., Fouad \& Smith, 1996) focused on the applicability of SCCT for ethnic minorities. Thus, it appears that further examination of SCCT's interest model, especially the role of learning experiences in SCCT, with an ethnic minority sample, is warranted. Finally, most of the extant research has focused on math and science domains, with only one study (i.e., 
Schaub \& Tokar, 2005) examining occupational constructs other than those related to math and science. Given the paucity of research on domains other than math and science, further examination of other domains in SCCT is important.

In the next section, I will review the studies that have primarily focused on the choice model in SCCT.

\section{Research primarily examining SCCT's choice model}

Lapan, Shaughnessy, and Boggs (1996) conducted a longitudinal study using a sample of 101 college students to examine the mediational role of math/science selfefficacy expectations in relation to sex differences in the choice of a math/science college major. Specifically, the authors examined several hypothesized relationships proposed by Lent et al. (1994): (a) there would be relationships of the person input (sex) to math/science interests and choice of a math/science college major (b) there would be a relationship between self-efficacy (math self-efficacy and self-efficacy for Strong Interest Inventory Investigative occupations) and mathematical and artistic interests, (c) selfefficacy expectations would mediate the relationship between math ability and math interests as well as the relationship between sex and choice of a math/science college major, and (d) there would be direct relationships of math/science self-efficacy and math/science interests to the science-relatedness of choice of a college major. As a point of clarification, abilities in SCCT are assessed by "achievement, aptitude, or past behavioral indices" (Lent et al, 1994, p. 99) and are seen as affecting choice goals indirectly through self-efficacy and outcome expectations. In this study, abilities were assessed using ACT math scores, and choice goal was represented by choice of a college major. 
Students completed the measures the summer before they began college courses. Students' intended choice of a college major was recorded during this time, and their actual choice was obtained from university records during their junior year. Math selfefficacy was measured by the 52 -item Mathematics Self-Efficacy scale (MSE; Betz \& Hackett, 1983, 1985). Investigative self-efficacy was measured by asking students to rate their confidence in their ability to meet the educational and occupational requirements of occupations organized under the Investigative General Occupational Themes of the Strong Interest Inventory Occupational Scales (SII; Hansen \& Campbell, 1985). To assess interest in mathematics, the Mathematics Basic Interest Scale from the Strong Interest Inventory (SII; Hansen \& Campbell, 1985) was used. Math ability was assessed using students' ACT math scores. The science-relatedness of intended choice of college major and actual choice of a college major was assessed using the math/science college major continuum (Goldman \& Hewitt, 1976), a 5-point Likert-type scale, with higher scores corresponding to a greater emphasis in science. Finally, to increase the ability to explain variance in the choice of a math/science major, the Artistic theme of the SII was used to measure Artistic vocational interests. The authors posited that there would be an inverse relationship between interest in art and interest in math/science. The Introversion/Extraversion scale of the SII was also included to provide an understanding of how this personality trait contributes to career decisions within the self-efficacy model. The authors posited that individuals interested in math/science occupations would be more introverted, and individuals less interested in math/science occupations would be more extroverted. 
Results of a path analysis supported several links posited by Lent et al. (1994). There was a strong positive relationship between math self-efficacy and math-related interests $(\beta=.58)$. Women (as compared to men) in this study took fewer math classes in high school, scored lower on the ACT math test, had lower math self-efficacy beliefs, and were less likely to choose math/science-related majors. However, self-efficacy was found to mediate the significant relationships of sex and math ability to math interests, as well as the significant positive relationship between sex and choice of math/science college major. Both efficacy for Investigative activities and math-related interests positively predicted the intention to choose and the actual choice of a math/sciencerelated major. Artistic interests predicted unique variance in anticipated choice of math or science major as a freshman, with students who reported more interest in art activities less likely to anticipate choosing a math/science-related college major. And, finally, students who described themselves as more introverted took more math classes, scored higher on the ACT math test, and had higher math/science-related interests than those who described themselves as extroverted. Extroverted students reported having greater Artistic interests. Overall, the path model explained a large proportion of the variance in math-related interests (48\%) and choice of a math/science-related major (48\%).

While the study by Lapan et al. (1996) provides support for many of the paths posited in SCCT, some potential limitations may be noted. First, the role of learning experiences was not evaluated. In this study, person inputs were modeled as being directly related to self-efficacy without including the intervening role of learning experiences. Thus, it is unknown how (e.g., through learning experiences) person inputs affect sociocognitive mechanisms in SCCT. Second, this study only focused on the 
domains of math and science; thus, the applicability of SCCT for other career choice domains remains unclear. Finally, this study did not include ethnic minorities in the sample. As such, the generalizability of this study's results to diverse ethnic populations is questionable.

In an attempt to respond to calls in the literature about the paucity of research using ethnic minority samples when examining career-related variables (e.g., Hackett \& Lent, 1992), Gainor and Lent (1998) examined the relationships among several constructs in SCCT's career choice model using a sample of 164 African-American college students. Specifically, the authors posited that (a) there would be a relationship between learning experiences (i.e., the four sources of self-efficacy information originally described by Bandura, 1977) and both math self-efficacy and math outcome expectations, with personal performance experiences accounting for the majority of the variance in selfefficacy and outcome expectations, (b) there would be relationships of math self-efficacy and math outcome expectations to math interests, (c) math interests would be related to math choice intentions, (d) math self-efficacy would have a direct and indirect (via outcome expectations) relationship with math choice intentions, (e) there would be a relationship between prior math ability and math self-efficacy, and (f) there would be gender differences (i.e., male students scoring higher) in math self-efficacy and math outcome expectations, mediated by learning experiences.

Scores on the math portion of the Scholastic Assessment Test: Reasoning Test (SAT:I; College Board, 1993a, 1993b) were used as an index of prior math ability/achievement. Math self-efficacy was measured with the Math Course SelfEfficacy scale (MSE; Betz \& Hackett, 1983), an instrument designed to assess the 
confidence one has in his or her ability to complete math-related courses. Math outcome expectations were measured using a 16-item scale developed by Lent et al. (1991). This measure assesses the level of agreement for positive anticipated outcomes from taking math courses. Sources of math self-efficacy (i.e., learning experiences) were assessed with a 40-item measure developed by Lent et al. (1991), which consists of four 10-item scales corresponding to Bandura's (1986) four sources of self-efficacy information (i.e., personal performance accomplishments, vicarious learning, social persuasion, and physiological/emotional arousal). Math interests were assessed with a measure developed by the authors. Participants were asked to rate their degree of interest for math/science activities. Math choice intentions were assessed two ways: (a) using an index of math course enrollment intentions, which asked participants to rate the likelihood of taking math and science-related courses, and (b) with a rating of participants' intended major choice on a science-nonscience continuum.

The authors tested the basic model twice, with the only difference between the two models being the outcome variable of intentions. Thus, the first model tested included paths from learning experiences to self-efficacy and outcome expectations, from selfefficacy to outcome expectations, from self-efficacy and outcome expectations to interests and math-related course enrollment intentions, and from interests to mathrelated course enrollment intentions. The second model tested included the same paths except that math-related course enrollment_intentions were substituted with math-related major choice intentions.

Results of a path analysis supported many of the relationships posited in SCCT. Consistent with predictions, both math self-efficacy and math outcome expectations were 
significantly and positively predicted by the sources of self-efficacy information.

However, contrary to the authors' hypothesis (i.e., that personal performance experiences would comprise the largest amount of variance in self-efficacy and outcome expectations and that all of the sources of self-efficacy would produce unique paths to outcome expectations), performance accomplishments did not comprise the largest amount of variance in self-efficacy and only verbal persuasion produced a significant unique path to outcome expectations. These findings suggest that future research should examine further the posited relationships of learning experiences to self-efficacy and outcome expectations. The fact that only verbal persuasion produced a significant unique path to outcome expectations perhaps suggests that personal performance accomplishments may not be as important in the development of outcome expectations for African American students as hypothesized by SCCT. Overall, the results of this study suggest that perhaps other learning experiences may be more important in the formation of African American students' self-efficacy and outcome expectations, at least for math-and science-related domains.

As predicted, the effect of gender on math self-efficacy was found to be significant, with Black men tending to report higher self-efficacy expectations than Black women. Further, gender continued to account for a significant amount of variance in self-efficacy when the influence of learning experiences was controlled for. This latter finding suggests that learning experiences only partly explained the gender differences in selfefficacy. The authors stated that additional variables (such as sex role socialization, conceptualized as a background contextual factor in SCCT) need to be included in future 
research to more fully understand observed gender differences in math self-efficacy beliefs.

Also consistent with prediction, math self-efficacy and math outcome expectations were significantly and positively related to math interests, with the combination of math self-efficacy and math outcome expectations accounting for more explained variance in math interest than either variable alone. In terms of the model of choice intentions, math interest had a direct and positive relationship to major choice, with the effects of math self-efficacy and math outcome expectations on major choice partially mediated by math interest. In terms of the model of math course enrollment intentions, math self-efficacy and math outcome expectations had significant direct and positive paths to math course enrollment intentions, with higher self-efficacy and outcome expectations associated with stronger intentions to enroll in math courses. However, contrary to prediction, math interests were not significantly related to math course enrollment intentions. The authors stated that these results suggest that students' beliefs about their efficacy in math and the consequences of taking math courses were the dominant factors in their motivation to pursue math courses, as opposed to their interests, which was the dominant factor in their college major preference. Finally, the authors reported that the path analyses predicting course enrollment intentions and major choice intentions both resulted in a CFI of .99. Thus, the authors concluded that the hypothesized models for course enrollment intentions and major choice intentions provided a good model-data fit.

This study generally supports many of the paths posited by SCCT and, importantly, extends the literature on SCCT by using a sample of African-American individuals. Mixed support was found, however, for SCCT's posited links between learning 
experiences and both self-efficacy and outcome expectations; therefore, further examination of these relationships is warranted. In addition, this study only examined the interest and choice models for the domain of mathematics, and thus, future studies should examine the interest and choice models for domains other than math (or science).

Although the results of the path analysis for the choice model revealed an excellent model-data fit, this finding represents a departure from Fouad and Smith's (1996) earlier work on SCCT with an African American sample. Recall that Fouad and Smith found that SCCT's interest model produced only a marginal fit to their data (AGFI of .88). Given the results of Gainor and Lent's (1998) study, it appears that SCCT's choice model may be appropriate for African Americans; however, the results of Fouad and Smith's (1996) study suggest that SCCT's interest model may not be appropriate for African Americans. Several mitigating factors may account for the differences in model-data fit between the two studies. First, the nature and size of the samples for each study were different. Fouad and Smith had only 40 African Americans in their sample (a perhaps inadequate $\underline{\underline{n}}$ for structural equation modeling), as opposed to the 164 African Americans in the Gainor and Lent study. In addition, Fouad and Smith's sample consisted of middle-school students (12-15 years old), whereas Gainor and Lent's sample consisted of college students (17-22 years old). Second, the first author developed many of the measures used in the Fouad and Smith study, and several demonstrated inadequate internal consistency. In contrast, Gainor and Lent used more established measures, which demonstrated adequate to good internal reliability. Lastly, each study examined a different piece of the SCCT model; Fouad and Smith examined SCCT's interest model and Gainor and Lent examined SCCT's choice model. Given the mixed findings and 
taking into consideration the potential mitigating factors, additional research examining both the interest and choice models with a sample of African Americans may help in determining the applicability of SCCT for African Americans.

Finally, Gainor and Lent (1998) concluded that more research is needed that examines other relevant SCCT constructs with African Americans. For example, they suggested that future research should examine the role of proximal contextual affordances (e.g., barriers and supports) in the career-development of African-Americans. More specifically, the authors suggested that it would be fruitful to examine how potential barriers such as perceptions of racism and gender discrimination might affect the career development process for African-Americans. In particular, Gainor and Lent stated that SCCT's proposed moderating role of proximal contextual affordances in the interest-choice goals relationship is important because the experience of barriers may inhibit African-Americans' ability to translate their interests into goals.

Tang, Fouad, and Smith (1999) explored cultural factors relevant to Asian Americans' career choice development using SCCT. Specifically, the authors were interested in examining how the background contextual factors of acculturation, family socioeconomic status (SES), and family involvement were related to self-efficacy for, interests in, and career choice of traditional versus nontraditional Asian American careers for 187 Asian American college students. The authors posited that (a) acculturation would influence the development of self-efficacy, interests and career choice, (b) family SES would influence the development of self-efficacy and interests, (c) family involvement would have a relationship with self-efficacy and occupational choice, (d) self-efficacy would be related to interests and choice, and finally (e) interests would not 
have a relationship with career choice because of family and cultural values (i.e., Asian Americans place more value on the opinions of their family and the norms of their culture when it comes to choosing a career, as opposed to using their personal interests as a guide to choosing a career). Notably, Tang et al. (1999) did not assess learning experiences and outcome expectations, two constructs posited by Lent et al. (1994) to be critical in the interest development and career choice process.

Acculturation was measured using the Suinn-Lew Asian self-identity acculturation scale (SL-Asia; Suinn \& Lew, 1987), which assesses Asian Americans’ level of assimilation to the mainstream culture in the United States. Interests were measured with the six GOTs of the Strong Interest Inventory (SII; Harmon et al., 1994). Self-efficacy was measured with the Confidence Inventory (CI; Betz, 1994), a 60-item measure that assesses confidence level for activities that correspond to the six personality types posited by Holland (1997). To assess cultural and familial factors, the authors developed a questionnaire that asked participants to describe the level of their family's SES, the level of their family's involvement in the career choice process, and intended occupational choice. The participants' specific occupational titles from the above-mentioned questionnaire were coded for SES level using the Socioeconomic Indexes measure (Stevens \& Chou, 1985). Scores for self-efficacy, interests, and career choice were converted to standardized scores using the Representation Index (RI; Hsia, 1988) to reflect the extent to which these variables were typical/traditional for Asian Americans. Specifically, the authors stated that more Asian Americans are represented and successful in the fields of science and technology, and as such, the Representation Index was used to indicate whether the participants' career choices were more or less traditional/typical 
(i.e., related to science/technology). For the conversion of self-efficacy and interests into standardized scores, the GOTs of the Strong Interest Inventory were used. The authors stated that the original scores of self-efficacy and interest are based on Holland's (1985) hexagon. The authors further stated that Asian Americans are typically highly represented in Investigative and Realistic occupations and less represented in Artistic and Social occupations. As such, the nontraditional (i.e., Artistic and Social) scores in selfefficacy and interest were subtracted from the traditional (i.e., Realistic and Investigative) scores to compute an index that reflects how traditional an individual is in her/his selfefficacy and interest. A higher positive value indicates more traditional self-efficacy and interest, and a higher negative value indicates more nontraditional self-efficacy and interests.

Results of a path analysis revealed that acculturation had a significant negative and direct relationship with self-efficacy, interests, and career choice. Those individuals who reported being more acculturated also reported greater self-efficacy for, interest in, and intention to pursue less traditional occupations (in comparison to occupations generally chosen by Asian Americans). Family involvement had a significant positive and direct relationship to career choice such that parental influence was associated with traditional occupational choices. Family's SES did not have a relationship with self-efficacy or interest. Self-efficacy had a direct positive relationship to interest and to career choice, and, as hypothesized by the authors but in contrast to SCCT, interests did not have a significant relationship with career choice.

Overall, Tang et al.'s (1999) results somewhat supported the applicability of SCCT with an Asian American sample. As posited by Lent et al. (1994), self-efficacy had a 
direct relationship with interests and career choice, and one of the background contextual affordances (i.e., acculturation) was related to self-efficacy. However, as previously noted, this study did not examine the role of learning experiences. Examining the role of learning experiences is particularly important when precursors to learning experiences (e.g., background contextual factors such as acculturation) are being related to outcomes of learning experiences (e.g., self-efficacy) because learning experiences are posited to be a mediator of the effects of person inputs and background contextual factors on selfefficacy. Thus, future research needs to account for this important SCCT construct to obtain an accurate understanding of the nature of the relationships among person inputs, background contextual factors, learning experiences, and self-efficacy in the SCCT interest model.

More recently, Lent, Brown, Nota, and Soresi (2003) were interested in examining SCCT's interest and choice models across Holland's (1997) RIASEC types for 796 Italian high school students. Specifically, Lent et al. (2003) hypothesized that (a) selfefficacy would be directly related to outcome expectations, (b) self-efficacy would be directly related to interests, (c) outcome expectations would be directly related to interests, (d) self-efficacy would be indirectly (via outcome expectations) related to interests, (e) self-efficacy would be directly related to choice considerations (conceptualized as an age-appropriate alternative for choice goals in SCCT), (f) outcome expectations would be directly related to choice considerations, (g) interests would be directly related to choice considerations, (h) interests would partially mediate the relations of self-efficacy and outcome expectations to choice considerations, (i) contextual supports and barriers would be directly related to choice considerations, and 
(j) self-efficacy would partially mediate the relation of contextual supports and barriers to choice considerations.

To assess the above constructs, Lent et al. (2003) used five different measures, with each measure corresponding to each of the six RIASEC types. The measures for selfefficacy, outcome expectations, interests, and occupational choice considerations were adapted from research by Gore (1996) and Gore and Leuwerke (2000). The self-efficacy measure asked participants to rate how confident they were in their ability to be a successful worker in each of the 42 occupational titles. The outcome expectations measure asked participants to rate the degree to which they thought they would achieve positive outcomes from each of the occupations listed. The interests measure asked participants to rate how much they would like or dislike the work activities of each occupation. The occupational choice considerations measure asked participants to rate how seriously they would consider each occupation as a future career. For each measure, higher scores reflected more positive self-efficacy beliefs and outcome expectations, stronger interests, and stronger consideration of each of the occupations within a particular Holland type. Finally, contextual supports and barriers were measured using an adapted scale from Lent, Brown et al.'s (2002). Participants were asked to rate how important people in their lives would react to them choosing a particular occupational path. Participants were provided with descriptions of six occupational paths (one for each Holland theme) and a selection of four support statements (e.g., "feel support for this decision from important people in my life") and four barrier statements (e.g., "receive negative comments or discouragement about this choice from friends.) Higher support scores indicated that participants perceived greater social support for the choice 
of a particular Holland coded occupation and higher barrier scores indicated that participants perceived greater negative reactions from important others for the choice of a particular Holland coded occupation.

Results of the confirmatory factor analyses for the measurement models indicated that each 6-factor model (self-efficacy, outcome expectations, interests, occupational choice consideration, social supports, and social barriers represented as six correlated latent constructs for each of the six Holland types) provided a good model-data fit (e.g., CFI ranged from .92 to .97$)$. Structural model tests were performed to generate fit indices for the direct effects and partially mediated effects of each 6-factor model corresponding to each RIASEC type. Results indicated that the direct effects and partially mediated effects models provided adequate to good model-data fit (e.g., CFIs of .91 to .97$)$; however, the partially mediated model produced slightly improved fit indices across most of the Holland themes.

Turning to specific paths, results indicated that self-efficacy had a direct positive relationship with outcome expectations across Holland themes. Self-efficacy and outcome expectations had direct positive relationships with interests across Holland themes. Self-efficacy also had an indirect relationship (via outcome expectations) to interests across Holland themes. In terms of occupational choice consideration, selfefficacy had a positive direct relationship with choice consideration only for the Investigative and Artistic themes. Outcome expectations had a direct positive relationship with choice consideration for Artistic, Social, Enterprising, and Conventional themes. Interests had a direct positive relationship with choice consideration across all Holland themes. The hypothesis that interests would partially mediate the relations of 
self-efficacy and outcome expectations to choice consideration was supported, but the extent of the mediation effect differed across Holland themes. Interests fully mediated the effects of self-efficacy and outcome expectations only for Realistic choice consideration. In all other cases, partial mediation was observed. Contrary to the authors' hypotheses, social barriers did not have a direct relationship with occupational consideration, and social supports had a direct positive relationship with occupational consideration only for the Realistic theme. Finally, all paths from social support to selfefficacy were found to be significant and positive. However, only two paths from social barriers to self-efficacy were significant and positive (i.e., Artistic and Conventional). Self-efficacy was found to partially mediate the relation of contextual supports and barriers to choice considerations Social supports and barriers were, themselves, significantly and inversely related, indicating that higher perceived social support is associated with lower perceived social barriers.

In general, results were supportive of SCCT's interest and choice models and supportive of the utility of Holland's theory in tests of SCCT paths. Many of the relationships posited by Lent et al. (1994) were supported in this study (e.g., selfefficacy's relationship with outcome expectations and interests). However, several limitations may be noted. Given the nature of the sample (Italian high school students), generalizing the study's findings to other groups would be difficult. In addition, several paths posited by Lent et al. (1994) (social supports and barriers to choice considerations) were not supported. Lent et al. (2003) stated that future research needs to re-examine the role of supports and barriers in choice consideration, as well as examine other potential relationships between environmental influences and choice consideration. For example, 
the authors noted that they did not examine the possible role of supports and barriers as moderators of the interest-goal relation. Finally, the authors stated that they only examined one facet of supports and barriers (i.e., social influences) and that future research should examine additional types of contextual supports and barriers.

Lent, Brown, et al. (2003) were interested in examining the utility of SCCT in explaining the choice goals and actions of 328 engineering majors. This study had two purposes. The first purpose was to test two different models by which proximal contextual factors related to choice goals and actions. According to the authors, SCCT posits that proximal contextual factors directly relate to choice goals and choice actions, while Bandura's $(1999,2000)$ social cognitive theory posits that the relationship of proximal contextual factors to choice actions is mediated by choice goals and selfefficacy beliefs. The second purpose of this study was to revisit the interest, choice, and action models of SCCT. The authors' hypothesized that (a) self-efficacy beliefs would be related to outcome expectations, (b) self-efficacy and outcome expectations would be related to interests, (c) self-efficacy and outcome expectations would both have an indirect relationship (via interests) to choice goals, and (d) choice goals would partially mediate the relationship of self-efficacy beliefs and outcome expectations to choice actions, and would fully mediate the relationship of interest.

Measures included estimates of engineering self-efficacy and engineering coping efficacy (a subtype of self-efficacy), outcome expectations, interests, major choice goals, and contextual supports and barriers. In addition, the authors collected "persistence" (conceptualized in SCCT as choice actions) data, which they defined as the declared major choices at the end of the semester for three consecutive semesters. Persistence was 
then scored on a 4-point scale, with each point indicating the number of semesters that the participants had been majoring in engineering (0-3 semesters).

Engineering self-efficacy was measured by adapting Lent et al.’s (1984) Selfefficacy for Technical/Scientific Fields measure. Participants were asked to indicate their confidence that they could successfully complete each of the 10 engineering majors presented (e.g., electrical engineering) with an overall grade point average of a B or better. Coping efficacy was assessed by using a 7-item measure that asked participants to indicate their confidence in their ability to cope with problems that they could experience as engineering majors (e.g., "cope with a lack of support from professors or your advisor.") Engineering outcome expectations were measured with a 10-item scale that asked participants to indicate how strongly they agreed that a bachelor of science degree in engineering would provide them with the opportunity to achieve positive outcomes. Technical interests were measured with a scale asking participants to rate their degree of interest in doing seven activities that related to science, technology, engineering, and mathematics fields. Contextual supports and barriers were measured with a modified version of Lent et al.'s (2001) social supports and social barriers measure. Participants were asked to indicate how important people in their lives would react to their choice of an engineering major (e.g., get encouragement or feel pressure to change their major). Educational goals were assessed by asking participants to indicate their level of agreement with four statements about their academic intentions (e.g., "I intend to major in a field of engineering").

Results of a path analysis revealed that the direct path model did not provide an adequate model-data fit $(\mathrm{CFI}=.73)$. However, the mediated model did provide a good 
model-data fit $(\mathrm{CFI}=.96)$, indicating that supports and barriers were related to choice goals and actions indirectly, via their relationship to self-efficacy. In addition, selfefficacy was directly and positively related to outcome expectations. Self-efficacy and outcome expectations were jointly predictive of interests. Interests were a partial mediator of the self-efficacy-choice goal relationship. Contrary to the authors' hypothesis, outcome expectations did not have a direct or indirect relationship to choice goals. Finally, choice goals fully mediated the relationship of self-efficacy and interests to persistence (i.e., choice actions).

While the majority of the posited paths in SCCT were supported in this study, several others were not. First, the posited direct relationships of proximal contextual factors to choice goals and choice actions were not supported. In fact, Bandura's (1999, 2000) mediated social cognitive model garnered good support, leaving researchers to question a key SCCT relationship. Additionally, outcome expectations were not significantly related to choice goals, as hypothesized. Several limitations also should be noted. First, given the composition of the sample (i.e., engineering majors, mostly male, and European-American), generalizing the findings across subsamples of women or different racial-ethnic minority groups is not possible. Second, results are once again limited to math/science/engineering domains. And, finally, results of Lent et al.'s study only begins to shed light on the role of proximal contextual affordances in SCCT. The authors noted that it would be important for future researchers to examine other key relationships involving proximal contextual affordances, particularly the posited role of proximal contextual factors as moderators of interest-goals and goals-action relationships in SCCT. 
Most recently, Lent, Brown, Sheu, Schmidt, Brenner, et al. (2005) examined the interest and choice models of SCCT with a sample of African American and Caucasian American college students majoring in engineering from one predominantly White university (63\% of sample was White and $9 \%$ were Black) and two historically Black universities ( $87 \%$ of the sample was Black and $2 \%$ were White). Specifically, the authors were interested in examining the degree to which the data fit the interest and choice models across gender and university type (White and Black universities). Lent et al. (2005) posited several relationship among the SCCT variables: (a) engineering selfefficacy would be related to engineering outcome expectations, (b) engineering selfefficacy and engineering outcome expectations would each be uniquely related to engineering interests, (c) engineering self-efficacy, engineering outcome expectations, and engineering interests would predict major choice goals (i.e., choosing to major in engineering), and (d) engineering interests would partially mediate the relationships of engineering self-efficacy and engineering outcome expectations to major choice goals. Finally, Lent et al. (2005) posited that proximal contextual supports (conceptualized as social supports and social barriers) could have a direct or an indirect (via self-efficacy) path to major choice goals.

Engineering self-efficacy was measured using two instruments, the self-efficacy for academic milestones measure (Lent et al., 1986) and the barrier coping efficacy measure (Lent et al., 2001; Lent, Brown, Schmidt, et al., 2003). The former instrument measures how confident individuals are in their ability to successfully perform tasks required for success as a science/engineering major. The latter instrument measures how confident individuals are in their ability to cope with problems that engineering students might 
expect (e.g., lack of professorial support). Engineering outcome expectations were assessed by asking participants to rate the degree to which they believed an engineering degree would allow them to obtain particular outcomes (e.g., obtaining steady employment). Interest in engineering-related activities was assessed by asking the participants to rate their degree of interest in seven technical interests related to engineering. Social supports and barriers were measured using a modified version of Lent et al.'s (2001) barriers and supports measure. Participants were asked to rate how likely it was that they would experience particular supports (e.g., getting encouragement from friends and family) and barriers (e.g., feeling pressures from friends and family to change major) if they were to choose engineering as a major. Finally, major choice goals were measured by asking participants to rate their level of agreement with statements regarding their academic intentions (e.g., "I plan to remain enrolled in an engineering major over the next semester").

Using structural equation modeling procedures, Lent et al. (2005) found support for their hypothesized relationships in SCCT. Engineering self-efficacy and engineering outcome expectations each contributed uniquely and directly to the prediction of engineering interests. Engineering self-efficacy and engineering interest had direct positive relationships with major choice goals. Social supports and social barriers were both directly predictive of self-efficacy, with social supports having a positive relationship to self-efficacy and social barriers having a negative relationship to selfefficacy. Both direct and indirect (via self-efficacy) paths were supported for the relationships of social supports and social barriers to major choice goals. Results of model-data fit by gender revealed that the model's structural coefficients did not 
significantly differ between men and women. However, results of the model-data fit by university type revealed that the covariance between supports and barriers differed significantly by group, such that the supports-barriers relation was larger in magnitude for the students enrolled at the historically Black colleges and universities than for the students enrolled at the White university $(\beta$ for historically black colleges $=-.30, \beta$ for White university $=-.10$ ).

In addition, several other noteworthy findings may be mentioned. Mean differences revealed that students from the historically Black colleges and universities had significantly higher engineering self-efficacy, engineering outcome expectations, technical interests, social supports, and engineering goals than students from the White university. Students from the two university groups did not differ in their experience of social barriers; however, women from both types of universities reported stronger social supports. Also, the path coefficients across university type revealed other potential group differences. Although the magnitude of the path coefficients across the Black-White university types did not differ statistically, it is interesting to note that there were some appreciable differences in the beta weights for certain paths. For example, the path from interests to goals had a significant beta weight of .24 for the Black university and a nonsignificant beta weight of .10 for the White university. The path from outcome expectations to choice goals had a nonsignificant beta weight of - .06 for the Black university and significant beta weight of .21 for the White university. Finally, the path from social supports to major choice goals had a significant beta weight of .15 for the Black university and a non-significant beta weight of .00 for the White university. 
Results of this study generally support the relationships posited by Lent et al. (1994) and contribute to the previous literature examining social cognitive career-related variables with African American students (Fouad \& Smith, 1996; Gainor \& Lent, 1998). Importantly, Lent et al.'s study is one of the first of its kind to demonstrate empirically the critical role of the proximal contextual factors of supports and barriers in engineering students' self-efficacy for and choice of an engineering major. Further, although not directly tested, results suggest that the relation between interests and choice goals may be affected (i.e., moderated by) by the experience of social supports and/or barriers. Students at the Black university reported greater social support, and interestingly, the interest-goals relationship was appreciably (though, not statistically) stronger for those students. These findings raise the possibility that the relation of interests to choice goals will be moderated by support systems and perceived barriers, consistent with SCCT's hypothesis 5B. Unfortunately, Lent et al. (2005) did not directly test for this possibility. Future researchers should further examine the role of barriers and supports in choice goals, particularly their posited moderating role in the interests-choice goals relation. Such a test seems particularly important for women and racial-ethnic minorities, who may perceive more barriers to and fewer supports for their career choices and for whom the translation of interests to choice goals may be most hindered (Lent, Brown, \& Hackett, 2000).

\section{Summary of the research examining SCCT's choice model}

Overall, the literature reviewed here generally supports the relationships proposed by Lent et al. (1994). Most notable is the fact that several of these studies (i.e., Gainor \& Lent, 1998; Tang et al., 1999; Lent et al., 2005) included ethnic-minority samples, 
lending some support for the applicability of SCCT with African Americans and Asian Americans. This body of research, however, represents the few studies that included ethnic minorities in the samples when examining SCCT variables, and thus, more research needs to be conducted with diverse racial/ethnic populations. In addition, some SCCT constructs typically have been ignored in the literature. For example, the studies by Tang et al. (1999) and Lapan et al. (1996) did not assess the important SCCT constructs of learning experiences and outcome expectations. The study by Gainor and Lent (1998) highlights the need for more work to be conducted examining the role of learning experiences in the development of interests (and perhaps other outcomes) for African Americans. Four of the six studies (Lapan et al., 1996; Gainor \& Lent, 1998; Lent et al., 2003; Lent et al., 2005) examined SCCT constructs for math and science domains only, thus indicating a need for future research to examine additional career domains. Finally, the studies by Lent, et al. (2003), Lent et al. (2003), and Lent et al. (2005) are important because they highlight the need for future research to further examine the role of academic supports and barriers in the formation of interests and choice goals.

The next section will review SCCT's performance model. This model includes choice actions and performance attainments as important constructs in the career development process.

\section{Research primarily examining SCCT's performance model}

Lopez, Lent, Brown, and Gore (1997) examined SCCT's interest and performance models with a sample of 296 high school students enrolled in either a geometry class or an advanced algebra class. The authors tested two models, one for math interests and one 
for academic performance in math. For the model of math interests, the authors hypothesized that (a) math interests would be directly affected by math self-efficacy and math outcome expectations, (b) math self-efficacy would indirectly affect math interests via math outcome expectations, (c) learning experiences would have a direct relationship to self-efficacy and they would affect interests through self-efficacy, and (d) a fully mediated model, whereby math ability (measured by the Stanford math variable) affects math self-efficacy, which in turn, affects math interest, would fit the data better than a partially mediated model, whereby math ability affects math interest both directly and indirectly through math self-efficacy. For the model of academic performance, the authors hypothesized that (a) math self-efficacy would directly affect academic achievement in math (measured by end of the term math course grade), (b) math ability would directly affect academic achievement in math, (c) learning experiences would have a direct relationship to self-efficacy and they would affect math grades through selfefficacy, and (d) a model whereby math self-efficacy partially mediates the effect of math ability on performance would have a better model-data fit than a fully mediated model whereby the effect of math ability on grades operates via math self-efficacy.

Math ability was assessed using scores from the Stanford Achievement Test Series (SAT; Stanford 7 Plus, 1987). For both the interest and performance models, the four sources of self-efficacy information (i.e., personal performance accomplishments, vicarious learning, social persuasion, and physiological/emotional arousal) were assessed using a revised instrument by Lent et al. (1991). This instrument is comprised of four scales designed to assess each of the four sources of self-efficacy. Students were asked to state their level of agreement to statements such as, "I have always had a natural talent 
for math" (tapping personal performance accomplishments) and "people I look up to are good at math" (tapping vicarious learning). Math self-efficacy was assessed by asking the participants to rate their confidence in successfully solving course-specific math problems. For the interest model, math outcome expectations were measured with the Usefulness of Mathematics Scale (UMS; Fennema \& Sherman, 1976; Betz, 1977), which assesses how relevant students believe math will be to their future work plans. Finally, math-related interests were assessed by asking the participants to rate their degree of interest in math-related activities.

Using structural equation modeling procedures, the authors first tested the hypothesized paths of the interest model. Results indicated that math ability had an indirect and positive relationship to math self-efficacy via its relation to past performance in math for both the geometry sample and the algebra sample. Math outcome expectations had a direct positive relation to math interest for both samples. Math selfefficacy had a direct positive relationship to math interest for the geometry sample only. For both samples, math self-efficacy had a positive indirect relationship to math interest through math outcome expectations. Personal performance accomplishments had a significant positive and direct relationship with self-efficacy for both samples, and selfefficacy partially mediated the relationship between performance accomplishments and interest. Social persuasion has a significant positive and direct path to self-efficacy for the advanced algebra group only, and self-efficacy mediated the relationship between social persuasion and interests for both groups. Finally, the fully mediated model (i.e., ability affects interests indirectly through self-efficacy) provided a better model-data fit for both samples, as expected. 
In terms of the performance model, the partially mediated model (i.e., math ability affects course grades both directly and indirectly through math self-efficacy) provided a better model-data fit for both samples, as expected. Both math self-efficacy and math ability had significant positive and direct relationships with math grades for both samples. In this analysis, gender was significantly correlated with grades in the algebra sample, and thus, the authors included gender effects into the partially mediated performance model. Results indicated that gender produced a significant, direct effect on grades and significantly covaried with verbal persuasion and vicarious learning. Female students generally received higher course grades and perceived more math-related social persuasion and vicarious influence. Finally, personal performance accomplishments had a significant positive and direct relationship with self-efficacy for both samples, and selfefficacy mediated the relationship between performance accomplishments and grades. Social persuasion had a significant positive and direct relationship with self-efficacy for the advanced algebra sample only, and self-efficacy mediated the relationship between social persuasion and math grades.

Thus, results of the interest model suggest that math ability directly affects math self-efficacy and math outcome expectations, which in turn, affect interest in math. Results of the performance model indicated that math ability directly and indirectly (via self-efficacy) affect grades in math. These results are generally supportive of Lent et al.'s (1994) suppositions. However, several limitations may be noted. First, the authors only examined the domain of math, leaving researchers to wonder how other academic domains fit within SCCT. Second, the sample used here was comprised almost entirely of Caucasian students; thus, the applicability of the SCCT performance model with any 
ethnic minority group is unknown. Third, only two of the four learning experiences (i.e., personal performance accomplishments and social persuasion) had relationships to selfefficacy. Future research should examine domains other than math (and science), further examine the role of learning experiences in SCCT, and examine SCCT's performance model with an ethnic minority sample.

Summary of the research examining SCCT's interest, choice, and performance models

Lent et al. (1994) proposed that SCCT consists of three "interlocking" models that explain the relationships among important person inputs, contextual factors, sociocognitive mechanisms, interests, choice goals, and performance that affect individuals' career development.

Research examining the interest model generally provides support for the posited relationships among person inputs, background contextual factors, self-efficacy, outcome expectations, and interests. As predicted by SCCT, self-efficacy and outcome expectations both affect the development of interests. Research focusing on person inputs, contextual background factors, and learning experiences provided preliminary support for relations of these variables to self-efficacy, outcome expectations, and interests. For example, support was provided for the relations of some learning experiences to self-efficacy and outcome expectations, and person inputs (e.g., personality, gender) were linked both directly and indirectly to vocational interests.

Research examining the choice model provides some support for the relationships between sociocognitive mechanisms, interests, and choice goals. Self-efficacy and vocational interests were found to predict choice goals in some of the studies reviewed (e.g., Gainor \& Lent, 1998). Preliminary support was found for the role of proximal 
contextual affordances in SCCT; proximal contextual affordances related directly to choice goals (Lent et al., 2005).

Research examining the performance model indicated that math ability directly and indirect (via self-efficacy) affects grades in math. In addition, personal performance accomplishments and social persuasion had direct relationships with self-efficacy and self-efficacy mediated the relationships between these two learning experiences and math interests and math grades.

\section{Limitations of SCCT Research}

Several limitations have been noted throughout this review. In the next section, I will discuss in greater detail three major limitations as they apply to SCCT research: (1) the paucity of research examining the interest and choice models in SCCT with an African American sample, (2) the almost exclusive focus of SCCT research on math and science-related self-efficacy, outcome expectations, and vocational interests, and (3) the lack of research focusing on the role of learning experiences and proximal contextual affordances in SCCT.

\section{Paucity of research examining SCCT with African Americans}

Since the inception of SCCT, many research studies have examined various constructs and relationships within the model. One noted advantage of SCCT over other career development models is that it takes into consideration the interactional role of the person and the environment in shaping career relevant behavior. Specifically, SCCT's constructs of person inputs (which include sex and race/ethnicity) and contextual factors (which include structural barriers and supports) allow for a more complex examination of career development. In addition, Lent et al. (1994) noted that SCCT is a particularly 
good framework for studying the career development of racial/ethnic minority groups, given that factors important to career development, such as the experience of racism and discrimination, can be accounted for in the model.

One racial minority group that remains underrepresented in the SCCT literature is African Americans. Of the studies previously reviewed, only three studies (i.e., Fouad \& Smith, 1996; Gainor \& Lent, 1998; and Lent et al., 2005) included African Americans in their respective samples, and of those three studies, only two (i.e., Fouad \& Smith, 1996; Gainor \& Lent, 1998) examined the model's fit to the data by group. Results of those two studies were mixed, with Fouad \& Smith (1996) finding a less than adequate modeldata fit for SCCT's interest model and Gainor \& Lent (1998) finding an excellent modeldata fit for SCCT's choice model. In addition, although not directly tested for racial/ethnic group differences, Lent et al. (2005) found appreciable differences in beta weights between the historically Black university group and the White university group for certain SCCT paths (e.g., interests to goals), suggesting that certain SCCT relationships may operate differently for African American students.

Further, the three studies that included African Americans as part of the sample only examined SCCT relationships for the domains of math and science. While this is certainly important given the under-representation of African Americans in the fields of math, science, and engineering, little is known about how SCCT applies to other domains for African Americans.

Given that African Americans remain underrepresented in the SCCT literature, results of research on the applicability of SCCT for African Americans have been mixed, and studies that have included African Americans have only examined SCCT constructs 
for the domains of math and science, it is vital that additional research examine the applicability of SCCT for African Americans. One focus of the present research, then, is to examine the applicability of SCCT with a sample comprised of African Americans.

\section{Focus on math- and science-related activities}

Of the studies previously reviewed, only two (Lent et al., 2003; Schaub \& Tokar, 2005) examined SCCT constructs for domains other than math and science. Smith and Fouad (1999) argued that SCCT was based almost exclusively on research examining math and science-related activities, and asserted that, "it is particularly critical to examine domain areas other than math and science if the social cognitive career model is to be applied generally across occupational areas" (p. 462).

One possible conceptual framework for assessing a range of occupational activities in tests of SCCT is Holland's (1997) theory. Holland's theory of vocational choice is based on the personality/interest pattern of the individual and the work environment. This model has been conceptualized in terms of RIASEC, an acronym for the interest types and occupational categories of Realistic, Investigative, Artistic, Social, Enterprising, and Conventional. A combination of these six interest types describes an individual's vocational interest pattern in an attempt to match the individual's interests and personality with the predominant interest/personality of a given work environment (Spokane, 1996). Betz, Harmon, and Borgen (1996) asserted that, "given the centrality of the RIASEC typology to our conceptualization of vocational interests, testing of the social cognitive theory using the RIASEC types is an obvious, needed step" (p. 90).

Lending credence to the idea that Holland's RIASEC theory may be a useful framework for examining SCCT for domains other than math and science, recall that two 
empirical investigations (Lent et al., 2003; Schaub \& Tokar, 2005) demonstrated support for many of SCCT's hypothesized paths using measures of SCCT constructs for Holland's RIASEC types. Additional research on SCCT needs to be conducted using the RIASEC typology to provide additional evidence of SCCT's utility across a broad range of important occupational areas.

The paucity of research on the experiential sources of self-efficacy and outcome beliefs According to Lent et al. (1994), the most important mechanisms in SCCT are the sociocognitive factors of self-efficacy and outcome expectations. Learning experiences (i.e., personal performance accomplishments, vicarious learning, verbal persuasion, and physiological arousal) are considered to be the precursors to these sociocognitive mechanisms, and, as such, help shape the formation of an individual's self-efficacy beliefs and outcome expectations. Learning experiences also are posited to be an intervening variable through which person inputs and background contextual affordances influence the formation of self-efficacy and outcome expectations. Despite the vital role of learning experiences in SCCT, very little empirical research had examined SCCT's posited relations involving learning experiences (with mixed findings), and only one study (Schaub \& Tokar, 2005) had examined the role of learning experiences in SCCT for a domain other than math and science. As such, one focus of this study is to examine SCCT's posited relationships of learning experiences to self-efficacy and outcome expectations for Holland's (1997) RIASEC domains.

Of the SCCT studies reviewed previously, only three included a measure of learning experiences (i.e., Gainor \& Lent, 1998; Lopez, et al., 1997; Schaub \& Tokar, 2005). Results of Gainor and Lent (1998) and Lopez et al. (1997), both of which measured 
SCCT constructs for math/science domains, provided mixed support for Lent et al.'s (1994) proposition that learning experiences contribute to the formation of self-efficacy beliefs and outcome expectations. Specifically, Lopez et al. (1997) found that selfefficacy was uniquely predicted by personal performance accomplishments and social persuasion, whereas Gainor and Lent (1998) found that self-efficacy was uniquely predicted by social persuasion and physiological arousal. In addition, Gainor and Lent (1998) found that only verbal persuasion uniquely predicted outcome expectations. Finally, both studies failed to support SCCT's hypothesis that personal performance accomplishments would be the strongest unique predictor (among learning experiences) of self-efficacy and outcome expectations.

Recall that Gainor and Lent (1998) examined SCCT constructs with a sample of African American college students. While their study provides some initial support for the applicability of SCCT for African Americans, some of their results- particularly those bearing on the role of learning experiences in self-efficacy and outcome expectationswere not consistent with prediction (as previously mentioned), leaving unclear how career relevant learning experiences inform corresponding self-efficacy beliefs and outcome expectations for African Americans.

Further, both of the aforementioned studies (Gainor \& Lent, 1998; Lopez et al., 1997) only examined SCCT constructs for the domains of math and science. Thus, it is unclear how learning experiences relate to self-efficacy and outcome expectations for career domains other than math and science.

In a study that did examine SCCT constructs for domains other than math and science (i.e., RIASEC themes), Schaub and Tokar (2005) found strong positive 
relationships of learning experiences to self-efficacy and outcome expectations, with the relationship of learning experiences to outcome expectations being largely mediated by self-efficacy. These results support several key hypotheses proposed by Lent et al. (1994). However, Schaub and Tokar's (2005) findings are somewhat limited by the fact that they measured learning experiences globally, and, as such, the unique contribution of each individual learning experience to corresponding self-efficacy and outcome expectations is unknown. In addition, their sample consisted of upper-middle class, European-American students. Thus, the applicability of SCCT (including hypothesized paths involving learning experiences) for other groups (such as African Americans) with domains other than math and science is also not known.

Examining the unique contribution of each learning experience to the formation of self-efficacy and outcome expectations may be of particular importance for African Americans. In a conceptual article, Hackett and Byars (1996) discussed the unique ways that learning experiences may inform self-efficacy and outcome expectations for African Americans (in comparison to European-Americans).

In terms of performance accomplishments, Hackett and Byars (1996) stated that African American students experience unpredictable environments in which rewards and punishments are given inconsistently; consequently, it is difficult for them to accurately assess their educational accomplishments. According to the authors, inconsistent information about the quality of one's performance may result in weakened self-efficacy beliefs. In addition, African American students encounter differential standards applied to the same behavior; thus, while they may be performing the same as their EuropeanAmerican peers, they may be receiving different performance feedback. Hackett and 
Byars (1996) suggested that this can result in lowered self-efficacy beliefs, despite successful performance.

Also, given the broader societal context of racism and sexism, African American women (and men who experience racism) may have negative outcome expectations about the value of their performance even if it is successful. This appears to be particularly true for African American men, as Hackett and Byars (1996) cited research that demonstrated that they (in comparison to African American women) do not believe that successful performance on their part will result in more educational or occupational opportunities. Recall that Gainor and Lent (1998) found that the relationship between personal performance accomplishments and self-efficacy and outcome expectations did not conform to theory, lending further credence to the possibility that personal performance accomplishments may not be the most important learning experience shaping the development of self-efficacy beliefs and outcome expectations for African Americans. With regard to vicarious learning, Hackett and Byars (1996) stated that there remains a "scarcity of competent African American female models from which African American girls can learn and formulate ambitious and realistic educational and occupational goals" (p. 324). They further stated that African American students in general are likely to benefit from exposure to African American models that are more similar in age and social background and who exhibit relevant coping responses to racism and prejudice. However, Hackett and Byars (1996) noted that the majority of societal role models remain White career models, especially White male career models. Thus, it seems unlikely that vicarious learning would be as significant a learning experience for African American women and men as it would be for White people. 
Physiological/affective states also may play a somewhat different role in the development of African Americans' self-efficacy and outcome expectations. Hackett and Byars (1996) argued that, for African American men and women, being ethnically different in conjunction with the experiences of racism, sexism, and prejudice can result in high levels of anxiety, depression, chronic stress, distrust, and discouragement, which may result in lowered self-efficacy beliefs and negative outcome expectations. SCCT predicts that higher negative affective states will result in lowered self-efficacy and negative outcome expectations, and one unique factor contributing to those negative affective states for African Americans is the experience of racism, which is considered both a background contextual barrier and a proximal contextual barrier in SCCT (see Figure 1). Thus, African Americans' perceptions of racism (and sexism for women) in their academic and career environments may uniquely contribute to their decreased selfefficacy and more negative outcome expectations.

Finally, in terms of verbal persuasion, Hackett and Byars (1996) stated that one of the most powerful sources of encouragement/discouragement for African American girls and boys is their parents. For African American girls, the verbal influence from their mothers is particularly important in their developing academic and career oriented goals. The premise that African American parents are potent verbal influences for their children is intimately tied to the idea stated previously, that is, African American children do not have many African American role models from which to garner self-efficacy and outcome expectation information. As such, reliance on the parents for modeling, encouragement, and verbal information in general becomes that much more important in the development of academic/career self-efficacy and outcome expectations. 
According to Hackett and Byars (1996), parental influence may be positive or negative. African American children may experience conflicting messages from their parents, such that parents may tell children that they can "make it" even if they have not. Or, parents may communicate how to deal with societal barriers. For example, they may communicate a positive coping style, which then contributes to their children's positive educational and occupational outcome expectations. This assertion (i.e., that the family and verbal persuasion are very important in the career development of African Americans) makes sense in the context of Gainor and Lent's (1998) finding that verbal persuasion was the only learning experience to uniquely contribute to self-efficacy and outcome expectations. As such, it seems reasonable to expect that verbal persuasion, not personal performance accomplishments, will account for the majority of the variance (contributed by learning experiences) in self-efficacy and outcome expectations for African Americans.

Considered collectively, the empirical work examining the role of learning experiences in SCCT and conceptual writings about learning experiences for African Americans strongly support the idea that learning experiences play an integral role in the formation of self-efficacy and outcome expectations. However, it is unclear from the extant empirical research exactly how each of the learning experiences contributes to self-efficacy and outcome expectations in SCCT for domains other than math and science with African American students. As such, future tests of SCCT with African Americans should examine each of the four learning experiences across a range of career-related activities in order to explore more fully their relations to corresponding self-efficacy beliefs and outcome expectations. 
The dearth of research examining the role of proximal contextual factors in SCCT

Lent, Brown, and Hackett (2000) provided a detailed description of the role of contextual/environmental influences in SCCT. From a broad perspective, environmental influences in SCCT are characterized by two factors, the objective versus perceived environment and the temporal period. The authors described the objective environment as one in which an individual can quantify the influences in their environment (e.g., financial resources). In contrast, the perceived environment is one in which an individual interprets the influences in their environment (e.g., the perception of racism). In addition, contextual factors may be distal or proximal depending on the time frame in which they occur (Lent et al., 2000). Distal contextual factors are those background contextual factors in SCCT that affect the formation of learning experiences (e.g., career role models). Proximal contextual factors are those factors that are important during active phases of education or career decision making (e.g., exposure to discriminatory hiring practices).

One category of contextual influences is career barriers (Lent et al., 2000). Career barriers in SCCT are defined as negative contextual influences, as opposed to negative intrapersonal influences (e.g., low self-efficacy). Career barriers in SCCT are domain and context specific and are also categorized along a temporal continuum (Lent et al., 2000). Distal career barriers are characterized in SCCT as background contextual factors that influence the SCCT constructs of learning experiences, sociocognitive factors, and vocational interests. Proximal career barriers are characterized in SCCT as proximal contextual influences that affect the opportunity structure within which career plans are made and implemented (Lent et al., 2000). 
Career barriers may also be distinguished from other career-related constructs. Lent et al. (2000) elaborated on the differences between career barriers, coping efficacy, dispositional affect, and outcome expectations. Coping efficacy is defined as individuals' beliefs about their ability to manage obstacles or their perception of their ability to cope. An individual's perception of his/her ability to cope will affect his/her perception of the contextual influence, that is, if a contextual influence is perceived to be more manageable, there is less of a likelihood that the contextual influence will be perceived as a barrier. The inverse is true as well, that is, if a contextual influence is perceived to be less manageable, there is a greater likelihood that the contextual influence will be perceived as a barrier.

Dispositional affect is defined as the tendency to experience either positive or negative affect (Lent et al., 2000). One's dispositional affect may also influence the perception of environmental factors, that is, an individual with higher negative affect may perceive more barriers and less supports in his/her environment. Conversely, an individual with higher positive affect may perceive fewer barriers and more supports in his/her environment.

Finally, outcome expectations are defined as personal beliefs about the consequences of performing a particular behavior. According to Lent et al. (2000), career-related barriers may be conceptualized as a particular form of outcome expectations related to one's perception of the environment (termed, "process expectations"). The authors stated that career barriers may be conceptualized as process expectations (i.e., the barriers people envision encountering while in the process of 
pursuing a particular course of action) about what will happen socially, financially, etc. in the near future if one chooses to pursue a particular career path.

In the present study, one proximal contextual factor that will be examined is the potential educational and career barrier of the perception of racism for African American individuals. Recall that in SCCT, proximal contextual factors play three roles in SCCT. They are posited to moderate the relation between interests and choice goals, moderate the relation between choice goals and actions, and have a direct relationship with choice goals and/or choice actions.

Of particular importance to the present study is the posited moderating role of proximal contextual influences in the relationship between career/educational interests and choice goals. Lent et al. (1994) hypothesized that the presence of more barriers and less supports would hinder an individual from translating his/her interests into choice goals. The inverse was also hypothesized; that is, the presence of more supports and fewer barriers would facilitate the translation of one's interests into choice goals.

To date, only one empirical study has examined the proposed moderating role of proximal contextual factors in SCCT. Lent et al. (2001) compared the correlations of interests to choice goals among mostly White college students in high- and low barrier and high- and low support environments. The results indicated that the moderator hypothesis was only partially supported. Specifically, interests were related more strongly to choice goals in the low barrier environment, but not in the high support environment. Given that only one study has examined this proposed moderating relationship, and the results from that one study were mixed, additional research is 
needed to examine SCCT's posited moderating role of proximal contextual factors in the interest-goal relation.

The proposed moderating role of proximal contextual factors may be of particular importance to African Americans. Recall that the results of the Lent et al. (2005) study suggested that students at the Black university (most of whom were African American) reported greater social support and that the interest-goals relationship was appreciably (although not statistically significantly) stronger for those students. Lent et al.'s (2005) findings raise the possibility that the relation of interests to choice goals will be moderated by supports and barriers for African Americans.

In addition, studies (e.g., Luzzo, 1993; Luzzo \& McWhirter, 2001) have demonstrated that African Americans tend to experience more educational and career barriers and fewer supports than their European-American counterparts. For example, Luzzo (1993) asked participants from five different ethnic groups to indicate the types of career barriers they have encountered and expected to encounter in the future. Results indicated that $42 \%$ of the African American college students sampled had encountered and expected to encounter ethnic identity barriers (e.g., racism) in their pursuit of a particular career, as opposed to less than 5\% of European Americans. Given African American students are more likely to perceive more environmental barriers and fewer supports, it may be particularly difficult for them to translate their interests into career choice goals.

As indicated above and in other bodies of literature (e.g., Bryant-Davis \& Ocampo, 2005; Landrine and Klonoff, 1996), racism is a salient and often detrimental factor in the lives of African Americans. A study by Landrine and Klonoff (1996) found that 98.1\% 
of their African American sample $(\underline{n}=153)$ reported experiencing racist discrimination within the past year, and $100 \%$ of the sample reported experiencing some type of racist discrimination during their lifetime. In addition, the authors found that experiencing racist discrimination was correlated with stress-related, somatic symptomatology, with feelings of inadequacy and low self-esteem, and with increased psychiatric symptomatology. In terms of career development, it seems reasonable to suggest that the perception of racism by African Americans would hinder their ability to translate their educational/career interests into goals. .

\section{Summary of Limitations}

The limitations of the extant SCCT research are as follows: (a) a relative paucity of research on SCCT with African American samples, (b) little research on domains other than math and science, (c) little research examining the direct relationships of learning experiences with self-efficacy and outcome expectations, and (d) the dearth of research examining the posited moderating role of proximal contextual affordances in the relationship between interests and choice goals.

Scholars (Lent et al., 1994; Lent et al., 2000) have asserted that SCCT is an ideal framework for examining the career development of women and ethnic minorities given its focus on the environmental conditions that affect career decision-making. However, little research has examined SCCT constructs with samples comprised of individuals other than European-Americans. African Americans remain one such underrepresented group, and, as such, the applicability of SCCT for African Americans remains in question. 
Additionally, the majority of the research on SCCT had focused on math- and science-related activities. As such, little is know about the applicability of SCCT for individuals who have interests and choice goals in fields other than math and science. One potential framework for assessing additional domains in SCCT research is Holland's (1997) RIASEC typology. Utilizing the RIASEC framework would allow for the examination of a broader range of career-related domains.

Finally, two important SCCT constructs have received limited attention in the literature. Despite Lent et al.’s (1994) assertion that self-efficacy and outcome expectations are largely informed by learning experiences, few studies have included measures of learning experiences in their examination of SCCT. Research by Schaub \& Tokar (2005) has demonstrated that learning experiences have a strong relationship with self-efficacy and outcome expectations. However, Schaub and Tokar's (2005) sample did not include African Americans, and learning experiences were measured globally. Proximal contextual influences are also posited to play an important role in SCCT. However, few studies have examined any of three posited roles of proximal contextual influences in choice goals and actions. In particular, the moderating role of proximal contextual influences in the translation of interests to choice goals has received limited empirical attention and may be of particular importance to African Americans, who likely experience more vocational/educational barriers and fewer supports, thus making it more difficult for them to translate their interests to goals.

In the following section, I will detail the proposed hypotheses of the present research. All of the hypotheses are based on Lent et al.'s (1994) SCCT propositions. The two hypotheses that do not conform to the original theory concern the role of learning 
experiences in the formation of self-efficacy beliefs and outcome expectations. Based on the previously reviewed literature (e.g., Gainor \& Lent, 1998), I hypothesize that verbal persuasion (not performance accomplishments) will explain more variance in selfefficacy for the six Holland interest types than will performance accomplishments, vicarious learning, or emotional arousal (Hypothesis $1 \mathrm{G}$ ) and verbal persuasion (not performance accomplishments) will explain more variance in outcome expectations for the six Holland interest types than will performance accomplishments, vicarious learning, and emotional arousal (Hypothesis $2 \mathrm{G})$. 


\section{Hypotheses}

The main research questions in this study involve: (1) the applicability of SCCT with a sample of African Americans, (2) the validity of SCCT across Holland's (1997) six vocational domains, (3) the relation of learning experiences to self-efficacy and outcome expectations, and (4) the moderating role of racism in the relationship between interests and choice goals.

As a point of clarification, hypotheses 1-8 describe the posited direct and/or total relationships in SCCT and hypotheses 9-12 describe the posited indirect relationships in SCCT that will be examined in this study.

\section{Hypothesis 1: The Relations of Learning Experiences to Self-Efficacy}

Performance accomplishments, vicarious learning, verbal persuasion, and emotional arousal are related to self-efficacy for the six Holland interest themes.

Hypothesis 1A. Realistic performance accomplishments, vicarious learning, verbal persuasion, and lower emotional arousal are related positively to self-efficacy for Realistic activities.

Hypothesis $1 B$. Investigative performance accomplishments, vicarious learning, verbal persuasion, and lower emotional arousal are related positively to self-efficacy for Investigative activities.

Hypothesis 1C. Artistic performance accomplishments, vicarious learning, verbal persuasion, and lower emotional arousal are related positively to self-efficacy for Artistic activities. 
Hypothesis 1D. Social performance accomplishments, vicarious learning, verbal persuasion, and lower emotional arousal are related positively to self-efficacy for Social activities.

Hypothesis 1E. Enterprising performance accomplishments, vicarious learning, verbal persuasion, and lower emotional arousal are related positively to self-efficacy for Enterprising activities.

Hypothesis $1 F$. Conventional performance accomplishments, vicarious learning, verbal persuasion, and lower emotional arousal are related positively to self-efficacy for Conventional activities.

Hypothesis 1G. Verbal persuasion explains more variance in self-efficacy for each of the six Holland themes than do performance accomplishments, vicarious learning, or emotional arousal.

Hypothesis 2: The Relations of Learning Experiences to Outcome Expectations

Performance accomplishments, vicarious learning, verbal persuasion, and emotional arousal are related to outcome expectations for the six Holland themes.

Hypothesis $2 A$. Realistic performance accomplishments, vicarious learning, verbal persuasion, and lower emotional arousal each are related positively to outcome expectations for Realistic activities.

Hypothesis 2B. Investigative performance accomplishments, vicarious learning, verbal persuasion, and lower emotional arousal each are related positively to outcome expectations for Investigative activities. 
Hypothesis 2C. Artistic performance accomplishments, vicarious learning, verbal persuasion, and lower emotional arousal each are related positively to outcome expectations for Artistic activities.

Hypothesis 2D. Social performance accomplishments, vicarious learning, verbal persuasion, and lower emotional arousal each are related positively to outcome expectations for Social activities.

Hypothesis 2E. Enterprising performance accomplishments, vicarious learning, verbal persuasion, and lower emotional arousal each are related positively to outcome expectations for Enterprising activities.

Hypothesis 2F. Conventional performance accomplishments, vicarious learning, verbal persuasion, and lower emotional arousal each are related positively to outcome expectations for Conventional activities.

Hypothesis 2G. Verbal persuasion explains more variance in outcome expectations for each of the six Holland themes than does performance accomplishments, vicarious learning, and emotional arousal.

Hypothesis 3: The Relation of Self-Efficacy to Outcome Expectations

Self-efficacy is related positively to outcome expectations for each of the six Holland themes.

Hypothesis 3A. Self-efficacy and outcome expectations for Realistic activities are related positively.

Hypothesis 3B. Self-efficacy and outcome expectations for Investigative activities are related positively. 
Hypothesis 3C. Self-efficacy and outcome expectations for Artistic activities are related positively.

Hypothesis 3D. Self-efficacy and outcome expectations for Social activities are related positively.

Hypothesis 3E. Self-efficacy and outcome expectations for Enterprising activities are related positively.

Hypothesis 3F. Self-efficacy and outcome expectations for Conventional activities are related positively.

Hypothesis 4: The Relation of Self-Efficacy to Vocational Interests

Self-efficacy is related positively to vocational interests for each of Holland's interest themes.

Hypothesis 4A. Self-efficacy for Realistic activities is related positively to Holland's Realistic interest theme.

Hypothesis 4B. Self-efficacy for Investigative activities is related positively to Holland's Investigative interest theme.

Hypothesis 4C. Self-efficacy for Artistic activities is related positively to Holland's Artistic interest theme.

Hypothesis $4 D$. Self-efficacy for Social activities is related positively to Holland's Social interest theme.

Hypothesis 4E. Self-efficacy for Enterprising activities is related positively to Holland's Enterprising interest theme.

Hypothesis 4F. Self-efficacy for Conventional activities is related positively to Holland's Conventional interest theme. 


\section{Hypothesis 5: The Relation of Outcome Expectations to Vocational Interests}

Outcome expectations are related positively to vocational interests for each of Holland's interest themes.

Hypothesis 5A. Outcome expectations for Realistic activities are related positively to Holland's Realistic interest theme.

Hypothesis 5B. Outcome expectations for Investigative activities are related positively to Holland's Investigative interest theme.

Hypothesis 5C. Outcome expectations for Artistic activities are related positively to Holland's Artistic interest theme.

Hypothesis $5 D$. Outcome expectations for Social activities are related positively to Holland's Social interest theme.

Hypothesis 5E. Outcome expectations for Enterprising activities are related positively to Holland's Enterprising interest theme.

Hypothesis 5F. Outcome expectations for Conventional activities are related positively to Holland's Conventional interest theme.

Hypothesis 6: The Relation of Self-Efficacy to Choice Goals

Self-efficacy is related positively to choice goals for each of the six Holland themes.

Hypothesis 6A. Self-efficacy and choice goals for Realistic activities are related positively.

Hypothesis $6 B$. Self-efficacy and choice goals for Investigative activities are related positively.

Hypothesis 6C. Self-efficacy and choice goals for Artistic activities are related positively. 
Hypothesis 6D. Self-efficacy and choice goals for Social activities are related positively.

Hypothesis 6E. Self-efficacy and choice goals for Enterprising activities are related positively.

Hypothesis 6F. Self-efficacy and choice goals for Conventional activities are related positively.

Hypothesis 7: The Relation of Outcome Expectations to Choice Goals

Outcome expectations are related positively to choice goals for each of the six Holland themes.

Hypothesis 7A. Outcome expectations and choice goals for Realistic activities are related positively.

Hypothesis 7B. Outcome expectations and choice goals for Investigative activities are related positively.

Hypothesis 7C. Outcome expectations and choice goals for Artistic activities are related positively.

Hypothesis 7D. Outcome expectations and choice goals for Social activities are related positively.

Hypothesis 7E. Outcome expectations and choice goals for Enterprising activities are related positively.

Hypothesis 7F. Outcome expectations and choice goals for Conventional activities are related positively. 


\section{Hypothesis 8: The Relation of Vocational Interests to Choice Goals}

Vocational interests are related positively to choice goals for each of the six Holland themes.

Hypothesis $8 A$. Realistic vocational interests and choice goals for Realistic activities are related positively.

Hypothesis $8 B$. Investigative vocational interests and choice goals for Investigative activities are related positively.

Hypothesis 8C. Artistic vocational interests and choice goals for Artistic activities are related positively.

Hypothesis $8 D$. Social vocational interests and choice goals for Social activities are related positively.

Hypothesis $8 E$. Enterprising vocational interests and choice goals for Enterprising activities are related positively.

Hypothesis $8 F$. Conventional vocational interests and choice goals for Conventional activities are related positively.

Hypothesis 9: The Indirect Relations of Learning Experiences to Outcome Expectations

Part of the total relations of performance accomplishments, vicarious learning, verbal persuasion, and emotional arousal to outcome expectations are indirect, via selfefficacy.

Hypothesis 9A. Realistic performance accomplishments, vicarious learning, verbal persuasion, and emotional arousal are related indirectly to outcome expectations for Realistic activities via self-efficacy. 
Hypothesis 9B. Investigative performance accomplishments, vicarious learning, verbal persuasion, and emotional arousal are related indirectly to outcome expectations for Investigative activities via self-efficacy.

Hypothesis 9C. Artistic performance accomplishments, vicarious learning, verbal persuasion, and emotional arousal are related indirectly to outcome expectations for Artistic activities via self-efficacy.

Hypothesis 9D. Social performance accomplishments, vicarious learning, verbal persuasion, and emotional arousal are related indirectly to outcome expectations for Social activities via self-efficacy.

Hypothesis 9E. Enterprising performance accomplishments, vicarious learning, verbal persuasion, and emotional arousal are related indirectly to outcome expectations for Enterprising activities via self-efficacy.

Hypothesis 9F. Conventional performance accomplishments, vicarious learning, verbal persuasion, and emotional arousal are related indirectly to outcome expectations for Conventional activities via self-efficacy.

Hypothesis 10: The Indirect Relation of Self-Efficacy to Vocational Interests

Part of the total relation of self-efficacy to vocational interests is indirect, via outcome expectations.

Hypothesis 10A. Self-efficacy for Realistic activities is related indirectly to Realistic interests via outcome expectations.

Hypothesis 10B. Self-efficacy for Investigative activities is related indirectly to Investigative interests via outcome expectations. 
Hypothesis 10C. Self-efficacy for Artistic activities is related indirectly to Artistic interests via outcome expectations.

Hypothesis 10D. Self-efficacy for Social activities is related indirectly to Social interests via outcome expectations.

Hypothesis 10E. Self-efficacy for Enterprising activities is related indirectly to Enterprising interests via outcome expectations.

Hypothesis 10F. Self-efficacy for Conventional activities is related indirectly to Conventional interests via outcome expectations.

Hypothesis 11: The Indirect Relation of Self-Efficacy to Choice Goals

Part of the total relation of self-efficacy to choice goals is indirect, via outcome expectations and vocational interests.

Hypothesis 11A. Self-efficacy and choice goals for Realistic activities are related indirectly via outcome expectations and interests.

Hypothesis 11B. Self-efficacy and choice goals for Investigative activities are related indirectly via outcome expectations and interests.

Hypothesis 11C. Self-efficacy and choice goals for Artistic activities are related indirectly via outcome expectations and interests.

Hypothesis 11D. Self-efficacy and choice goals for Social activities are related indirectly via outcome expectations and interests.

Hypothesis 11E. Self-efficacy and choice goals for Enterprising activities are related indirectly via outcome expectations and interests.

Hypothesis 11F. Self-efficacy and choice goals for Conventional activities are related indirectly via outcome expectations and interests. 
Hypothesis 12: The Indirect Relations of Outcome Expectations to Choice Goals

Part of the total relations of outcome expectations to choice goals is indirect, via interests.

Hypothesis 12A. Outcome expectations and choice goals for Realistic activities are related indirectly via interests.

Hypothesis 12B. Outcome expectations and choice goals for Investigative activities are related indirectly via interests.

Hypothesis 12C. Outcome expectations and choice goals for Artistic activities are related indirectly via interests.

Hypothesis 12D. Outcome expectations and choice goals for Social activities are related indirectly via interests.

Hypothesis 12E. Outcome expectations and choice goals for Enterprising activities are related indirectly via interests.

Hypothesis 12F. Outcome expectations and choice goals for Conventional activities are related indirectly via interests.

Hypothesis 13: The Moderating Role of Racism in the Relation between Interests and Choice Goals

The perception of racism will moderate the interest-choice goals relation for each of the six Holland interest themes.

Hypothesis 13A. The perception of racism will moderate the interest-choice goals relation for Realistic activities such that a greater perception of racism will weaken the interest-choice goals relation. Inversely, a weaker perception of racism will strengthen the interest-choice goals relation. 
Hypothesis 13B. The perception of racism will moderate the interest-choice goals relation for Investigative activities such that a greater perception of racism will weaken the interest-choice goals relation. Inversely, a weaker perception of racism will strengthen the interest-choice goals relation.

Hypothesis 13C. The perception of racism will moderate the interest-choice goals relation for Artistic activities such that a greater perception of racism will weaken the interest-choice goals relation. Inversely, a weaker perception of racism will strengthen the interest-choice goals relation.

Hypothesis 13D. The perception of racism will moderate the interest-choice goals relation for Social activities such that a greater perception of racism will weaken the interest-choice goals relation. Inversely, a weaker perception of racism will strengthen the interest-choice goals relation.

Hypothesis 13E. The perception of racism will moderate the interest-choice goals relation for Enterprising activities such that a greater perception of racism will weaken the interest-choice goals relation. Inversely, a weaker perception of racism will strengthen the interest-choice goals relation.

Hypothesis 13F. The perception of racism will moderate the interest-choice goals relation for Conventional activities such that a greater perception of racism will weaken the interest-choice goals relation. Inversely, a weaker perception of racism will strengthen the interest-choice goals relation. 


\section{CHAPTER III}

\section{METHODOLOGY}

\section{Participants and Procedure}

The sample consisted of 208 students (130 women and 78 men) enrolled at a large, public, Midwestern university. The participants ranged in age from 18 to 43 years $(M=$ $21.1, S D=2.9$ ) with $16.9 \%$ in their first year of study, $25.1 \%$ in their second year, $22.2 \%$ in their third year, $23.2 \%$ in their fourth year, $5.8 \%$ pursuing graduate studies, and $6.7 \%$ post-baccalaureate or other. The majority (98.1\%) of students identified as AfricanAmerican, with $1.9 \%$ identifying as biracial/multiracial. The sample was evenly distributed across SES with $24.4 \%$ of the participants identifying as middle class, $21.5 \%$ indicating upper class, $17.6 \%$ working class, $22.9 \%$ lower class, and 13.7\% upper middle class. The median grade point average was $2.8(S D=.44)$ out of a 4.0 scale with $100 \%$ reporting, and the median SAT score was $1091.2(S D=175.5)$ with $100 \%$ reporting.

Fifty-nine academic majors were represented in this sample. The majors were categorized into 10 academic areas. The number of students majoring in each area was as follows: Art/Music, 7; Business/Marketing, 43; International/Cultural Studies, 5; Economics, 2; English/History, 22; Government/Politics, 11; Language, 2; Math/Science, 50; Social Science, 59; Undecided/Undeclared/Missing, 6. Participants individually completed a research packet consisting of the Learning Experiences Questionnaire (LEQ; 
Schaub, 2003), a measure of self-efficacy, the Occupational Outcome Expectations (OOE; Gore \& Leuwerke, 2000), a measure of interests, a measure of choice goals, the Schedule of Racist Events (SRE; Landrine \& Klonoff, 1996), and a demographic questionnaire. The order of the instruments was counter-balanced to control for possible order effects. The participants completed the instruments at a cultural center and were paid ten dollars for completing the survey packet.

Instruments

Learning Experiences Questionnaire (LEQ; Schaub, 2003). Learning experiences were measured with the LEQ. The LEQ is a rationally derived measure that consists of 120 items designed to measure four types of learning experiences (i.e., performance accomplishments, vicarious learning, verbal persuasion, and physiological arousal) for the six Holland (1997) themes.

Each of the four types of learning experiences was assessed with five items corresponding to Holland's six RIASEC themes, yielding twenty items for each RIASEC type. Respondents indicated the extent to which they have had the learning experiences on a 6-point Likert-type scale ranging from Strongly Disagree (1) to Strongly Agree (6). Scores for each type of learning experience are the summed responses of the five items on that scale. Sample items include, "I have made repairs around the house" (Realistic Performance Accomplishment) and "While growing up, I recall seeing people I respected reading scientific articles" (Investigative Vicarious Learning).

Schaub (2003) reported adequate internal consistency estimates for the LEQ subscales and total scales (i.e., the sum of the four subscales for each RIASEC theme) for samples of female and male college students. For the 24 LEQ subscales, Schaub (2003) 
initially reported alpha coefficients ranging from .51 (Enterprising Vicarious Learning) to .84 (Realistic Performance Accomplishments) $(M d n=.69)$. For the 6 LEQ total scores, Schaub (2003) reported alpha coefficients ranging from .72 (Conventional) to .89 (Realistic) $(M d n=.82)$. However, given that each subscale was only comprised of 5 items, the Spearman-Brown prophecy formula was employed to calculate reliability estimates for 10 items per subscale. This formula calculation resulted in alpha coefficients for LEQ subscales ranging from .68 (Enterprising Vicarious Learning) to .91 (Realistic Performance Accomplishments) $(M d n=.82)$. Content validity was assessed by three counseling psychologists who are experts in vocational research. The reviewers evaluated the extent to which the items reflected what they were intended to measure, whether the Holland domain was adequately represented, and the clarity of wording. Construct validity evidence was demonstrated by Schaub and Tokar (2005), who found that LEQ summary scale scores were strongly and positively related to scores for corresponding self-efficacy and outcome expectations.

Occupational Outcome Expectations (OOE; Gore \& Leuwerke, 2000). Outcome expectations were assessed with the OOE, a self-report measure that includes 84 occupational titles, fourteen representing each of Holland's (1997) six RIASEC types. Respondents indicated the "degree to which they would get what they wanted" from each of the 84 occupational titles using a 9-point scale ranging from 1 (Not Very Much) to 9 (Very Much). Outcome expectation scores for the Holland types are the summed responses of the fourteen items for each scale, with possible scores ranging from 0 to 126. 
Using a sample of 93 college students, Gore and Leuwerke (2000) reported excellent internal consistency estimates for the OOE across Holland's six themes $(.91, .94, .94, .95$, .92 , and .96 for R, I, A, S, E, and C, respectively). Gore (1996) found that the OOE scores correlated with vocational interests for each of Holland's six themes ( $\underline{\mathrm{s}}=.36, .60$, $.56, .70, .57$, and .47 for R, I, A, S, E, and C, respectively). Finally, Gore and Leuwerke (2000) found that outcome expectations correlated positively with both self efficacy beliefs and occupational considerations. In addition, the authors found that OOE scores were a stronger predictor of occupational consideration than was the person-environment interest congruence (i.e., the correspondence between participants' Holland code and occupational considerations).

Self-Efficacy. Self-efficacy was measured with a slightly modified version of Gore and Leuwerke's (2000) Occupational Self-Efficacy Beliefs (OSB) measure. The modified OSB consisted of the same 84 occupational titles as those comprising the OOE, with the same fourteen occupations representing each of Holland's (1997) RIASEC themes. The original version of the measure asks respondents to indicate whether or not they have the abilities to enter each occupation and instructs respondents to indicate both level ("Could you become a (n)..."), and strength ("How sure are you”) of their selfefficacy beliefs. Dichotomous scores (i.e., yes, no) are used to assess level ratings and strength ratings are assessed using a 9-point scale ranging from 1 (Completely Unsure) to 9 (Completely Sure).

To simplify the directions and scoring, a modification to the instructions was made. Following Lent et al. (2003), who developed a self-efficacy measure from a subset of Gore and Leuwerke's (2000) OOE items, the instructions read, "Indicate how much 
confidence you have in your ability to become a successful worker in each of these occupations" using a 10-point scale $(0=$ No Confidence, $9=$ Complete Confidence $)$. Self-efficacy scores for the Holland types were the summed responses of the fourteen items for each scale, with possible scores ranging from 0 to 126 , and higher scores indicating more positive self-efficacy beliefs.

For the original OSB measure, Gore and Leuwerke (2000) reported internal consistency estimates ranging from .89 for Artistic to .95 for Investigative using a sample of 93 college students. Consistent with SCCT, the authors reported that OSB scores correlated positively with measures of outcome expectations and occupational considerations. Finally, Gore and Leuwerke (2000) found that OSB scores were a stronger predictor of occupational consideration than was the person-environment interest congruence (i.e., the correspondence between participants' Holland code and occupational considerations).

Interests. Interests were assessed using the same 84 occupational titles used in Gore and Leuwerke's (2000) self-efficacy and outcome expectations measures. Following the template of Lent et al.'s (2003) interest measure (a modified version of Gore and Leuwerke's [2000] self-efficacy and outcome expectations measures), the interest measure asked participants to indicate how much "You think you would like or dislike the work activities that people in each of these occupations perform" on a 0 (Strongly Dislike) to 9 (Strongly Like) scale. Vocational interest scores for the Holland types are the summed responses of the fourteen items for each scale, with possible scores ranging from 0 to 126. 
For their 42-item vocational interest measure (adapted from a subset of Gore and Leuwerke's [2000] 84 occupational titles), Lent et al. (2003) found internal consistency estimates ranging from .80 for Realistic to .94 for Conventional. Consistent with SCCT, Lent et al.'s RIASEC interest measure demonstrated positive associations with corresponding measures of self-efficacy, outcome expectations, and occupational considerations.

Choice Goals. Choice goals were assessed with the same 84 occupational titles from Gore and Leuwerke's (2000) self-efficacy and outcome expectation measures. Per Lent et al.'s (2003) 42-item occupational consideration measure (a modified version of Gore and Leuwerke's self-efficacy and outcome expectation measures), participants were asked to indicate "how seriously you would consider" each occupation "as a possible career for yourself”' along a scale of 0 (Not Very Seriously) to 9 (Very Seriously). Choice goal scores for the Holland types are the summed responses of the fourteen items for each scale, with possible scores ranging from 0 to 126.

Using a sample of 796 Italian high school students, Lent et al. (2003) reported internal consistency estimates ranging from .85 for Realistic to .94 for Conventional for their occupational consideration measure. Consistent with SCCT, scores for Lent et al.'s 42-item choice consideration measure were significantly predicted by corresponding measures of self-efficacy, outcome expectations, and vocational interests across all six RIASEC themes.

Given that the measures of self-efficacy, outcome expectations, interests, and choice goals all share the same set of 84 occupational titles, there exists the possibility that linked measurement procedures may override any theoretical difference between the 
constructs. To test this possibility for their 42-item measures of self-efficacy, outcome expectations, interests, and choice considerations, Lent et al. (2003) performed a series of confirmatory factory analyses (CFAs) to examine the latent structure underlying these measures (also included in the model were measures of social supports and social barriers). The authors compared three models. The first representation of the data was a correlated 2-factor model in which self-efficacy, outcome expectations, interests, and choice consideration composed a single latent dimension, and social supports and barriers composed a second latent dimension. The second model contained three correlated latent dimensions of self-efficacy and outcome expectations, interest and choice consideration, and social supports and barriers. In the third model, self-efficacy, outcome expectations, interests, choice consideration, and social supports and barriers were represented as six distinct but correlated latent dimensions.

Lent et al. (2003) tested each of the three models six times, once for each Holland theme. Item parcels were created on the basis of exploratory factor analysis by fitting single-factor solutions to each measure, and then using item-factor loadings to form composite indicators of each construct. Self-efficacy, outcome expectations, interests, and choice consideration were each represented by three indicators in each model test. Initial CFA results revealed that, while the 6-factor model fit the data better in comparison to the other two models, the CFI values were below the recommended .90 value. To produce a better model-data fit, Lent et al. (2003) allowed six sets of measurement errors to covary in the tests for each Holland type. The revised 6-factor models produced adequate-to-good model-data fits (e.g., CFI ranged from .92 to .97; NNFI from .89 to .95$)$. The authors concluded that these results supported the 
representation of self-efficacy, outcome expectations, interests, choice consideration, social supports, and social barriers as six distinct but correlated latent dimensions.

Schedule of Racist Events (SRE; Landrine \& Klonoff, 1996). Racism was measured using the SRE, an 18-item self-report measure designed to assess racist discrimination in the lives of African Americans. The SRE measures the frequency of racist discrimination in the past year and in one's entire life, and the extent to which the perceived discrimination was stressful. Each of the 18 items was completed three times on 6-point scales for frequency of racist events in the past year and during one's entire life, and appraisal of the stressfulness of racist events. The 6-point scales for frequency of racist event in the past year and during one's entire life ranged from 1 (Never Happened) to 6 (70\% of the Time). The 6-point scale for appraisal of stressfulness ranged from 1 (Not at all Stressful) to 6 (Extremely Stressful). According to the authors, these three ratings can be used separately as different subscales to yield information on recent racist events, lifetime racist events, and appraised racist events.

Preliminary evidence reported by Landrine and Klonoff (1996) with a sample of 153 African Americans revealed excellent internal consistency reliability coefficients of .95, .95, and .94 for Recent, Lifetime, and Appraised events, respectively. Concurrent validity evidence was demonstrated by strong, positive correlations between the SRE and the Hopkins Symptom Checklist (HSCL-58; Derogatis, Lipman, Rickles, Uhlenhuth, \& Coui, 1974), a measure of five psychiatric symptoms (anxiety, depression, obsessivecompulsive, interpersonal sensitivity, and somatization), the SRE and smoking, and the SRE and acculturation (Landrine \& Klonoff, 1996). 
In a cross-validation study of the SRE, Klonoff and Landrine (1999) used a sample of 520 African Americans to test the SRE's factor structure and relationships to psychiatric symptoms, as measured by the Symptom Checklist-58 (SCL; Derogatis, Lipman, Rickels, Uhlenhuth, \& Coui, 1994). Results of reliability analyses revealed excellent internal consistency reliability coefficients of $.95, .94$, and .94 for Recent, Lifetime, and Appraised racism scores, respectively. Further, the authors reported positive correlations between the SRE subscales and the SCL-58 total symptoms score (rs $=.25, .30$, and .33 for Lifetime, Recent, and Appraisal, respectively). However, results of principal components analysis revealed that the SRE is a unidimensional measure and does not, in fact, measure three different dimensions of racism. Thus, for the purposes of this dissertation research, racism was measured globally by the SRE.

Demographic Variables. Participants completed demographic items concerning their age, sex, race-ethnicity, year in school, major/intended major, GPA, college admission test scores (SAT, ACT), anticipated career choice, and mother's and father's educational level. 


\section{CHAPTER IV}

\section{RESULTS}

In this chapter I will describe the results of this dissertation. The chapter is organized by the following sections: a summary of the descriptive statistics and internal consistency estimates for the measures, a summary of the correlation analyses, a description of the path models, a summary of the structural invariance analyses, the results of the path models, the results of the simultaneous regression analyses, and the results of the moderated regression analyses.

\section{Descriptive Statistics and Internal Consistency Estimates of the Measures}

The means, standards deviations, ranges, and internal consistency estimates for the LEQ, the measure of self-efficacy, the OOE, the measure of interests, the measure of choice goals, and the SRE are described in Table 1.

The LEQ subscale and total scale means were comparable (i.e., within a half a standard deviation) to previously reported means from primarily White samples (Schaub, 2003; Schaub \& Tokar, 2005). Notable exceptions to this trend include the scores for most of the Emotional Arousal subscales, some of the Vicarious Learning subscales, Social Performance Accomplishments for men, and Social total scores for women. For the current samples of male and female African American students, Emotional Arousal scores were appreciably higher than those reported by Schaub (2003) and Schaub and 
Table 1. Descriptive Statistics and Internal Consistency Estimates for the LEQ, the Measure of Self-Efficacy, the OOE, the Measure of Interests, the Measure of Choice Goals, and the SRE.

\begin{tabular}{|c|c|c|c|c|}
\hline Scale & $M$ & $S D$ & Range & Alpha \\
\hline \multicolumn{5}{|l|}{ LEQ } \\
\hline \multicolumn{5}{|l|}{$\underline{\text { Realistic }}$} \\
\hline \multicolumn{5}{|l|}{ Performance } \\
\hline Accomplishments & $18.13(19.7)$ & $5.3(5.5)$ & $5-30(8-30)$ & $.73(.69)$ \\
\hline Vicarious Learning & $21.12(20.2)$ & $5.6(5.5)$ & $5-30(8-30)$ & $.76(.69)$ \\
\hline Verbal Persuasion & $15.90(18.14)$ & $5.1(5.4)$ & $5-30(6-30)$ & $.71(.67)$ \\
\hline Emotional Arousal & $20.59(19.1)$ & $4.3(4.7)$ & $12-30(10-30)$ & $.57(.50)$ \\
\hline Realistic Total Score & $75.74(77.3)$ & $15.1(15.2)$ & $40-114(56-120)$ & $.83(.80)$ \\
\hline \multicolumn{5}{|l|}{ Investigative } \\
\hline \multicolumn{5}{|l|}{ Performance } \\
\hline Accomplishments & $20.9(20.2)$ & $4.3(5.0)$ & $6-30(9-30)$ & $.59(.60)$ \\
\hline Vicarious Learning & $17.4(18.0)$ & $4.8(5.4)$ & $5-30(6-30)$ & $.68(.69)$ \\
\hline Verbal Persuasion & $18.9(19.4)$ & $5.2(5.0)$ & $5-30(8-30)$ & $.68(.64)$ \\
\hline Emotional Arousal & $19.5(19.3)$ & $5.2(4.9)$ & $8-30(7-30)$ & $.65(.55)$ \\
\hline Investigative Total Score & $76.7(77.0)$ & $14.0(15.0)$ & $35-115(46.120)$ & $.80(.80)$ \\
\hline \multicolumn{5}{|l|}{$\underline{\text { Artistic }}$} \\
\hline \multicolumn{5}{|l|}{ Performance } \\
\hline Accomplishments & $20.0(18.9)$ & $5.1(5.0)$ & $6-30(8-29)$ & $.62(.57)$ \\
\hline Vicarious Learning & $17.5(17.1)$ & $5.3(5.7)$ & $5-28(5-30)$ & $.65(.66)$ \\
\hline Verbal Persuasion & $18.1(17.5)$ & $5.4(5.0)$ & $5-29(5-30)$ & $.60(.54)$ \\
\hline Emotional Arousal & $19.5(18.7)$ & $4.9(5.2)$ & $8-30(5-30)$ & $.60(.61)$ \\
\hline Artistic Total Score & $75.2(72.3)$ & $14.9(14.6)$ & $42-112(46-114)$ & $.79(.76)$ \\
\hline
\end{tabular}


Table 1 (continued). Descriptive Statistics and Internal Consistency Estimates for the LEQ, the Measure of Self-Efficacy, the OOE, the Measure of Interests, the Measure of Choice Goals, and the SRE.

\begin{tabular}{|c|c|c|c|c|}
\hline Scale & $M$ & $S D$ & Range & Alpha \\
\hline \multicolumn{5}{|l|}{ LEQ } \\
\hline \multicolumn{5}{|l|}{$\underline{\text { Social }}$} \\
\hline \multicolumn{5}{|l|}{ Performance } \\
\hline Accomplishments & $25.6(22.1)$ & $3.5(3.4)$ & $9-30(9-30)$ & $.70(.79)$ \\
\hline Vicarious Learning & $22.6(19.7)$ & $4.7(5.5)$ & $10-30(8-30)$ & $.62(.68)$ \\
\hline Verbal Persuasion & $22.0(20.0)$ & $4.4(4.8)$ & $8-30(10-30)$ & $.57(.55)$ \\
\hline Emotional Arousal & $21.5(19.4)$ & $4.2(4.8)$ & $12-30(7-30)$ & $.53(.54)$ \\
\hline Social Total Score & $91.9(81.4)$ & $11.8(15.9)$ & $56-115(55-120)$ & $.76(.84)$ \\
\hline \multicolumn{5}{|l|}{ Enterprising } \\
\hline \multicolumn{5}{|l|}{ Performance } \\
\hline Accomplishments & $22.8(21.8)$ & $4.3(4.8)$ & $10-30(9-30)$ & $.63(.67)$ \\
\hline Vicarious Learning & $20.1(19.1)$ & $5.0(5.6)$ & $9-30(9-30)$ & $.61(.69)$ \\
\hline Verbal Persuasion & $19.1(19.3)$ & $5.3(5.8)$ & $8-30(6-30)$ & $.70(.71)$ \\
\hline Emotional Arousal & $20.3(19.5)$ & $5.0(5.0)$ & $8-30(8-30)$ & $.70(.59)$ \\
\hline Enterprising Total Score & $82.4(79.8)$ & $13.4(14.8)$ & $47-113(51-115)$ & $.78(.80)$ \\
\hline \multicolumn{5}{|l|}{ Conventional } \\
\hline \multicolumn{5}{|l|}{ Performance } \\
\hline Accomplishments & $23.0(20.4)$ & $3.9(4.6)$ & $12-30(11-30)$ & $.48(.53)$ \\
\hline Vicarious Learning & $21.5(19.3)$ & $5.2(5.5)$ & $6-30(6-30)$ & $.67(.68)$ \\
\hline Verbal Persuasion & $19.8(19.1)$ & $5.1(5.5)$ & $5-30(6-30)$ & $.66(.68)$ \\
\hline Emotional Arousal & $20.6(19.4)$ & $4.4(5.0)$ & $11-306-30)$ & $.49(.61)$ \\
\hline Conventional Total Score & $85.0(78.4)$ & $12.2(14.3)$ & $53-115(50-118)$ & $.72(.78)$ \\
\hline \multicolumn{5}{|l|}{ Self-Efficacy } \\
\hline Realistic & $47.5(70.3)$ & $27.8(33.0)$ & $14-126(14-126)$ & $.94(.96)$ \\
\hline Investigative & $52.9(66.3)$ & $30.0(35.1)$ & $14-126(14-126)$ & $.95(.97)$ \\
\hline
\end{tabular}


Table 1 (continued). Descriptive Statistics and Internal Consistency Estimates for the LEQ, the Measure of Self-Efficacy, the OOE, the Measure of Interests, the Measure of Choice Goals, and the SRE

\begin{tabular}{lllll}
\hline Scale & $M$ & $S D$ & Range & Alpha \\
\hline Self-Efficacy & & & & \\
$\quad$ Artistic & $63.7(72.8)$ & $28.5(31.5)$ & $14-126(14-126)$ & $.93(.94)$ \\
Social & $83.2(77.4)$ & $27.4(34.0)$ & $14-126(14-126)$ & $.93(.96)$ \\
Enterprising & $74.7(76.3)$ & $30.2(32.3)$ & $14-126(14-126)$ & $.94(.96)$ \\
Conventional & $66.7(72.8)$ & $34.2(34.4)$ & $14-126(14-126)$ & $.97(.97)$
\end{tabular}

OOE

Realistic

Investigative

Artistic

Social

Enterprising

Conventional

Interests

Realistic

Investigative

Artistic

Social

Enterprising

Conventional

Choice Goals

Realistic

Investigative

Artistic

Social

Enterprising

$\begin{array}{llll}33.5(47.6) & 25.1(30.1) & 14-126(14-126) & .96(.96) \\ 36.0(45.9) & 25.3(29.5) & 12-108(12-108) & .96(.97) \\ 57.2(63.2) & 31.7(34.0) & 14-126(14-126) & .95(.96) \\ 71.6(63.6) & 31.0(33.3) & 14-126(14-126) & .95(.96) \\ 53.2(57.5) & 29.2(32.1) & 14-126(14-126) & .94(.96) \\ 42.4(54.5) & 30.7(35.4) & 14-126(14-126) & .97(.97)\end{array}$

$\begin{array}{llll}38.5(53.9) & 29.9(29.5) & 14-126(14-126) & .97(.96) \\ 47.0(57.5) & 31.9(32.4) & 14-126(14-126) & .96(.97) \\ 64.5(69.4) & 33.9(33.1) & 14-126(14-126) & .95(.96) \\ 73.4(64.7) & 29.3(30.8) & 14-126(14-126) & .94(.95) \\ 53.2(59.5) & 29.8(29.1) & 14-126(14-126) & .94(.95) \\ 44.3(55.8) & 33.4(34.4) & 14-126(14-126) & .98(.97)\end{array}$

$44.3(55.8) \quad 33.4(34.4)$

$14-126(14-126)$

$.98(.97)$

$\begin{array}{llll}24.2(42.0) & 18.5(27.7) & 14-126(14-126) & .95(.96) \\ 36.4(47.8) & 28.0(30.9) & 14-126(14-126) & .95(.96) \\ 46.9(58.4) & 31.2(33.1) & 14-126(14-126) & .95(.95) \\ 62.9(59.6) & 30.6(30.3) & 14-126(14-126) & .93(.95) \\ 42.5(52.2) & 27.1(28.9) & 14-112(14-126) & .94(.94)\end{array}$


Table 1 (continued). Descriptive Statistics and Internal Consistency Estimates for the LEQ, the Measure of Self-Efficacy, the OOE, the Measure of Interests, the Measure of Choice Goals, and the SRE.

\begin{tabular}{lllll}
\hline Scale & $M$ & $S D$ & Range & Alpha \\
\hline Choice Goals & & & & \\
\multicolumn{1}{c}{ Conventional } & $35.6(49.9)$ & $29.1(33.1)$ & $14-126(14-126)$ & $.97(.97)$ \\
SRE & & & & \\
$\quad$ Past Year & $41.4(46.7)$ & $15.1(19.7)$ & $19-89(18-88)$ & $.89(.93)$ \\
$\quad$ Lifetime & $50.2(55.8)$ & $16.9(20.1)$ & $21-97(18-104)$ & $.90(.92)$ \\
$\quad$ Stress & $48.7(50.5)$ & $20.0(19.7)$ & $16-96(16-96)$ & $.93(.93)$ \\
$\quad$ Total & $140.8(153.1)$ & $45.7(56.0)$ & $57-277(52-276)$ & $.95(.97)$ \\
\hline
\end{tabular}

Note. Results for women are indicated first $(\mathrm{N}=130)$, results for men are indicated in parenthesis $(\mathrm{N}=$ 78). The LEQ = The Learning Experiences Questionnaire; OOE = Occupational Outcome Expectations; $\mathrm{SRE}=$ Schedule of Racist Events.

Tokar (2005), suggesting that African American students in the current sample experienced more physiologically-based learning experiences, on average, than samples in the aforementioned studies. In addition, Enterprising and Conventional Vicarious Learning scores were appreciably lower for the African American men in the current sample than the corresponding scores reported by Schaub (2003) and Schaub \& Tokar (2005), suggesting that African American men did not observe individuals engaging in Enterprising and Conventional behavior as much as individuals from the aforementioned studies. Finally, Social Performance Accomplishments scores were appreciably lower for the African American men in the current sample, while Social total scores were appreciably higher for African American women in the current sample. Lower Social Performance Accomplishment means for the men in the current sample suggest that they did not experience as many personal accomplishments for Social tasks as did individuals 
in previous studies (Schaub, 2003; Schaub \& Tokar, 2005). Higher Social total scores for the African American women in the current sample suggest that they engaged more in multiple learning experiences associated with Social tasks than individuals from previous studies.

LEQ total scale internal consistency estimates ranged from .72 (Conventional) to.83 (Realistic) for women $(m d n=.79)$ and from .76 (Artistic) to .84 (Social) for men $(m d n=$ .80). Alphas for the individual learning experiences subscales for women ranged from .48 (Conventional Performance Accomplishments) to .76 (Realistic Vicarious Learning) $(m d n=.62)$. Alphas for the individual learning experiences subscales for men rangedfrom .50 (Realistic Emotional Arousal) to .79 (Social Performance Accomplishments) $(m d n=.64)$. Although some alphas were low, they generally were consistent with those reported by Schaub (2003). Moreover, when Schaub (2003) applied the Spearman-Brown prophecy formula to calculate alphas for 10-item scales, all but two of the 24 LEQ subscales met the recommended cutoff of . 70 for self-report attitude measures (Nunnally \& Bernstein, 1994). Applying the Spearman-Brown prophecy formula for 10 items per LEQ subscale to the current data resulted in alphas for women ranging from .62 (Conventional Performance Accomplishment) to .86 (Realistic Vicarious Learning) ( $m d n=.74)$, with 21 of the 24 alphas $\geq .70$. Applying the SpearmanBrown prophecy formula for 10 items per LEQ subscale to the current data resulted in alphas for men ranging from .66 (Realistic Emotional Arousal) to .88 (Social Performance Accomplishments) $(m d n=.77)$, with 22 of the 24 alphas $\geq .70$.

The means for the self-efficacy measure, OOE, interests measure, and choice goals measure generally were quite comparable (i.e., within a half standard deviation or less) to 
those reported in previous studies (Gore \& Leuwerke, 2000; Lent et al., 2002). The alpha estimates for the self-efficacy, OOE, interests, and choice goals measures ranged from .93 to $.98(m d n=.96)$ for women and from .94 to $.97(m d n=.96)$ for men. These estimates parallel, and in many cases exceed, estimates reported previously (Gore \& Leuwerke, 2000; Lent et al., 2002).

The means for the SRE generally were quite comparable (i.e., within a half standard deviation or less) to those reported in previous studies (Klonoff \& Landrine, 1995; Landrine \& Klonoff, 1996). The alpha estimates for the SRE ranged from .89 to .93 $(m d n=.90)$ for women and from .92 to $.93(m d n=.93)$ for men. These estimates parallel estimates reported previously (Klonoff \& Landrine, 1995; Landrine \& Klonoff, 1996).

\section{Correlations}

The correlations between the constructs of interest, within each RIASEC theme, are described in Tables 2-7. For both men and women, correlations among self-efficacy, outcome expectations, interests, and choice goals were positive and statistically significant, ranging from .35 to $.83(m d n=.65)$ for women and from .23 to $.80(m d n=$ .65 ) for men. When considered in light of the very high alphas (most in the mid .90s) for these scales, the magnitudes of the observed intercorrelations generally suggest moderate proportions of shared variance among the measures of self-efficacy, outcome expectations, interests, and choice goals. Interestingly, all three observed correlations $\geq$ .80 involved outcome expectations and choice goals.

Learning experiences correlated significantly and positively with self-efficacy across the six RIASEC themes for women $(m d n r=.37)$ and men $(m d n r=.40)$. (The lone 
exception to this pattern involved the Conventional theme for men; see Table 7).

Correlations between learning experiences and the other constructs of interest tended to be weaker and, for men, nonsignificant.

Table 2. Correlations Among Realistic Sociocognitive Variables, Realistic Interests, and Realistic Choice Goals.

\begin{tabular}{|l|l|l|l|l|l|}
\hline \multicolumn{1}{|c|}{ Variable } & 1 & 2 & 3 & 4 & 5 \\
\hline 1. Learning Experiences & & $.387^{* *}$ & $.214^{*}$ & $.209^{*}$ & $.294^{* *}$ \\
\hline 2. Self-Efficacy & $.471^{* *}$ & & $.518^{* *}$ & $.348^{* *}$ & $.413^{* *}$ \\
\hline 3. Outcome Expectations & .096 & $.501^{* *}$ & & $.528^{* *}$ & $.653^{* *}$ \\
\hline 4. Interests & .046 & $.233^{*}$ & $.559^{* *}$ & & $.470^{* *}$ \\
\hline 5. Choice Goals & .053 & $.355^{* *}$ & $.800^{* *}$ & $.678^{* *}$ & \\
\hline
\end{tabular}

Note. Women's data are above the diagonal $(\mathrm{N}=130)$, men's data are below the diagonal $(\mathrm{N}=78)$.

$* \mathrm{p}<.05 . * * \mathrm{p}<.01$

Table 3. Correlations Among Investigative Sociocognitive Variables, Investigative Interests, and Investigative Choice Goals.

\begin{tabular}{|l|l|l|l|l|l|}
\hline Variable & 1 & 2 & 3 & 4 & 5 \\
\hline 1. Learning Experiences & & $.405^{* *}$ & $.208^{* *}$ & $.257^{* *}$ & $.309^{* *}$ \\
\hline 2. Self-Efficacy & $.408^{* *}$ & & $.651^{* *}$ & $.507^{* *}$ & $.635^{* *}$ \\
\hline 3. Outcome Expectations & .120 & $.645^{* *}$ & & $.663^{* *}$ & $.802^{* *}$ \\
\hline 4. Interests & .013 & $.377^{* *}$ & $.657^{* *}$ & & $.642^{* *}$ \\
\hline 5. Choice Goals & .145 & $.511^{* *}$ & $.746^{* *}$ & $.731^{* *}$ & \\
\hline
\end{tabular}

Note. Women's data are above the diagonal $(\mathrm{N}=130)$, men's data are below the diagonal $(\mathrm{N}=78)$.

$* \mathrm{p}<.05 . * * \mathrm{p}<.01$ 
Table 4. Correlations Among Artistic Sociocognitive Variables, Artistic Interests, and Artistic Choice Goals.

\begin{tabular}{|l|l|l|l|l|l|}
\hline Variable & 1 & 2 & 3 & 4 & 5 \\
\hline 1. Learning Experiences & & $.490^{* *}$ & $.373^{* *}$ & $.263^{* *}$ & $.299^{* *}$ \\
\hline 2. Self-Efficacy & $.400^{* *}$ & & $.673^{* *}$ & $.497^{* *}$ & $.563^{* *}$ \\
\hline 3. Outcome Expectations & .139 & $.685^{* *}$ & & $.687^{* *}$ & $.768^{* *}$ \\
\hline 4. Interests & .105 & $.443^{* *}$ & $.636^{* *}$ & & $.714^{* *}$ \\
\hline 5. Choice Goals & .102 & $.482^{* *}$ & $.644^{* *}$ & $.672^{* *}$ & \\
\hline
\end{tabular}

Note. Women's data are above the diagonal $(\mathrm{N}=130)$, men's data are below the diagonal $(\mathrm{N}=78)$.

$* \mathrm{p}<.05 .{ }^{* *} \mathrm{p}<.01$.

Table 5. Correlations Among Social Sociocognitive Variables, Social Interests, and Social Choice Goals.

\begin{tabular}{|l|l|l|l|l|l|}
\hline \multicolumn{1}{|c|}{ Variable } & 1 & 2 & 3 & 4 & 5 \\
\hline 1. Learning Experiences & & $.290^{* *}$ & $.277^{* *}$ & .162 & $.206^{*}$ \\
\hline 2. Self-Efficacy & $.403^{* *}$ & & $.694^{* *}$ & $.572^{* *}$ & $.620^{* *}$ \\
\hline 3. Outcome Expectation & .160 & $.731^{* *}$ & & $.752^{* *}$ & $.834^{* *}$ \\
\hline 4. Interests & .173 & $.536^{* *}$ & $.721^{* *}$ & & $.764^{* *}$ \\
\hline 5. Choice Goals & .104 & $.487^{* *}$ & $.705^{* *}$ & $.691^{* *}$ & \\
\hline
\end{tabular}

Note. Women's data are above the diagonal $(\mathrm{N}=130)$, men's data are below the diagonal $(\mathrm{N}=78)$.

$* \mathrm{p}<.05 .{ }^{* *} \mathrm{p}<.01$. 
Table 6. Correlations Among Enterprising Sociocognitive Variables, Enterprising Interests, and Enterprising Choice Goals.

\begin{tabular}{|l|l|l|l|l|l|}
\hline Variable & 1 & 2 & 3 & 4 & 5 \\
\hline 1. Learning Experiences & & $.337^{* *}$ & .130 & .148 & .146 \\
\hline 2. Self-Efficacy & $.240^{* *}$ & & $.578^{* *}$ & $.471^{* *}$ & $.450^{* *}$ \\
\hline 3. Outcome Expectations & .006 & $.650^{* *}$ & & $.658^{* *}$ & $.744^{* *}$ \\
\hline 4. Interests & -.103 & $.228^{*}$ & $.587^{* *}$ & & $.739^{* *}$ \\
\hline 5. Choice Goals & -.123 & $.400^{* *}$ & $.782^{* *}$ & $.660^{* *}$ & \\
\hline
\end{tabular}

Note. Women's data are above the diagonal $(\mathrm{N}=130)$, men's data are below the diagonal $(\mathrm{N}=78)$.

$* \mathrm{p}<.05 .{ }^{* *} \mathrm{p}<.01$.

Table 7. Correlations Among Conventional Sociocognitive Variables, Conventional Interests, and Conventional Choice Goals.

\begin{tabular}{|l|l|l|l|l|l|}
\hline \multicolumn{1}{|c|}{ Variable } & 1 & 2 & 3 & 4 & 5 \\
\hline 1. Learning Experiences & & $.267^{* *}$ & .026 & .036 & .129 \\
\hline 2. Self-Efficacy & .167 & & $.544^{* *}$ & $.434^{* *}$ & $.496^{* *}$ \\
\hline 3. Outcome Expectations & .005 & $.662^{* *}$ & & $.588^{* *}$ & $.724^{* *}$ \\
\hline 4. Interests & -.095 & $.264^{*}$ & $.595^{* *}$ & & $.734^{* *}$ \\
\hline 5. Choice Goals & .054 & $.514^{* *}$ & $.792^{* *}$ & $.724^{* *}$ & \\
\hline
\end{tabular}

Note. Women's data are above the diagonal $(\mathrm{N}=130)$, men's data are below the diagonal $(\mathrm{N}=78)$.

$* \mathrm{p}<.05 .{ }^{* *} \mathrm{p}<.01$. 


\section{Description of the Path Model}

To test hypotheses 1-12, a series of path analyses was performed to test the extent to which the data fit a model consistent with SCCT's (Lent et al., 1994) choice goal model for each of the six RIASEC themes. Specifically, I tested the fit of the data to a model (Figure 2) in which learning experiences (measured globally) predicted self-efficacy beliefs (path $a$ ) and outcome expectations (path $b$ ); self-efficacy beliefs predicted outcome expectations (path $c$ ), vocational interests (path $d$ ), and choice goals (path $e$ ); outcome expectations predicted vocational interests (path $f$ ) and choice goals (path $g$ ); and, vocational interests predicted choice goals (path $h$ ).

Six separate models were tested, one for each of Holland's (1997) RIASEC themes. In each model, relations among corresponding learning experiences, sociocognitive mechanisms, vocational interests, and choice goals were tested. RIASEC scale scores for the LEQ, the measure of self-efficacy, the OOE, the measure of interests, and the measure of choice goals were used as single indicators of learning experiences, selfefficacy, interests, and choice goal constructs, respectively. Each of the six models used the corresponding set of RIASEC-based scale scores.

All path models were analyzed with M-Plus (Múthen and Múthen, 1998-2001), using maximum likelihood estimation procedures. Several indicators of model-data fit were used, including the chi-square significance test, comparative fit index (CFI), root mean square error of approximation (RMSEA), and standardized root mean square residual (SRMR). Values above .90 for the CFI and below .08 for the RMSEA and SRMR indicate good model-data fit (Hu \& Bentler, 1999). For tests of hypothesized relations of learning experiences with outcome expectations, learning experiences with 


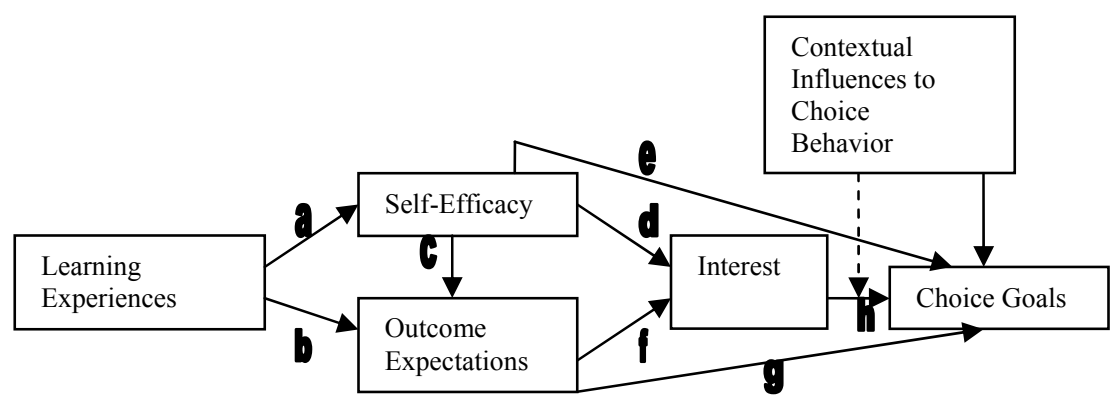

Figure 2. Hypothesized SCCT structural model for the path analyses. Note that the dotted path indicates a moderator effect on the interest-choice goals relation.

self-efficacy, self-efficacy with vocational interests, outcome expectations with vocational interests, self-efficacy with choice goals, outcome expectations with choice goals, and vocational interests with choice goals, the emphasis moved from model-data fit to analyzing specific parameter estimates and decomposition of total effects into direct and indirect effects. Kline (1998) recommended a minimum of five to ten cases for every parameter that is estimated when using path analysis. Given this criterion with twelve parameters being estimated, a minimum sample size of 60 to 120 participants was necessary to achieve adequate power. Thus, the current samples (130 women, 78 men, 208 total) provided adequate power for these analyses.

\section{Structural Invariance by Gender}

A multiple group path analysis was performed to compare the estimates of unstandardized direct effects across the two groups (women and men). This comparison is designed to determine whether the magnitudes of estimated direct effects are appreciably different across groups. I imposed cross-group equality constraints on the estimates of the effects to test whether or not the unconstrained path model fit 
significantly better than the constrained model. If the decrement in fit, indicated by an increase in the chi-square value, of the constrained model is not statistically significant, then the constrained paths are equivalent in the two samples. However, if the chi-square difference test is statistically significant, then at least one of the paths that were constrained to be equivalent instead differs in the two groups. As can be seen in Table 8 , the results of the constrained model were not statistically significant for the Investigative, Artistic, Social, Enterprising, and Conventional models. As such, the data were collapsed across gender groups for subsequent analyses. The results of the Realistic constrained Table 8. Tests of Structural Invariance for RIASEC Path Models.

\begin{tabular}{lccccc} 
Path Model & Constrained $\chi^{2}$ & Unconstrained $\chi^{2} \chi^{2}$ Difference & $\boldsymbol{d} f$ & P-Value \\
\hline Realistic & 31.009 & 4.875 & 26.134 & 8 & $.001 * * *$ \\
Investigative & 15.426 & 1.413 & 14.013 & 8 & .081 \\
Artistic & 7.096 & .116 & 6.980 & 8 & .538 \\
Social & 13.832 & 1.779 & 12.053 & 8 & .148 \\
Enterprising & 15.150 & 2.196 & 13.954 & 8 & .083 \\
Conventional & 14.001 & 2.466 & 12.535 & 8 & .128
\end{tabular}

Note. $\mathrm{N}=208$. The statistically significant $\mathrm{p}$-value for the Realistic path model denotes that the model is not structurally invariant. 
model were statistically significant, and thus, the data were analyzed separately for women and men in subsequent analyses.

\section{Path Model Results}

Standardized path coefficients and fit statistics for the six RIASEC models are summarized in Table 9. The overall fit of the models to the data was excellent for all six models.

Consistent with SCCT, I hypothesized that learning experiences would have a direct, positive relation to self-efficacy and a positive relation to outcome expectations, with the relation to outcome expectations being both direct and indirect (via self-efficacy). Selfefficacy would have a direct, positive relation to outcome expectations, and positive relations to vocational interests and choice goals, with the relations to vocational interests and choice goals being both direct and indirect (via outcome expectations and vocational interests). Outcome expectations would have a direct, positive relation to interests and a positive relation to choice goals, with the relation to choice goals being both direct and indirect (via vocational interests). Finally, vocational interests would have a direct, positive relation to choice goals. Tables 10-16 present a summary of the total effects, broken down by direct and total indirect effects for the six RIASEC models.

The results provided at least partial support for all of the aforementioned hypotheses. Consistent with Hypothesis 1, results indicated that learning experiences had a positive and significant direct relation to self-efficacy for all six models. Contrary to Hypothesis 2, learning experiences had a nonsignificant direct relation to outcome expectations for all six models; however, significant total effects were observed for the 
Table 9. Standardized Path Coefficients and Fit Statistics for the Six RIASEC Models.

\begin{tabular}{|c|c|c|c|c|c|c|}
\hline Path & Realistic & Investigative & Artistic & Social & Enterprising & Conventional \\
\hline $\mathrm{a}$ & $.38 * *(.47 * *)$ & $.39 * *$ & $.43 * *$ & $.35 * *$ & $.29 * *$ & $.19 * *$ \\
\hline $\mathrm{b}$ & $.01 \quad(-.18)$ & -.06 & -.03 & -.01 & -.11 & -.15 \\
\hline $\mathrm{c}$ & $.51 * *(.58 * *)$ & $.69 * *$ & $.69 * *$ & $.71 * *$ & $.64 * *$ & $.62 * *$ \\
\hline d & $.10 \quad(-.06)$ & .04 & .04 & .06 & -.01 & .02 \\
\hline $\mathrm{e}$ & $.08 \quad(-.03)$ & $.12 *$ & .07 & -.01 & -.04 & .07 \\
\hline $\mathrm{f}$ & $.47 * *(.59 * *)$ & $.64 * *$ & $.64 * *$ & $.70 * *$ & $.63 * *$ & $.58 * *$ \\
\hline g & $.52 * *(.62 * *)$ & $.51 * *$ & $.40 * *$ & $.53 * *$ & $.54 * *$ & $.46^{* *}$ \\
\hline $\mathrm{h}$ & $.16^{*}(.34 * *)$ & $.28 * *$ & $.38 * *$ & $.34 * *$ & $.38 * *$ & $.43 * *$ \\
\hline $\begin{array}{r}\text { Mode } \\
\mathrm{H}\end{array}$ & $\begin{array}{l}\chi^{2}(\mathrm{df}) \\
\text { Men } .100(2) \\
\text { omen } 4.816(2)\end{array}$ & $1.16(2)$ & $.23(2)$ & $.76(2)$ & $.29(2)$ & $1.13(2)$ \\
\hline Mode & $\begin{array}{l}\text { RMSEA } \\
\text { Men .000 } \\
\text { Jomen .104 }\end{array}$ & .00 & .00 & .00 & .00 & .00 \\
\hline Mode & $\begin{array}{l}\text { CFI } \\
\text { Men } 1.000 \\
\text { Women .984 }\end{array}$ & 1.0 & 1.0 & 1.0 & 1.0 & 1.0 \\
\hline Mode & $\begin{array}{l}\text { SRMR } \\
\text { Men .005 } \\
\text { Jomen .037 }\end{array}$ & .01 & .00 & .01 & .01 & .01 \\
\hline
\end{tabular}

Note. $\mathrm{N}=208$. For the Realistic model, the path coefficients in parentheses denote the men's data $(\mathrm{N}=$ 78). For the Realistic model, $\mathrm{N}=130$ for the women's data.

${ }^{*} \mathrm{p}<.05 .{ }^{* *} \mathrm{p}<.01$ 
Table 10. Summary of the Total Effects, Broken Down by Total Indirect Effects and Direct Effects for Hypothesized Paths for the Realistic Model for Women.

\section{From Learning Experiences to Self-Efficacy}

Direct Effect $=.38^{* *}$

Indirect Effect (total) $=\mathrm{NA}$

Total Effect $=.38 * *$

From Learning Experiences to Outcome Expectations

Direct Effect $=.01$

Indirect Effect (total) $=.19 * *$

By Self-Efficacy

Total Effect $=.20 * *$

From Self-Efficacy to Outcome Expectations

Direct Effect $=.51^{* *}$

Indirect Effect (total) $=$ NA

Total Effect $=.51^{* *}$

From Self-Efficacy to Interests

Direct Effect $=.10$

Indirect Effect (total) $=.24 * *$

By Outcome Expectations

Total Effect $=.34 * *$

From Self-Efficacy to Choice Goals

Direct Effect $=.08$

Indirect Effect $($ total $)=.32 * *$

By Outcome Expectations and Interests

Total Effect $=.40^{* *}$

From Outcome Expectations to Interests

Direct Effect $=.47^{* *}$

Indirect Effect (total) $=$ NA

Total Effect $=.47 * *$

From Outcome Expectations to Choice Goals

Direct Effect $=.52^{* *}$

Indirect Effect (total) $=.08$

By Interests

Total Effect $=.60 * *$

\section{From Interests to Choice Goals}

Direct Effect $=.16^{*}$

Indirect Effect (total) $=$ NA

Total Effect $=.16^{*}$

Note. $\mathrm{N}=130$

$* \mathrm{p}<.05 . * * \mathrm{p}<.01$ 
Table 11. Summary of the Total Effects, Broken Down by Total Indirect Effects and Direct Effects for Hypothesized Paths for the Realistic Model for Men.

\section{From Learning Experiences to Self-Efficacy}

Direct Effect $=.47^{* *}$

Indirect Effect (total) $=\mathrm{NA}$

Total Effect $=.47 * *$

From Learning Experiences to Outcome Expectations

Direct Effect $=-.18$

Indirect Effect (total) $=.27 * *$

By Self-Efficacy

Total Effect $=.09$

From Self-Efficacy to Outcome Expectations

Direct Effect $=.58^{* *}$

Indirect Effect (total) $=$ NA

Total Effect $=.58 * *$

From Self-Efficacy to Interests

Direct Effect $=-.06$

Indirect Effect (total) $=.34 * *$

By Outcome Expectations

Total Effect $=.28 * *$

From Self-Efficacy to Choice Goals

Direct Effect $=-.03$

Indirect Effect $($ total $)=.46^{* *}$

By Outcome Expectations and Interests

Total Effect $=.42 * *$

From Outcome Expectations to Interests

Direct Effect $=.59^{* *}$

Indirect Effect (total) $=\mathrm{NA}$

Total Effect $=.59 * *$

From Outcome Expectations to Choice Goals

Direct Effect $=.62^{* *}$

Indirect Effect $($ total $)=.20 * *$

By Interests

Total Effect $=.83 * *$

From Interests to Choice Goals

Direct Effect $=.34^{* *}$

Indirect Effect (total) $=$ NA

Total Effect $=.34 * *$

Note. $\mathrm{N}=78$

$* \mathrm{p}<.05 .{ }^{*} \mathrm{p}<<.01$. 
Table 12. Summary of the Total Effects, Broken Down by Total Indirect Effects and Direct Effects for Hypothesized Paths for the Investigative Model.

\section{From Learning Experiences to Self-Efficacy}

Direct Effect $=.39 * *$

Indirect Effect (total) $=\mathrm{NA}$

Total Effect $=.39 * *$

From Learning Experiences to Outcome Expectations

Direct Effect $=-.06$

Indirect Effect (total) $=.26^{* *}$

By Self-Efficacy

Total Effect $=.20 * *$

From Self-Efficacy to Outcome Expectations

Direct Effect $=.69 * *$

Indirect Effect (total) $=$ NA

Total Effect $=.69 * *$

From Self-Efficacy to Interests

Direct Effect $=.04$

Indirect Effect (total) $=.43 * *$

By Outcome Expectations

Total Effect $=.48 * *$

From Self-Efficacy to Choice Goals

Direct Effect $=.12 *$

Indirect Effect $($ total $)=.49 * *$

By Outcome Expectations and Interests

Total Effect $=.61 * *$

From Outcome Expectations to Interests

Direct Effect $=.64^{* *}$

Indirect Effect $=\mathrm{NA}$

Total Effect $=.64 * *$

From Outcome Expectations to Choice Goals

Direct Effect $=.51^{* *}$

Indirect Effect $($ total $)=.18^{* *}$

By Interests

Total Effect $=.69 * *$

From Interests to Choice Goals

Direct Effect $=.28^{* *}$

Indirect Effect (total) $=$ NA

Total Effect $=.28 * *$

Note. $\mathrm{N}=208$

${ }^{*} \mathrm{p}<.05 . * * \mathrm{p}<.01$. 
Table 13. Summary of the Total Effects, Broken Down by Total Indirect Effects and Direct Effects for Hypothesized Paths for the Artistic Model.

\section{From Learning Experiences to Self-Efficacy}

Direct Effect $=.43 * *$

Indirect Effect (total) $=$ NA

Total Effect $=.43 * *$

From Learning Experiences to Outcome Expectations

Direct Effect $=-.03$

Indirect Effect $($ total $)=.29 * *$

Total Effect $=.27 * *$

From Self-Efficacy to Outcome Expectations

Direct Effect $=.69^{* *}$

Indirect Effect (total) $=$ NA

Total Effect $=.69 * *$

From Self-Efficacy to Interests

Direct Effect $=.04$

Indirect Effect $($ total $)=.44 * *$

Total Effect $=.48^{* *}$

From Self-Efficacy to Choice Goals

Direct Effect $=.07$

Indirect Effect $($ total $)=.47 * *$

Total Effect $=.55^{* *}$

Outcome Expectations to Interests

Direct Effects $=.63 * *$

Indirect Effect (total) $=$ NA

Total Effect $=.63 * *$

From Outcome Expectations to Choice Goals

Direct Effect $=.40^{* *}$

Indirect Effect $($ total $)=.24 * *$

Total Effect $=.65^{* *}$

From Interests to Choice Goals

Direct Effect $=.38^{* *}$

Indirect Effect (total) $=$ NA

Total Effect $=.38 * *$

Note. $\mathrm{N}=208$

${ }^{*} \mathrm{p}<.05 . * * \mathrm{p}<.01$. 
Table 14. Summary of the Total Effects, Broken Down by Total Indirect Effects and Direct Effects for Hypothesized Paths for the Social Model.

\section{From Learning Experiences to Self-Efficacy}

Direct Effect $=.35^{* *}$

Indirect Effect (total) $=$ NA

Total Effect $=.35^{* *}$

From Learning Experiences to Outcome Expectations

Direct Effect $=-.01$

Indirect Effect $($ total $)=.24 * *$

Total Effect $=.23 * *$

From Self-Efficacy to Outcome Expectations

Direct Effect $=.71^{* *}$

Indirect Effect (total) $=\mathrm{NA}$

Total Effect $=.71 * *$

From Self-Efficacy to Interests

Direct Effect $=.06$

Indirect Effect $($ total $)=.50 * *$

Total Effect $=.56^{* *}$

From Self-Efficacy to Choice Goals

Direct Effect $=-.01$

Indirect Effect $($ total $)=.57 * *$

Total Effect $=.56^{* *}$

From Outcome Expectations to Interests

Direct Effect $=.70^{* *}$

Indirect Effect $($ total $)=\mathrm{NA}$

Total Effect $=.70 * *$

From Outcome Expectations to Choice Goals

Direct Effect $=.53^{* *}$

Indirect Effect $($ total $)=.24 * *$

Total Effect $=.57^{* *}$

From Interests to Choice Goals

Direct Effect $=.34^{* *}$

Indirect Effect (total) $=$ NA

Total Effect $=.34 * *$

Note. $\mathrm{N}=208$

${ }^{*} \mathrm{p}<.05 .{ }^{* *} \mathrm{p}<.01$. 
Table 15. Summary of the Total Effects, Broken Down by Total Indirect Effects and Direct Effects for Hypothesized Paths for the Enterprising Model.

From Learning Experiences to Self-Efficacy

Direct Effect $=.29^{* *}$

Indirect Effect (total) $=$ NA

Total Effect $=.29 * *$

From Learning Experiences to Outcome Expectations

Direct Effect $=-.11$

Indirect Effect $($ total $)=.18^{* *}$

Total Effect $=.07$

From Self-Efficacy to Outcome Expectations

Direct Effect $=.64^{* *}$

Indirect Effect (total) $=$ NA

Total Effect $=.64 * *$

From Self-Efficacy to Interests

Direct Effect $=-.01$

Indirect Effect (total) $=.40 * *$

Total Effect $=.39 * *$

From Self-Efficacy to Choice Goals

Direct Effect $=-.04$

Indirect Effect $($ total $)=.50 * *$

Total Effect $=.45^{* *}$

From Outcome Expectations to Interests

Direct Effect $=.63^{* *}$

Indirect Effect (total) $=$ NA

Total Effect $=.63 * *$

From Outcome Expectations to Choice Goals

Direct Effect $=.54 * *$

Indirect Effect $($ total $)=.24 * *$

Total Effect $=.79 * *$

From Interests to Choice Goals

Direct Effect $=.38^{* *}$

Indirect Effect (total) $=$ NA

Total Effect $=.38 * *$

Note. $\mathrm{N}=208$

${ }^{*} \mathrm{p}<.05 .{ }^{* *} \mathrm{p}<.01$. 
Table 16. Summary of the Total Effects, Broken Down by Total Indirect Effects and Direct Effects for Hypothesized Paths for the Conventional Model.

From Learning Experiences to Self-Efficacy

Direct Effect $=.19^{* *}$

Indirect Effect (total) $=$ NA

Total Effect $=.19 * *$

From Learning Experiences to Outcome Expectations

Direct Effect $=-.15$

Indirect Effect $($ total $)=.12 *$

Total Effect $=-.03$

From Self-Efficacy to Outcome Expectations

Direct Effect $=.62^{* *}$

Indirect Effect (total) $=$ NA

Total Effect $=.62 * *$

From Self-Efficacy to Interests

Direct Effect $=.02$

Indirect Effect $($ total $)=.36^{* *}$

Total Effect $=.39 * *$

From Self-Efficacy to Choice Goals

Direct Effect $=.07$

Indirect Effect (total) $=.45^{* *}$

Total Effect $=.52 * *$

From Outcome Expectations to Interests

Direct Effect $=.58 * *$

Indirect Effect $($ total $)=\mathrm{NA}$

Total Effect $=.58 * *$

From Outcome Expectations to Choice Goals

Direct Effect $=.46^{* *}$

Indirect Effect $($ total $)=.25^{* *}$

Total Effect $=.71 * *$

From Interests to Choice Goals

Direct Effect $=.43^{* *}$

Indirect Effect (total) $=$ NA

Total Effect $=.43 * *$

Note. $\mathrm{N}=208$.

${ }^{*} \mathrm{p}<.05 .{ }^{* *} \mathrm{p}<.01$. 
Realistic (women only), Investigative, Artistic, and Social models. Furthermore, significant total indirect effects (via self-efficacy) occurred for all six models. Thus, partially consistent with Hypothesis 9, learning experiences had an indirect effect on outcome expectations.

As hypothesized, self-efficacy had a positive and significant direct relation to outcome expectations for all six models. Contrary to Hypothesis 4, self-efficacy had a nonsignificant direct relation to vocational interests for all six models; however, examination of the total effects and total indirect effects indicated that self-efficacy was significantly and positively related to interests, and that outcome expectations fully mediated the relationship between self-efficacy and vocational interests for all six models. These results provide partial support for Hypothesis 10 .

Outcome expectations had a positive and significant direct relation to vocational interests for all six models, as hypothesized. Unexpectedly, self-efficacy had a nonsignificant direct relation to choice goals for the Realistic, Artistic, Social, Enterprising, and Conventional models, and a positive and significant (albeit weak) direct relation for the Investigative model; however, significant and positive total effects were observed for all six models. Furthermore, significant total indirect effects (via outcome expectations) occurred for all six models. Thus, partially consistent with Hypothesis 11, self-efficacy had an indirect and positive effect on choice goals.

As hypothesized, outcome expectations had a positive and significant direct relation to choice goals for all six models. Significant total effects of outcomes expectations on choice goals were observed for all six models, and significant total indirect effects (via interests) were observed for the Realistic (men only), Investigative, Artistic, Social, 
Enterprising, and Conventional models. These results indicate that vocational interests partially mediated the relationship between outcome expectations and choice goals for the Realistic (men only), Investigative, Artistic, Social, Enterprising, and Conventional models, and fully mediated the relationship between outcome expectations and choice goals for the Realistic (women only) model. These findings partially support Hypothesis 12.

Finally, vocational interests had a positive and significant direct relation to choice goals for all six models; these findings fully support Hypothesis 8 .

Results of the Regression Analyses Predicting Self-Efficacy and Outcome Expectations from Learning Experiences

To test the unique contributions of each learning experience to the formation of corresponding self-efficacy and outcome expectations (Hypotheses $1 \mathrm{G}$ and $2 \mathrm{G}$ ), a series of simultaneous regression analyses was performed. In the first series of regression analyses, the criterion variable (i.e., total scores for self-efficacy for each RIASEC theme) was regressed onto the predictor variables (i.e., scores for each of the four corresponding learning experiences). (The full correlation matrix of learning experiences and self-efficacy for all six RIASEC themes can be found in Appendix H.) In the second series of regression analyses, the criterion variable (i.e., total scores for outcome expectations) was regressed onto the predictor variables (i.e., scores for each of the four corresponding learning experiences). (The full correlation matrix of learning experiences and outcome expectations for all six RIASEC themes can be found in Appendix I.) In both series of regression analyses, an examination of the beta weights indicated which (in any) predictor variable (i.e., scores for performance accomplishments, vicarious learning, 
verbal persuasion, and/or physiological arousal) contributed the largest amount of unique variance to self-efficacy and outcome expectations.

Regarding hypotheses $1 \mathrm{G}$ and $2 \mathrm{G}$, which state that verbal persuasion will explain more variance in self-efficacy and outcome expectations, respectively, for each of the six Holland themes than will performance accomplishments, vicarious learning, or emotional arousal, the results of the regression analyses were mixed. The results are summarized in Table 17. An examination of the beta weights revealed that, consistent with Hypothesis $1 \mathrm{G}$, verbal persuasion contributed the largest amount of unique variance to self-efficacy for the Conventional model $(\beta=.28)$. However, contrary to Hypothesis $1 \mathrm{G}$, the beta weights indicated that performance accomplishments contributed the largest amount of unique variance to self-efficacy for the Realistic model for men $(\beta=.46)$, as well as the Artistic $(\beta=.25)$, Social $(\beta=.20)$, and Enterprising $(\beta=.15)$ models. An examination of the beta weights revealed that vicarious learning contributed the largest amount of unique variance to self-efficacy for the Investigative model $(\beta=.23)$. Finally, the beta weights revealed that physiological arousal contributed the largest amount of unique variance to self-efficacy for the Realistic model for women $(\beta=.23)$.

Consistent with Hypothesis $2 \mathrm{G}$ (see Table 18), the beta weights indicated that verbal persuasion contributed the largest amount of unique variance to outcome expectations for the Realistic model for males $(\beta=.38)$, and for the Enterprising $(\beta=.24)$, Artistic $(\beta=$ .23 ), and Conventional $(\beta=.19)$ models. However, contrary to Hypothesis $2 \mathrm{G}$, the beta weights revealed that performance accomplishments contributed the largest amount of unique variance to outcome expectations for the Realistic model for women $(\beta=.25)$. Finally, the beta weights indicated that vicarious learning contributed the largest amount 
Table 17. Simultaneous Regression Analyses Predicting Self-Efficacy from Learning Experiences.

\section{Realistic Self -Efficacy (women only)}

Variable $\beta$

Performance Accomplishments

Vicarious Learning

\begin{tabular}{|c|c|}
\hline $22 *$ & 2.12 \\
\hline
\end{tabular}

Verbal Persuasion

$\begin{array}{lll}-.01 & -.14 & .88\end{array}$

Emotional Arousal

$.13 \quad 1.38$

.17

$.23 * * \quad 2.79$

.01

Overall $F(4,125)=7.02^{* *}, p<.01$

$$
R^{2}=.18
$$

\section{Realistic Self-Efficacy (men only)}

Variable

Performance Accomplishments

Vicarious Learning

$\begin{array}{lll}\beta & t & p \\ .46^{* * *} & 3.59 & .001 \\ .07 & .59 & .56 \\ -.00 & -.02 & .96 \\ .08 & .73 & .47\end{array}$

Emotional Arousal

Overall $F(4,73)=7.06^{* *}, p<.01$
$R^{2}=.28$

\section{Investigative Self-Efficacy}

Variable

Performance Accomplishments

Vicarious Learning

Verbal Persuasion

Emotional Arousal

$\begin{array}{lll}\beta & t & p \\ .06 & .67 & .50 \\ .23^{* *} & 2.82 & .01 \\ .13 & 1.59 & .11 \\ .15^{*} & 2.14 & .03\end{array}$

Overall $F(4,203)=10.03^{* *}, p<.01$
$R^{2}=.17$

\section{Artistic Self-Efficacy}

Variable

Performance Accomplishments

Vicarious Learning

Verbal Persuasion

Emotional Arousal

$\beta$

$\beta$

$.25 * *$

.03

$.21 *$

.09 $t$

$3.18 \quad .002$

$\begin{array}{ll}.36 & .72\end{array}$

$\begin{array}{ll}2.45 & .02\end{array}$

$1.46 \quad .15$

Overall $F(4,203)=12.90^{* *}, p<.01$

Social Self-Efficacy

Variable

Performance Accomplishments

Vicarious Learning

Verbal Persuasion

Emotional Arousal

$$
R^{2}=.20
$$

$\begin{array}{lll}\beta & t & p \\ .201^{*} & 2.45 & .02 \\ .09 & 1.03 & .31 \\ .16 & 1.91 & .06 \\ -.01 & -.12 & .91\end{array}$

Overall $F(4,203)=8.35^{* *}, p<.01$

$$
R^{2}=.14
$$


Table 17 (continued). Simultaneous Regression Analyses Predicting Self-Efficacy from Learning Experiences.

\section{Enterprising Self-Efficacy}

Variable

Performance Accomplishments

Vicarious Learning

Verbal Persuasion

Emotional Arousal

$\begin{array}{lll}\beta & t & p \\ .15 & 1.71 & .09 \\ .09 & 1.07 & .29 \\ .12 & 1.46 & .15 \\ .03 & .49 & .63\end{array}$

Overall $F(4,203)=5.13^{* *}, p<.01$

$R^{2}=.09$

\section{Conventional Self-Efficacy}

Variable

Performance Accomplishments

Vicarious Learning

Verbal Persuasion

Emotional Arousal

$\begin{array}{lll}\beta & t & p \\ .01 & .06 & .95 \\ -.11 & -1.25 & .21 \\ .28^{* * *} & 3.28 & .001 \\ .16^{*} & 2.25 & .03\end{array}$

Overall $F(4,203)=4.29 * *, p<.01$
$R^{2}=.08$

Note. For the Realistic model (women only), $\mathrm{N}=130$. For the Realistic model (men only), $\mathrm{N}=78$. For the Investigative, Artistic, Social, Enterprising, and Conventional models, $\mathrm{N}=208$.

$* \mathrm{p}<.05 * * \mathrm{p}<.01 * * * \mathrm{p}<.001$ 
Table 18. Simultaneous Regression Analyses Predicting Outcome Expectations from Learning Experiences.

\section{Realistic Outcome Expectations (women only)}

Variable $\beta$

Performance Accomplishments

Vicarious Learning

Verbal Persuasion

\begin{tabular}{|c|c|}
\hline $25^{*}$ & 2.28 \\
\hline
\end{tabular}

Emotional Arousal

$-.15$

$-1.45$

.15

$\begin{array}{lll}.17 & 1.61 & .11\end{array}$

$\begin{array}{lll}-.00 & -.01 & .99\end{array}$

Overall $F(4,125)=3.33^{* *}, p<.01$

$$
R^{2}=.10
$$

\section{Realistic Outcome Expectations (men only)}

Variable

Performance Accomplishments

$\beta$

Vicarious Learning

Verbal Persuasion

Emotional Arousal

$\begin{array}{lll}\beta & t & p \\ -.10 & -.72 & .48 \\ -.21 & -1.48 & .14 \\ .38^{* *} & 2.51 & .01 \\ .12 & .98 & .33\end{array}$

Overall $F(4,73)=1.68, p>.05$

$$
R^{2}=.08
$$

\section{Investigative Outcome Expectations}

Variable

Performance Accomplishments

Vicarious Learning

Verbal Persuasion

Emotional Arousal

$\beta$

$-.24 * *$
$.31 * * *$

.16

.11

$t$

$-2.07$

3.70

1.92

1.43

Overall $F(4,203)=6.62^{* *}, p<.01$

.01

.00

.05

.15

\section{Artistic Outcome Expectations}

Variable

Performance Accomplishments

Vicarious Learning

Verbal Persuasion

Emotional Arousal

$\begin{array}{lll}\beta & t & p \\ .20^{*} & 2.36 & .02 \\ -.08 & -.89 & .37 \\ .23^{* *} & 2.55 & .01 \\ -.03 & -.46 & .65\end{array}$

Overall $F(4,203)=6.33^{* *}, p<.01$

$$
R^{2}=.11
$$

\section{Social Outcome Expectations}

Variable

Performance Accomplishments

Vicarious Learning

Verbal Persuasion

Emotional Arousal

$\begin{array}{lll}\beta & t & p \\ .03 & .30 & .77 \\ .25^{* *} & 2.93 & .004 \\ .11 & 1.30 & .19 \\ -.09 & -1.16 & .25\end{array}$

\footnotetext{
Overall $F(4,203)=6.04^{* *}, p<.01$ $R^{2}=.11$
} 
Table 18 (continued). Simultaneous Regression Analyses Predicting Outcome Expectations from Learning Experiences.

\section{Enterprising Outcome Expectations}

Variable

Performance Accomplishments

Vicarious Learning

Verbal Persuasion

$\beta$

$-.07$

.03

Emotional Arousal

$\begin{array}{ll}t & p \\ -.83 & .41 \\ .39 & .70 \\ 2.92 & .004 \\ -2.41 & .02\end{array}$
Overall $F(4,203)=4.24 * *, p<.01$ $R^{2}=.08$

\section{Conventional Outcome Expectations}

Variable

Performance Accomplishments

Vicarious Learning

Verbal Persuasion

Emotional Arousal

$\begin{array}{lll}\beta & t & p \\ -.19^{*} & -2.35 & .02 \\ -.02 & -.30 & .76 \\ .19^{*} & 2.14 & .03 \\ .00 & .00 & 1.0\end{array}$

Overall $F(4,203)=2.21, \mathrm{p}>.05$

$$
R^{2}=.04
$$

Note. For the Realistic model (women only), $\mathrm{N}=130$. For the Realistic model (men only), $\mathrm{N}=78$. For the Investigative, Artistic, Social, Enterprising, and Conventional models, $\mathrm{N}=208$.

$* \mathrm{p}<.05 * * \mathrm{p}<.01 * * * \mathrm{p}<.001$

of unique variance to outcome expectations for the Investigative $(\beta=.31)$ and Social $(\beta=$ .25) models.

Results of the Moderated Regression Analyses

To test Hypothesis 13, which states that the perception of racism will moderate the interest-choice goals relation for each of the six Holland interest themes, seven moderated regression analyses were performed, one for each of the RIASEC types (separate analyses were performed for women and men for the Realistic model). The criterion variable in each regression was choice goals, the predictor variable was interests, and the potential moderator was racism. Interests were entered at Step 1, racism was entered at Step 2, and the interaction term of interest $\mathrm{x}$ racism was entered at Step 3. It was hypothesized that the presence of racism would decrease the strength of 
the relationship between interests and choice goals, and vice versa. A statistically significant change in $\underline{\mathrm{R}}^{2}$ at step 3 would demonstrate evidence of a moderator effect.

To account for the possibility of multicollinearity between the main effect and interaction terms, scale scores for the predictor and moderator variables were centered. The moderated regressions were run with the raw (uncentered) and centered scale scores. The results of the moderated regression analyses were essentially identical for the centered and uncentered data, and for ease of interpretation the results reported are based on the uncentered data.

Results of the moderated regression analyses revealed a statistically significant change in $\underline{\mathrm{R}}^{2}$ at step 3 for the Realistic (male), Investigative, and Enterprising models, indicating the presence of a moderator effect (see Table 19). However, contrary to the hypothesis, there was not a statistically significant change in $\underline{\mathrm{R}}^{2}$ at step 3 for Realistic (female), Artistic, Social, and Conventional models, indicating that there was not the presence of a moderator effect (see Table 19). 
Table 19. Summary of Moderated Regression Analyses

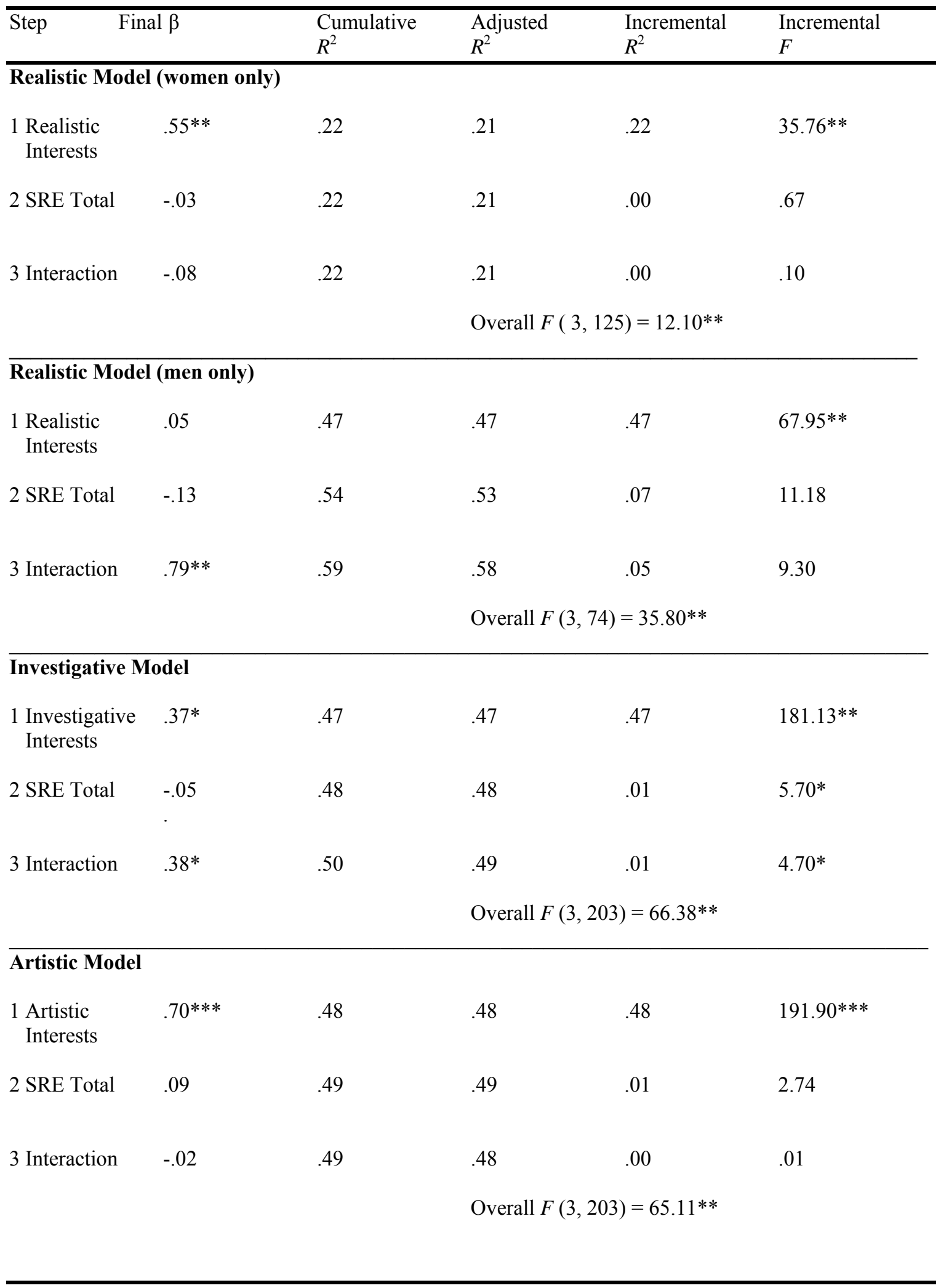


Table 19 (continued). Summary of Moderated Regression Analyses.

\begin{tabular}{|c|c|c|c|c|c|}
\hline Step & al $\beta$ & $\begin{array}{l}\text { Cumulative } \\
R^{2}\end{array}$ & $\begin{array}{l}\text { Adjusted } \\
R^{2}\end{array}$ & $\begin{array}{l}\text { Incremental } \\
R^{2}\end{array}$ & $\begin{array}{l}\text { Incremental } \\
F\end{array}$ \\
\hline \multicolumn{6}{|l|}{ Social Model } \\
\hline $\begin{array}{l}1 \text { Social } \\
\text { Interests }\end{array}$ & $.57 * * *$ & .54 & .53 & .54 & $237.09 * * *$ \\
\hline 2 SRE Total & -.03 & .55 & .54 & .01 & $4.19 *$ \\
\hline \multirow[t]{2}{*}{3 Interaction } & .22 & .55 & .54 & .00 & 1.40 \\
\hline & & & \multicolumn{3}{|c|}{ Overall $F(3,203)=82.28 * *$} \\
\hline \multicolumn{6}{|c|}{ Enterprising Model } \\
\hline $\begin{array}{l}1 \text { Enterprising } \\
\text { Interests }\end{array}$ & $.37 *$ & .50 & .50 & .50 & $207.93 * *$ \\
\hline 2 SRE Total & -.08 & .52 & .52 & .02 & $7.72 * *$ \\
\hline 3 Interaction & $.43 *$ & .54 & .53 & .07 & $6.04 *$ \\
\hline & & & \multicolumn{3}{|c|}{ Overall $F(3,203)=77.90 * *$} \\
\hline \multicolumn{6}{|c|}{ Conventional Model } \\
\hline $\begin{array}{l}1 \text { Conventional } \\
\text { Interests }\end{array}$ & $.46^{* *}$ & .54 & .54 & .54 & $242.70 * * *$ \\
\hline 2 SRE Total & -.05 & .55 & .55 & .01 & 3.12 \\
\hline 3 Interaction & .32 & .56 & .55 & .01 & 3.90 \\
\hline & & & \multicolumn{3}{|c|}{ Overall $F(3,203)=85.24 * *$} \\
\hline
\end{tabular}


In order to understand the meaning of the moderator effects for the Realistic (men only), Investigative, and Enterprising models, follow-up analyses were performed. Specifically, I compared the correlations between interests and choice goals at high and low levels of racism for each model. For the Realistic (men only) model, I performed a median split to divide the sample into high and a low racism groups, resulting in 39 cases in each group. For the Investigative and Enterprising models, the high and low racism groups were created by taking the top and bottom third of the SRE scores, resulting in 70 cases in each group.

For the Realistic (men only) model, the correlation between interest and choice goals was .54 for the low racism group and .82 for the high racism group. For the Investigative model, the correlation between interests and choice goals was . 70 for the low racism group and .75 for the high racism group. For the Enterprising model, the correlation between interests and choice goals was .65 for the low racism group and .76 for the high racism group. Unexpectedly, the correlations between interests and choice goals were stronger for the high racism groups than the low racism groups.

To test whether the interests-goals correlations for the high and low racism groups were statistically significantly different from each other, I performed $r$ to $z^{\prime}$ transformations for each correlation and then performed a series of two-tailed z-tests on the independent correlations.

For the Realistic model (male), $z=2.26, p<.05$. For the Investigative model, $z=$ $.887, p>.05$. For the Enterprising model, $z=1.85, p>.05$. Contrary to Hypothesis 13A, the results indicated that for men a greater perception of racism actually strengthened the Realistic interest-choice goals relation. Further, the results of z-tests did not support 
Hypotheses $13 \mathrm{~B}$ and $13 \mathrm{E}$, in that the perception of racism did not significantly moderate the interests-choice goals relation for either the Investigative or Enterprising model. 


\section{CHAPTER V}

\section{DISCUSSION}

Lent et al.'s (1994) social cognitive career theory (SCCT) has generated a wealth of empirical research since its inception. Overall, empirical evidence has supported several posited paths of the model. However, several aspects of the model have been underresearched or have received mixed empirical support. The purpose of this study was to extend the research on SCCT by examining several of these aspects using an underresearched population--African Americans. In this chapter, I will discuss the major findings of the present research, implications for counseling, limitations of the present study, and areas for future research. 


\section{Major Findings of the Present Study}

The present study sought to address four limitations of the extant SCCT research. First, there is little research on the applicability of SCCT for African Americans. The present study sampled 208 African American college students and examined most of the key paths in SCCT's career choice model. Second, a large portion of the published research has examined SCCT constructs for the domains of math and science, leaving the applicability of SCCT for domains other than math and science in question. The present

study sought to address this limitation by measuring each of the SCCT constructs (i.e., learning experiences, self-efficacy, outcome expectations, vocational interests, and choice goals) for Holland's (1997) RIASEC themes. Third, the role of learning experiences (i.e., personal performance accomplishments, vicarious learning, verbal persuasion, and physiological arousal) has not been adequately examined. The present study examined how each of the four learning experiences for Holland's (1997) RIASEC themes related to corresponding self-efficacy beliefs and outcome expectations. Finally, the present study examined the previously unknown role of perceptions of racism, conceptualized in SCCT as a proximal contextual factor potentially moderating the relationship between vocational interests and choice goals. In the sections to follow, I will discuss in greater detail each of the major findings and how they relate to the aforementioned limitations. The Applicability of SCCT for African Americans using Holland's RIASEC Themes

Lent et al. (1994) suggested that SCCT may be an appropriate framework for examining the career development of racial/ethnic minority groups because the model takes into account potentially important factors for such groups, such as background and proximal contextual affordances and barriers. Despite Lent et al.'s and others' (Byars \& 
Hackett, 1998; Fouad \& Smith, 1996; Gainor \& Lent, 1998; Lent et al., 2000; Luzzo, 2001) suggestions that SCCT is a potentially useful framework for understanding minority career development, there has been a relative paucity of research on SCCT using African Americans, and the evidence to date has revealed mixed support. Studies that have been conducted using African Americans as part of the sample (e.g., Fouad \& Smith, 1996) have found less than adequate model-data fit for African Americans. Further, the few published studies (e.g., Fouad \& Smith, 1996; Gainor \& Lent, 1998; Lent et al., 2005) that included African Americans only examined SCCT relationships for the domains of math and science, leaving unknown how applicable SCCT is with African Americans for other career-related domains. Several recent studies (Lent et al., 2003; Schaub \& Tokar, 2005) have provided strong support for many of SCCT's hypothesized paths using measures of SCCT constructs for Holland's (1997) RIASEC types. The present study sought to extend these earlier efforts by testing hypothesized paths between SCCT constructs for each of Holland's RIASEC themes using a sample of African American college students. It was hypothesized that corresponding learning experiences, self-efficacy beliefs, outcome expectations, vocational interests, and choice goals would have positive and, in some cases (e.g., the relation between self-efficacy and choice goals), partially mediated relations, as outlined by Lent et al. (1994).

Results of path analyses revealed that the overall fit of all six models to the data was excellent. In addition, results revealed strong support for all of the hypothesized relations involving corresponding learning experiences, self-efficacy beliefs, outcome expectations, interests, and choice goals for each of the six Holland themes. 
Nevertheless, the nature of some of the observed relations (i.e., direct vs. indirect) represented a departure from my hypotheses, and thus from SCCT. As hypothesized, direct effects of learning experiences to self-efficacy, self-efficacy to outcome expectations, outcome expectations to interests, outcome expectations to choice goals, and interests to choice goals were significant and substantial across the six Holland themes. Contrary to prediction, however, direct effects of learning experiences to outcome expectations, self-efficacy to interests, and self-efficacy to choice goals were non-significant (with the notable exception of the relation between Investigative selfefficacy and choice goals), whereas the indirect effects of all of these relations were significant and substantial. Thus, learning experiences had all of their effect on outcome expectations through self-efficacy, whereas self-efficacy had most of its effect on interests and choice goals via outcome expectations and the combination of outcome expectations and interests, respectively.

Although the nature of some of the significant relations was not exactly as hypothesized, it is interesting to note the similarity of the current findings to those of other tests of SCCT for Holland themes using primarily (Schaub \& Tokar, 2005) or exclusively (Lent et al., 2003) White samples. For example, Schaub and Tokar found that the relation of learning experiences to outcome expectations was largely mediated by self-efficacy for most of the Holland themes. In a similar vein, both Lent et al. and Schaub and Tokar found that self-efficacy's relation to interests was at least partially mediated by outcome expectations. Thus, although some of the hypothesized direct effects among SCCT constructs were not supported by the current study, the current findings are fairly consistent with previous findings using largely White samples. 
Lent et al. (1994) proposed that the relationship between learning experiences and outcome expectations would be partially mediated by self-efficacy. They also proposed that the relationship between self-efficacy and interests would be partially mediated by outcome expectations. However, in this study, self-efficacy fully mediated the relationship between learning experiences and outcomes expectations, and outcome expectations fully mediated the relationship between self-efficacy and interests for all six RIASEC themes. It may be that for African Americans the mediator roles of selfefficacy and outcome expectations in SCCT are different and need further examination.

In addition, the complete mediation of the relationship between learning experiences and outcome expectations through self-efficacy may be because the LEQ items are measuring experiential sources of self-efficacy, but not outcome expectations. A perusal of the LEQ items (e.g., "I performed well in biology courses in school" and "People whom I respect have encouraged me to work hard in math courses") reveals that the items do not tap recollections of outcomes associated with prior direct or vicarious experiences. Perhaps the development of a learning experiences questionnaire that more explicitly taps experiential sources of outcome beliefs would provide a more accurate picture of the nature of the relationship between learning experiences and outcome expectations.

Interestingly, the only hypothesized relation that demonstrated consistent, significant direct and indirect effects involved the relation between outcome expectations and choice goals. Similar results have been found in studies that included African Americans as part of the sample (Fouad \& Smith, 1996; Gainor \& Lent, 1998; Lent et al., 2005), as well as other studies using exclusively White samples (e.g., Lent et al., 2001; 
Lent et al., 2003). These results are consistent with Lent et al.'s (1994) propositions 4A, $\mathrm{B}$, and $\mathrm{C}$, which state that the relationship between outcome expectations and choice goals may direct or indirect, via vocational interests. According to Lent et al. (1994), the relationship between outcome expectations and choice goals will be direct when individuals perceive their opportunity structure as one that does not afford them the option to set goals based on their interests. These individuals will set goals and make decisions based on their perceptions of the expected outcomes of a particular choice. For example, individuals who perceive their choices as being constrained by such things as academic performance or financial considerations are less likely to be influenced by their interests than by their outcome expectations. However, individuals who perceive their opportunity structure as more favorable are more likely to set goals based on their vocational interests. Thus, in any given sample, there will be individuals for whom making a more direct link from their outcome expectations to their choice goals is appropriate and individuals who can afford to base their goals on their interests.

Considered collectively, these findings largely support Lent et al.'s (1994) propositions regarding the nature of the aforementioned relationships in SCCT and provide further support that SCCT is a valid model to use with African Americans. In addition, findings provide additional support for the applicability of SCCT to Holland's (1997) RIASEC themes.

\section{The Role of Learning Experiences in SCCT}

Lent et al. (1994) posited that self-efficacy and outcome expectations are the two most important constructs in SCCT. Learning experiences, particularly personal performance accomplishments, are posited to contribute importantly to the formation of 
an individual's self-efficacy beliefs and outcome expectations. Despite the importance of self-efficacy and outcome expectations in SCCT, very little research has examined how these sociocognitive mechanisms are influenced by each of the four learning experiences. For the purposes of the present study, it is unclear from the extant empirical research exactly how each of the specific learning experiences contributes to corresponding selfefficacy and outcome expectations for domains other than math and science with an African American sample.

The small number of studies that has examined learning experiences' relation to self-efficacy and outcome expectations (Gainor \& Lent, 1998; Lopez et al., 1997; Schaub, 2003) failed to support SCCT's hypothesis that personal performance accomplishments are the strongest unique predictor among the four learning experiences of both self-efficacy and outcome expectations. Contrary to SCCT, Byars and Hackett (1996) suggested that verbal persuasion may be more important than performance accomplishments in the formation of self-efficacy and outcome expectations for African American individuals. Their rationale for this suggestion was based on the premise that African American parents are potent verbal influences for their children because African American children do not have many African American role models from which to garner self-efficacy and outcome expectation information. As such, reliance on the parents for modeling, encouragement, and verbal information in general becomes that much more important in the development of academic/career self-efficacy and outcome expectations.

The results of the simultaneous regression analyses revealed partial support for both the present study's hypotheses (and thus Byars and Hackett's, 1996, predictions) and 
those of SCCT. Consistent with my hypothesis, verbal persuasion contributed the largest amount of unique variance to Conventional self-efficacy as well as to Realistic (men only), Artistic, Enterprising, and Conventional outcome expectations. However, consistent with SCCT, performance accomplishments contributed the largest amount of unique variance to Realistic (men only), Artistic, Social, and Enterprising self-efficacy as well as to Realistic (women only) outcome expectations. Unexpectedly, vicarious learning contributed the largest amount of unique variance to Investigative self-efficacy as well as to Investigative and Social outcome expectations. Finally, physiological arousal contributed the largest amount of unique variance to Realistic (women only) selfefficacy.

Taken together, these findings suggest that for African American college students, the relative contributions of their learning experiences to subsequent self-efficacy beliefs and outcome expectations are domain-specific. Importantly, contrary to SCCT, in nine of the 14 regressions predicting self-efficacy and outcome expectations, learning experiences other than personal performance accomplishments contributed most strongly. These findings are somewhat consistent with those of Pearson and Bieschke (2001), who found in their qualitative study of familial factors influencing the career success of 14 African American women that verbal persuasion and vicarious learning, not performance accomplishments, were the most important learning experiences contributing to high selfefficacy and positive outcome expectations. The current findings and those of Pearson and Bieschke strongly suggest that further examination of the unique contributions of African Americans' learning experience to self-efficacy and outcome expectations is warranted. Moreover, if additional studies replicate the findings revealed in the current 
study, then SCCT's propositions regarding the experiential sources of self-efficacy beliefs and outcome expectations for African Americans may require revision.

\section{The Moderating Role of Racism}

Lent et al. (1994) and Lent et al. (2000) proposed that proximal contextual factors, those environmental factors that are more immediate in one's career development process, play an important moderating role in the relationship between vocational interests and choice goals. To date, only one study (Lent et al, 2001) has examined the proposed moderating role of proximal contextual factors, and the results of that study were inconclusive. Examining the role of proximal contextual factors, such as the experience of racism, for African Americans is important if career interventions are to be designed to enhance African Americans' career development.

The present study examined the potential moderating role of perceptions of racism in the relationship between vocational interests and choice goals. The results of the moderated regression analyses were generally unsupportive of Hypotheses 13A-F, which stated that the perception of racism will moderate the interest-choice relation for RIASEC-related activities, such that a greater perception of racism will weaken the interest-choice goals relation. Specifically, the results revealed the presence of a moderator effect for the Realistic (male), Investigative, and Enterprising models, but not for the Realistic (female), Artistic, Social, and Conventional models. The lack of a moderator effect for four of the seven relations may be due to the fact that it is generally difficult to detect moderator effects using particular types of research methods, such as survey data (Wampold \& Freund, 1987). It may also be that individuals in the sample simply did not perceive their experience of racism to play a role in choosing career fields 
that involve Realistic (women only), Artistic, Social, and Conventional tasks and abilities.

When the significant moderator effects for the Realistic (male), Investigative, and Enterprising models were examined more closely, results revealed that the Investigative and Enterprising interests-choice goals relations did not significantly differ for the high and low racism. This suggests that greater perceptions of racism were not a deterrent in the translation of Investigative and Enterprising interests into corresponding choice goals, as expected. Further, the results of follow-up analyses indicated that for men, a greater perception of racism actually strengthened the Realistic interest-choice goals relation. While this result is initially puzzling, results of two studies (Adams, Cahill, \& Ackerlind, 2004; Pearson \& Bieschke, 2001) have shown that potential barriers to successful career development, including perceptions of racism, may be potent motivators to succeed in a particular field.

In a qualitative study examining the career development process of eight Latino lesbian and gay youth, Adams et al. (2004) found that the participants believed they could succeed in any career they chose, did not eliminate career choices based on perceived barriers, and used excelling in a particular career field as one way of coping with perceived homophobia and racism. Adams et al. (2004) concluded that Lent et al.'s (2000) hypothesis that negative environmental factors would lower career interests for those occupations for which there are perceived barriers was not supported by their study. Pearson and Bieschke (2001) found that the African American women in their sample became more determined to succeed in a particular career field when they perceived racism and discrimination. Thus, it may be that for the men in the present sample, greater 
perceptions of racism motivated them to translate their Realistic interests into Realistic career goals.

In addition, the general lack of moderator effects may have been due to the fact that this particular sample had good coping efficacy for racism, and thus did not perceive it as a deterrent to their academic/career pursuits (Hung-Bin \& Sedlacek, 2004; Sedlacek, 1999). Recall that the sample was solicited from a university Black cultural center. As such, it may be that the current participants had relatively well-developed racial identity, which also could be a buffer against racism.

Finally, the way in which racism was measured in this study may have influenced the results. Racism was measured with the SRE (Landrine \& Klonoff, 1996), a selfreport measure that asks participants to rate the degree to which they have experienced racism in a variety of situations. It may be that the SRE and similar self-report measures of perceived racism are not valid measures of the actual experience of racism. It may also be that the items on the SRE were not as relevant for a college student population. Some of the wording is a bit dated for this generation (e.g., use of the word "coon"), and it may be that college students today are experiencing more subtle forms of racism or racism in other situations (e.g., on the Internet). Finally, the SRE items may not be tapping a proximal contextual factor, as defined by SCCT. SRE items tap perceptions of lifetime experiences of racism and racism experienced within the past year. Thus, the SRE does not directly assess an individual's experience with racism in the present, making it difficult to determine if a respondent is viewing racism as a current deterrent in her/his academic/career endeavors. 


\section{Implications for Counseling}

Results of this study support the use of SCCT by career researchers and counselors. In terms of identifying important factors in the development of self-efficacy and outcome expectations, it is important for career counselors to adequately address the nature of the individual's learning experiences. There is support for the assertion that verbal persuasion is a vital learning experience for African American individuals and that encouragement about one's abilities from mentors, family members, and significant others will help to enhance one's self-efficacy and outcome expectations, particularly for Artistic, Enterprising, and Conventional activities (Hackett \& Byars, 1996; Hackett \& Byars, 1998; Pearson \& Bieschke, 2001). Findings also suggest that role models are an important influence in the development of African Americans' Investigative and Social self-efficacy and outcome expectations. Career counselors should encourage their African American clients to identify and/or seek out family members and other positive role models, particularly those involved in Investigative careers and related activities, as these are careers in which African Americans have been greatly underrepresented (Fouad \& Smith, 1996; Gainor \& Lent, 1998; Lent et al., 2005).

The results of this study also suggest that it is important for career counselors to adequately assess the role that racism plays in the career development process of their African American clients. Research suggests that the perception of racism may not be a barrier to the translation of vocational interests into goals. It is important for career counselors to not assume that the experience of racism and other contextual barriers and/or affordances will affect all clients similarly. Instead, counselors should conduct a 
comprehensive assessment of what the client perceives as helpful or not helpful to meeting their academic and career goals.

Finally, the results of this study suggest that examining the role of outcome expectations is important when exploring an African American client's career development. Results of this study suggest that outcome expectations play an important role in the development of interests and choice goals. Thus, assessing a client's expected outcomes for pursuing different academic/career goal(s) will be important to gain a more accurate understanding of the client's vocational choices. 


\section{Limitations and Implications for Future Research}

Several limitations of this research should be addressed. First, this study used a cross-sectional design, and data were collected at a single point in time. Thus, causal relationships cannot be established. The excellent model-data fit found for all seven models does not rule out the possibility that alternative models fit the data equally well or better. Future researchers are encouraged to cross-validate the present study's findings on independent samples and to consider using alternative (e.g., longitudinal) designs that allow for causal inferences.

Another limitation is that this study did not take into account several constructs in SCCT. Person inputs, background contextual factors, and performance attainments were not included in this study. Lent et al. (1994) posited that person inputs and background contextual factors interact to influence the development of learning experiences. In an effort to more thoroughly understand the role of learning experiences in SCCT for African Americans, it will be important for future researchers to examine the posited precursors of learning experiences. Further, Lent et al. (1994) asserted that performance accomplishments provide a feedback loop to person inputs and background contextual factors. Thus, to obtain a comprehensive understanding of the adequacy of SCCT for African Americans, future researchers are also encouraged to include assessments of performance attainments in their tests of SCCT.

A final limitation involves the reliability estimates of some of the LEQ subscales. Many of the LEQ subscales were below the recommended cutoff of .70 (Nunnally \& Bernstein, 1994), although only two subscales were below .70 after using the SpearmanBrown prophecy formula for 10 items per subscale. If future researchers are to continue 
to use the LEQ, it will be important to further establish the measure's psychometric properties, particularly on samples that are more diverse in terms of ethnicity and social class than the sample on which the LEQ was developed (Schaub, 2003).

There are several additional directions for future research. First, given that this is one of only a handful of studies examining SCCT using an African American sample, it will be important for future researchers to conduct additional studies on African Americans as well as other racial/ethnic minority groups to establish the validity, and thus applicability, of SCCT for racial-ethnic minorities. Second, given the domainspecific findings regarding the unique contributions of learning experiences to corresponding self-efficacy beliefs and outcome expectations, future researchers are encouraged to re-visit the complex role of learning experiences in SCCT. Finally, given the unexpected findings regarding the moderating role of racism in the relation between vocational interests and choice goals, it will be important for future researchers to attempt to shed additional light on how and why African Americans' experience of racism may discourage and/or motivate the translation of vocational interests into corresponding career goals and choices. 


\section{REFERENCES}

Adams, E.M., Cahill, B.J., \& Ackerlind, S.J. (2005). A qualitative study of latino lesbian and gay youths' experiences with discrimination and the career development process. Journal of Vocational Behavior, 66, 199-218.

Bandura, A. (1977). Self-efficacy: Toward a unifying theory of behavior change. Psychological Review, 84, 191-215.

Bandura, A. (1986). Social foundations of thought and action: A social cognitive theory. Englewood Cliffs, NJ: Prentice-Hall.

Betz, N.E. (1977). Math anxiety: What is it? Paper presented at the $85^{\text {th }}$ Annual Convention of the American Psychological Association, San Francisco, CA.

Betz, N.E. (1994). Confidence measures for the general occupational themes: Using the Confidence Inventory. In Manual for the Strong Interest Inventory. Palo Alto, CA: Consulting Psychologist Press.

Betz, N.E., Borgen, F.H., Harmon, L.W. (1996). Skills Confidence Inventory applications and technical guide. Palo Alto, CA: Consulting Psychologists Press, Inc.

Betz, N.E., \& Hackett, G. (1983). The relationship of mathematics self-efficacy expectations to the selection of science-based college majors. Journal of Vocational Behavior, 23, 329-345.

Betz, N.E., Harmon, L.W., \& Borgen, F.H. (1996). The relationships of self-efficacy for the Holland themes to gender, occupational group membership, and vocational interests. Journal of Counseling Psychology, 43, 90-98.

Bieschke, K.J., \& Bishop, R.M. (1994). Research Outcome Expectations Questionnaire. Unpublished scale.

Bishop, R.M., \& Bieschke, K.J. (1994). Interest in Research Questionnaire. Unpublished scale.

Bishop, R.M., \& Bieschke, K.J. (1998). Applying social cognitive theory to interest in research among counseling psychology doctoral students: A path analysis. Journal of Counseling Psychology, 45, 182-188. 
Bishop, R.M., \& Bieschke, K.J. (1998). Applying social cognitive theory to interest in research among counseling psychology doctoral students: A path analysis. Journal of Counseling Psychology, 45, 182-188.

Bryant-Davis, T., \& Ocampo, C. (2005). Racist incident-based trauma. The Counseling Psychologist, 33, 479-500.

Byars, A.M., \& Hackett, G. (1998). Applications of social cognitive theory to the career development of women of color. Applied and Preventive Psychology, 7, 255-267.

Byrne, B.M. (1989). A primer for Lisrel: Basic applications and programming for confirmatory factory analytic models. New York: Springer-Verlag.

College Board. (1993a). Introducing the new SAT: The College Board's official guide. New York: College Entrance Examination Board.

College Board (1993b). The new SAT: Moving "beyond prediction.” New York: College Entrance Examination Board.

Costa, P.T., Jr., \& McCrae, R.R. (1992). Revised NEO Personality Inventory (NEO-PI$R$ ) and NEO Five-Factor Inventory (NEO-FFI) professional manual. Odessa, FL: Psychological Assessment Resources.

Derogatis, L.R., Lipman, R.S., Rickles, K., Uhlenhuth, E., \& Covi, L. (1994). The Hopkins Symptom Checklist: A self-report symptom inventory. Behavioral Science, 19, 1-15.

Fennema, E., \& Sherman, J.A. (1976). Fennema-Sherman Mathematics Attitude Scales: Instruments designed to measure attitudes toward learning of mathematics by females and males. Catalog of Selected Documents in Psychology, 6 (31, Manuscript No. 1225).

Fouad, N.A., \& Smith, P.L. (1996). A test of a social cognitive model for middle school students: Math and science. Journal of Counseling Psychology, 43, 338-346.

Gainor, K.A., \& Lent, R.W. (1998). Social cognitive expectations and racial attitudes in predicting the math choice intentions of black college students. Journal of Counseling Psychology, 45, 403-413.

Gelso, C.J., Mallinckrodt, B., \& Royalty, G.M. (1991). The Research Training Environment Scale. In Tests in Microfiche. Princeton, NJ: Educational Testing Service. 
Goldman, R.D., \& Hewitt, B.N. (1976). The Scholastic Aptitude Test "explains" why college men major in science more often then college women. Journal of Counseling Psychology, 23, 50-54.

Gore, P.A., Jr. (August, 1996). A structural analysis of a social-cognitive model of career interests (Doctoral dissertation, Loyola University Chicago, 1996). Dissertation Abstracts International, 56, 4663.

Gore, P.A., \& Leuwerke, W.C. (2000). Predicting occupational considerations: A comparison of self-efficacy beliefs, outcome expectations, and personenvironment congruence. Journal of Career Assessment, 8, 237-250.

Greeley, A.T., Johnson, E., Seem, S., Braver, M., Dias, L., Evans, K., Kincade, E., \& Pricken, P. (1989). Research Self-Efficacy Scale. Unpublished scale, Pennsylvania State University, University Park.

Hackett, G., \& Byars, A.M. (1996). Social cognitive theory and the career development of african american women. Career Development Quarterly, 44, 322-340.

Hackett, G., Lent, R.W. (1992). Theoretical advances and current inquiry in career psychology. In S.D. Brown \& R.W. Lent (Eds.), Handbook of counseling psychology ( $2^{\text {nd }}$ ed., pp. 419-451). New York: Wiley.

Hansen, J.C., \& Campbell, D.P. (1985). Manual for the SVIB-SCII ( ${ }^{\text {th }}$ ed.). Palo Alto, CA: Consulting Psychologists Press.

Harmon, L.W., Hansen, J.C., Borgen, F.H., \& Hammer, A.L. (1994). Strong Interest Inventory: Applications and technical guide. Stanford, CA: Stanford University Press.

Holland, J.L. (1985). Making vocational choices: A theory of vocational personalities and work environments ( $2^{\text {nd }}$ ed.). Englewood Cliffs, NJ: Prentice-Hall.

Holland, J.L. (1985). Vocational Preference Inventory Manual. Odessa, FL: Psychological Assessment Resources.

Holland, J.L. (1997). Making vocational choices: A theory of vocational personalities and work environments ( $3^{\text {rd }}$ ed.). Psychological Assessment Resources: Odessa, FL.

Hsia, J. (1988). Asian americans in higher education and at work. Hillsdale, NJ: Erlbaum. 
Hu, L., \& Bentler, P.M. (1999). Cutoff criteria for fit indexes in covariance structural analysis: Conventional criteria versus new alternatives. Structural Equation Modeling, 6, 1-55.

Kline, R.B. (1998). Principles and practice of structural equation modeling. New York: Guilford.

Klonoff, E.A., \& Landrine, H. (1999). Cross-validation of the Schedule of Racist Events. Journal of Black Psychology, 25, 231-254.

Lamb, R., \& Prediger, D. (1995). Technical manual: Revised unisex edition of the ACT Interest Inventory. Iowa City, IA-American College Testing Program.

Landrine, H., \& Klonoff, E.A., (1996). The schedule of racist events: A measure of racial discrimination and a study of its negative physical and mental health consequences. Journal of Black Psychology, 22, 144-168.

Lapan, R.T., Shaughnessy, P., \& Boggs, K. (1996). Efficacy expectations and vocational interests as mediators between sex and choice of math/science college majors: A longitudinal study. Journal of Vocational Behavior, 49, 277-291.

Larson, L.M., Rottinghaus, P.J., \& Borgen, F.H. (2002). Meta-analyses of Big Six interests and Big Five personality factors. Journal of Vocational Behavior, 61, 217-239.

Lent, R.W., Brown, S.D., \& Larkin, K.C. (1986). Self-efficacy in the prediction of academic performance and perceived career options. Journal of Counseling Psychology, 33, 265-269.

Lent, R.W., Brown, S.D., \& Hackett, G. (1994). Toward a unifying social cognitive theory of career and academic interest, choice, and performance. Journal of Vocational Behavior, 45, 79-122.

Lent, R.W., Brown, S.D., \& Hackett, G. (2000). Contextual supports and barriers to career choice: A social cognitive analysis. Journal of Counseling Psychology, 47, 36-49.

Lent, R.W., Brown, S.D., Brenner, B., Chopra, S.B., Davis, T., Talleyrand, R., \& Suthakaran, V. (2001). The role of contextual supports and barriers in the choice of math/science educational options: A test of social cognitive hypotheses. Journal of Counseling Psychology, 48, 474-483.

Lent, R.W., Brown, S.D., Nota, L., \& Soresi, S. (2003). Testing social cognitive interest and choice hypotheses across holland types in italian high school students. Journal of Vocational Behavior, 62, 101-118. 
Lent, R.W., Brown, S.D., Schmidt, J., Brenner, B, Lyons, H., \& Treistman, D. (2003). Relation of contextual supports and barriers to choice behavior in engineering majors: Test of alternative social cognitive models. Journal of Counseling Psychology, 50, 458-465.

Lent, R.W., Brown, S.D., Sheu, H., Schmidt, J., Brenner, B.R., Gloster, C.S., Wilkins, G., Schmidt, L.C., Lyons, H., \& Treistman, D. (2005). Social cognitive predictors of academic interests and goals in engineering: Utility for women and students at historically black universities. Journal of Counseling Psychology, 52, 84-92.

Lent, R.W., Lopez, F.G., Bieschke, K.J. (1991). Predicting mathematics-related choice and success behaviors: Test of an expanded social cognitive model. Journal of Vocational Behavior, 42, 223-236.

Lent, R.W., Lopez, F.G., \& Bieschke, K.J. (1991) Mathematics self-efficacy: Sources and relation to science-based career choice. Journal of Counseling Psychology, $38,424-430$.

Loehlin, J.C. (1987). Latent variable models: An introduction to factor, path, and structural analysis. Hillsdale, NJ: Erlbaum.

Lopez, F.G., Lent, R.W., Brown, S.D., \& Gore, P.A. (1997). Role of social-cognitive expectations in high school students' mathematics-related interest and performance. Journal of Counseling Psychology, 44, 44-52.

Luzzo, D.A. (1993). Ethnic differences in college students' perceptions of barriers to career development. Journal of Multicultural Counseling and Development, 21, 227-237.

Luzzo, D.A., \& McWhirter, E.H. (2001). Sex and ethnic differences in the perception of educational and career-related barriers and levels of coping efficacy. Journal of Counseling and Development, 79, 61-67.

Múthen, L.K. \& Múthen, B.O. (1998-2004). Mplus user's guide ( ${ }^{\text {rd }}$ ed.). Los Angeles: Múthen \& Múthen.

Nunnally, J.C., \& Bernstein, I.H. (1994). Psychometric theory ( $3^{\text {rd }}$ Ed.). New York: McGraw-Hill.

Pearson, S.M., \& Bieschke, K.J. (2001). Succeeding against the odds: An examination of familial influences on the career development of professional african american women. Journal of Counseling Psychology, 48, 301-309.

Schaub (2004). The Learning Experiences Questionnaire. Unpublished measure. 
Schaub, M. (2004). Social cognitive career theory: Examining the mediating role of sociocognitive variables in the relation of personality to vocational interests. Dissertation Abstracts International Section A: Humanities \& Social Sciences, 64 (7-A), 2463. (UMI No. AAT 3098455).

Schaub, M., \& Tokar, D.M. (2005). The role of personality and learning experiences in social cognitive career theory. Journal of Vocational Behavior, 66, 304-325.

Sheu, H.B., Sedlacek, W.E. (2004). An exploratory study of help-seeking attitudes and coping strategies among college students by race and gender. Measurement and Evaluation in Counseling and Development, 37, 130-143.

Sedlacek, W.E. (1999). Black students on white campuses: 20 years of research. Journal of College Student Development, 40, 538-550.

Smith, P.L., \& Fouad, N.A. (1999). Subject-matter specificity of self-efficacy, outcome expectancies, interests, and goals: Implications for the social-cognitive model. Journal of Counseling Psychology, 46, 461-471.

Spokane, A.R. (1996). Holland's theory. In D. Brown \& L. Brooks (Eds.). Career choice and development ( $3^{\text {rd }}$ ed., pp. 33-74). San Francisco: Jossey-Bass.

Stanford 7 Plus Task1/Task2, Forms E/F, National Norms Booklet (1987). New York: Psychological Corporation, Harcourt Brace Jovanovich.

Stevens, G., \& Chou, J.H. (1985). Socioeconomic indexes and the new 1980 census occupational classification scheme. Social Science Research, 14, 142-168.

Suinn, R.M., Rickard-Figueroa, K., Lew, S., \& Vigil, P. (1987). The Suinn-Lew Asian Self-Identity acculturation scale: An initial report. Educational and Psychological Measurement, 47, 401-407.

Tang, M., Fouad, N.A., \& Smith, P.L. (1999). Asian americans' career choices: A path model to examine factors influencing their career choices. Journal of Vocational Behavior, 54, 142-157.

Turner, S.L., Steward, J.C., \& Lapan, R.T. (2004). Family factors associated with sixthgrade adolescents' math and science career interests. The Career Development Quarterly, 53, 41-52.

Wampold, B.E., \& Freund, R.D. (1987). Use of multiple regression in counseling psychology research: A flexible data-analytic strategy. Journal of Counseling Psychology, 34, 372-382. 
APPENDICES 
APPENDIX A

DEMOGRAPHIC QUESTIONNAIRE

\section{Please circle or fill in the blank with the most appropriate response.}

1. How old are you?

2. Your sex is: Female Male

3. Please circle the race/ethnic group to which you feel you belong:

African American/Black Asian American Bi/Multiracial American

Latino/a American Native American/Indian European American/White

Other

4. Please circle your current academic standing:

First Year Second Year Third Year Fourth Year

Post-Baccalaureate Graduate Student Other

5. To which school do you belong?

6. What is your actual or intended major(s)?

First major:

Second major:

7. What is your current overall grade point average?

(Please estimate if unknown):

8. What was your final high school grade point average? (e.g., 4.0)

out of 
9. What was your SAT total score? and/or ACT total score?

10. What occupation would you like to pursue when you complete all of your education (i.e., after completing undergraduate and, if applicable, after completing graduate school or volunteer work)?

11. Which of the following best describes your social class? (Please Circle)

$0-\$ 10,000 \quad \$ 10,000-\$ 20,000 \quad \$ 20,000-\$ 30,000 \quad \$ 30,000-\$ 40,000$

$\$ 40,000-\$ 60,000 \quad \$ 60,000-\$ 100,000 \quad$ More than $\$ 100,000$

12. Please list your father's occupation (if applicable):

13. Please list your mother's occupation (if applicable):

14. Please check the highest level of education your father and/or mother have completed:

Less than high school

Father Mother

Some high school, but no diploma

Graduated high school

Graduated from a 2-year college or technical school

Some college, but no degree

Graduated from a 4-year college with a degree

Some graduate or professional school, but no degree

Completed an advanced degree (M.A., M.Ed., Ph.D.) 


\section{APPENDIX B \\ LEARNING EXPERIENCES QUESTIONNAIRE}

Michael Schaub (2003)

Using the following scale, write the number corresponding to your response on the line next to the statement. Please respond to ALL of the statements.

\begin{tabular}{|c|c|c|c|c|c|}
\hline $\begin{array}{c}\text { Strongly } \\
\text { Disagree }\end{array}$ & Disagree & $\begin{array}{c}\text { Slightly } \\
\text { Disagree }\end{array}$ & $\begin{array}{c}\text { Slightly } \\
\text { Agree }\end{array}$ & Agree & $\begin{array}{c}\text { Strongly } \\
\text { Agree }\end{array}$ \\
\hline 1 & 2 & 3 & 4 & 5 & 6 \\
\hline
\end{tabular}

1.___ I performed well in biology courses in school.

2. People whom I respect have encouraged me to work hard in math courses.

3.___ I remember seeing my family plan out the details of vacations.

4. I I have made simple car repairs.

5. Wh_ While growing up, I saw people whom I admire work in youth ministry.

6.___ I have become nervous while solving math problems.

7. I I have become uptight while trying to repair something that was broken.

8. I I I have seen people whom I respect read business magazines.

9. I I have seen family members perform work which involved organizing information. 


\begin{tabular}{|c|c|c|c|c|c|}
\hline $\begin{array}{c}\text { Strongly } \\
\text { Disagree }\end{array}$ & Disagree & $\begin{array}{c}\text { Slightly } \\
\text { Disagree }\end{array}$ & $\begin{array}{c}\text { Slightly } \\
\text { Agree }\end{array}$ & Agree & $\begin{array}{c}\text { Strongly } \\
\text { Agree }\end{array}$ \\
\hline 1 & 2 & 3 & 4 & 5 & 6 \\
\hline
\end{tabular}

10. People I respect have urged me to learn how to fix things that are broken.

11. I I was successful performing science experiments in school.

12. In school, I saw teachers whom I admired work on science projects.

13. I I have felt uneasy when people would come to me with their problems.

14. I I I have seen people whom I trust successfully manage a business.

15. The artwork I have created usually turned out well.

16. I r r remember my family telling me that it is important to be able to solve science problems.

17. People whom I looked up to told me that it is important to read scholarly articles.

18. I _ I remember watching members of my family create art.

19. My teachers have encouraged me to explore jobs in the helping professions (e.g., counseling).

20. I I I have kept accurate records of my financial documents.

21. I I I have been able to sell a product effectively.

22. I I I have observed members of my family build things.

23. I I have made repairs around the house.

24. I I have become anxious while learning new computer software.

25. I I received good grades in my art courses in school.

26. I I I have become nervous when working on mechanical things (e.g., appliances).

27. I I L I L seen people whom I respect enter the teaching profession. 
28. I have done a good job at proofreading my papers for mistakes.

\begin{tabular}{|c|c|c|c|c|c|}
\hline $\begin{array}{c}\text { Strongly } \\
\text { Disagree }\end{array}$ & Disagree & $\begin{array}{c}\text { Slightly } \\
\text { Disagree }\end{array}$ & $\begin{array}{c}\text { Slightly } \\
\text { Agree }\end{array}$ & Agree & $\begin{array}{c}\text { Strongly } \\
\text { Agree }\end{array}$ \\
\hline 1 & 2 & 3 & 4 & 5 & 6 \\
\hline
\end{tabular}

29. I I have seen my parents keep organized records of their important financial documents.

30. I I have been successful when I used tools to work on things.

31. I I have felt anxious when I had to act in a play.

32. I I I have been successful at caring for children.

33. I I have listened to members of my family speak in public.

34. I received high scores on the math section of my college entrance exam (e.g., SAT).

35.___ I have felt nervous when I had to sell something.

36. I I I have been successful at teaching people.

37. I I have felt nervous while debating a topic.

38. I I watched people whom I respect work in the outdoors.

39. I I have felt anxious about creating artwork.

40. Teachers I admired encouraged me to take classes in which I can use my mechanical abilities.

41. ___ I watched my friends as they participated in school plays.

42. ___ People whom I admire have told me that it is important to learn new computer software.

43. W__ While growing up, I saw people I respected using math to solve problems.

44. I I have felt anxious while taking a science course in school.

45. I I I have seen people whom I respect participating in activities that require math abilities. 
46. I have seen people whom I respect enter politics.

47. I have become nervous while teaching something new to a classmate.

\begin{tabular}{|c|c|c|c|c|c|}
\hline $\begin{array}{c}\text { Strongly } \\
\text { Disagree }\end{array}$ & Disagree & $\begin{array}{c}\text { Slightly } \\
\text { Disagree }\end{array}$ & $\begin{array}{c}\text { Slightly } \\
\text { Agree }\end{array}$ & Agree & $\begin{array}{c}\text { Strongly } \\
\text { Agree }\end{array}$ \\
\hline 1 & 2 & 3 & 4 & 5 & 6 \\
\hline
\end{tabular}

48. ___ I have felt uneasy while using tools to build something.

49. I I I have felt anxious while organizing resources for a term paper.

50. I I I have seen people whom I admire dedicate their lives to helping others.

51.___ I recall seeing adults whom I admire working in a research laboratory.

52. ___ I have successfully persuaded people to do things my way.

53. I I have done a good job at writing poetry.

54.___ People whom I respect have encouraged me to play a musical instrument.

55. ___ I have observed people whom I admire perform volunteer work.

56. ___ I have felt uneasy while learning new topics in biology courses.

57. I I have easily understood new math concepts after learning about them in class.

58. __ My parents have encouraged me to pursue jobs that involve keeping track of records.

59.___ I observed people whom I respect repair mechanical things.

60. My family encouraged me to take social science courses (e.g., psychology).

61. Teachers whom I respect have told me that it is important to have good organizational skills.

62. I I I have demonstrated skill at conducting research for my term papers.

63. While growing up, I watched adults whom I respect fix things. 
64. I have seen people whom I admire write fiction stories.

65. ___ Reading scientific articles has made me feel uneasy.

66. I have felt anxious while performing basic repairs on a car.

\begin{tabular}{|c|c|c|c|c|c|}
\hline $\begin{array}{c}\text { Strongly } \\
\text { Disagree }\end{array}$ & Disagree & $\begin{array}{c}\text { Slightly } \\
\text { Disagree }\end{array}$ & $\begin{array}{c}\text { Slightly } \\
\text { Agree }\end{array}$ & Agree & $\begin{array}{c}\text { Strongly } \\
\text { Agree }\end{array}$ \\
\hline 1 & 2 & 3 & 4 & 5 & 6 \\
\hline
\end{tabular}

67. My family has encouraged me to find a job which involves performing basic office tasks.

68. I I I have accurately balanced a checkbook.

69. I I L I have been successful at creating a sculpture with clay.

70. ___ My family taught me that it is important to develop my interpersonal communication skills.

71. I I L I have watched people whom I respect perform detail-oriented work.

72. I I I have been able to hold a conversation with all types of people.

73. ___ I have felt nervous learning how to operate office machines.

74. ___ During school, I admired teachers whom I saw create art.

75. Teachers whom I respect have encouraged me to take a business management course.

76. Adults whom I admire have urged me to enter a profession in which I manage others.

77. I I I have been successful at playing a musical instrument.

78. I I have listened well to people who are having personal difficulties.

79. Teachers whom I respect have encouraged me to take an art class.

80. I I have done a good job at things that involved physical labor (e.g., landscaping).

81. People whom I respect have encouraged me to develop my leadership skills. 
82. I have felt uneasy about taking a leadership role in a group.

83. __ I have done a good job at operating new computer programs (e.g., word processing).

84. I have felt uptight while entering data at a computer terminal.

\begin{tabular}{|c|c|c|c|c|c|}
\hline $\begin{array}{c}\text { Strongly } \\
\text { Disagree }\end{array}$ & Disagree & $\begin{array}{c}\text { Slightly } \\
\text { Disagree }\end{array}$ & $\begin{array}{c}\text { Slightly } \\
\text { Agree }\end{array}$ & Agree & $\begin{array}{c}\text { Strongly } \\
\text { Agree }\end{array}$ \\
\hline 1 & 2 & 3 & 4 & 5 & 6 \\
\hline
\end{tabular}

85. I I have felt dread while using math in a job.

86. D__ During school, I have felt uptight while working as a part of a small group.

87. While growing up, I recall seeing people I respected reading scientific articles.

88. I I I have seen people whom I respect hold jobs which involved performing routine office work.

89. I _ I remember feeling anxious while working on something that required manual labor.

90. I I have done a good job at performing basic office work (e.g., filing).

91. ___ Family members have urged me to learn how to sing.

92. People whom I trust have told me that it is important to be able to persuade others to do things.

93. I I have become anxious initiating conversations with people I do not know.

94. I I I have felt uptight while writing a short story for school.

95. I I I have been a successful leader in school.

96. ___ My friends have encouraged me to use my research abilities.

97. Teachers whom I admire have encouraged me to take science courses.

98. I I I have seen people whom I admire lead others.

99. I I remember feeling uptight when I had to keep clear, precise records. 


\begin{tabular}{|c|c|c|c|c|c|}
\hline $\begin{array}{c}\text { Strongly } \\
\text { Disagree }\end{array}$ & Disagree & $\begin{array}{c}\text { Slightly } \\
\text { Disagree }\end{array}$ & $\begin{array}{c}\text { Slightly } \\
\text { Agree }\end{array}$ & Agree & $\begin{array}{c}\text { Strongly } \\
\text { Agree }\end{array}$ \\
\hline 1 & 2 & 3 & 4 & 5 & 6 \\
\hline
\end{tabular}

100. ___ I observed people whom I admire work in a garden.

101. ___ While growing up, adults I respected encouraged me to work with tools.

102. ___ While growing up, I listened to family members play musical instruments.

103. ___ People whom I respect have encouraged me to be a detail-oriented person.

104.___ I have felt uneasy while supervising the work of others.

105. I I I have done well in building things.

106. P__ People whom I admire have encouraged me to be a salesperson.

107.___ I have done well at public speaking.

108. While growing up, adults whom I admired told me that it is important to be a good writer.

109.___ I have felt uneasy while drawing something.

110. I I have felt uncomfortable while playing a musical instrument for other people.

111. ___ Friends have urged me to act in a play.

112. I I I have become nervous while developing new friendships.

113. People whom I look up to have urged me to pursue activities that require manual dexterity.

114. I I have felt anxious when I attempted to persuade someone to do things my way.

115. I I have seen people I know enter work in the helping professions (e.g., social work).

116. People whom I respect have encouraged me to perform volunteer work. 


\begin{tabular}{|c|c|c|c|c|c|}
\hline $\begin{array}{c}\text { Strongly } \\
\text { Disagree }\end{array}$ & Disagree & $\begin{array}{c}\text { Slightly } \\
\text { Disagree }\end{array}$ & $\begin{array}{c}\text { Slightly } \\
\text { Agree }\end{array}$ & Agree & $\begin{array}{c}\text { Strongly } \\
\text { Agree }\end{array}$ \\
\hline 1 & 2 & 3 & 4 & 5 & 6 \\
\hline
\end{tabular}

117. I I earned good grades in social science courses.

118. Family members have encouraged me to pursue activities that involve working outdoors.

119. My friends have urged me to help others resolve their personal difficulties.

120. I I I have successfully supervised the work of others. 


\begin{abstract}
APPENDIX C
SELF-EFFICACY MEASURE

Adapted from Paul Gore and Wade Leuwerke (2000)

SELF-EFFICACY
\end{abstract}

Instructions: For each of the occupations listed below indicate HOW MUCH

CONFIDENCE YOU HAVE IN YOUR ABILITY TO BECOME A SUCCESSFUL

WORKER IN EACH OF THESE OCCUPATIONS on a 9-point scale.

Occupation

Not Very Much

Very Much

$\begin{array}{llllllllll}\text { Airplane Mechanic } & 1 & 2 & 3 & 4 & 5 & 6 & 7 & 8 & 9 \\ \text { Firefighter } & 1 & 2 & 3 & 4 & 5 & 6 & 7 & 8 & 9 \\ \text { Auto Mechanic } & 1 & 2 & 3 & 4 & 5 & 6 & 7 & 8 & 9 \\ \text { Carpenter } & 1 & 2 & 3 & 4 & 5 & 6 & 7 & 8 & 9 \\ \begin{array}{l}\text { Fish and Wildlife } \\ \text { Specialist }\end{array} & 1 & 2 & 3 & 4 & 5 & 6 & 7 & 8 & 9 \\ \text { Tree Surgeon } & 1 & 2 & 3 & 4 & 5 & 6 & 7 & 8 & 9 \\ \text { Truck Driver } & 1 & 2 & 3 & 4 & 5 & 6 & 7 & 8 & 9 \\ \text { Surveyor } & 1 & 2 & 3 & 4 & 5 & 6 & 7 & 8 & 9 \\ \text { Construction } & & & & & & & & & \\ \text { Inspector } & 1 & 2 & 3 & 4 & 5 & 6 & 7 & 8 & 9 \\ \text { Radio Operator } & 1 & 2 & 3 & 4 & 5 & 6 & 7 & 8 & 9 \\ \text { Bus Driver } & 1 & 2 & 3 & 4 & 5 & 6 & 7 & 8 & 9 \\ \text { Locomotive } & & & & & & & & & \\ \text { Engineer } & 1 & 2 & 3 & 4 & 5 & 6 & 7 & 8 & 9 \\ \text { Machinist } & 1 & 2 & 3 & 4 & 5 & 6 & 7 & 8 & 9 \\ \text { Electrician } & 1 & 2 & 3 & 4 & 5 & 6 & 7 & 8 & 9 \\ \text { Meteorologist } & 1 & 2 & 3 & 4 & 5 & 6 & 7 & 8 & 9\end{array}$


Self-efficacy, continued: Confidence in becoming a successful worker

\begin{tabular}{|c|c|c|c|c|c|c|c|c|c|}
\hline \multirow{2}{*}{$\begin{array}{l}\text { Occupation } \\
\text { Biologist }\end{array}$} & \multicolumn{7}{|c|}{ Not Very Much } & \multicolumn{2}{|c|}{ Very Much } \\
\hline & 1 & 2 & 3 & 4 & 5 & 6 & 7 & 8 & 9 \\
\hline Astronomer & 1 & 2 & 3 & 4 & 5 & 6 & 7 & 8 & 9 \\
\hline \multicolumn{10}{|l|}{ Medical Laboratory } \\
\hline Technician & 1 & 2 & 3 & 4 & 5 & 6 & 7 & 8 & 9 \\
\hline Anthropologist & 1 & 2 & 3 & 4 & 5 & 6 & 7 & 8 & 9 \\
\hline Zoologist & 1 & 2 & 3 & 4 & 5 & 6 & 7 & 8 & 9 \\
\hline Chemist & 1 & 2 & 3 & 4 & 5 & 6 & 7 & 8 & 9 \\
\hline \multicolumn{10}{|l|}{ Independent Research } \\
\hline Scientist & 1 & 2 & 3 & 4 & 5 & 6 & 7 & 8 & 9 \\
\hline \multicolumn{10}{|l|}{ Writer of Scientific } \\
\hline Articles & 1 & 2 & 3 & 4 & 5 & 6 & 7 & 8 & 9 \\
\hline \multicolumn{10}{|l|}{ Editor of Scientific } \\
\hline Articles & 1 & 2 & 3 & 4 & 5 & 6 & 7 & 8 & 9 \\
\hline Geologist & 1 & 2 & 3 & 4 & 5 & 6 & 7 & 8 & 9 \\
\hline Botanist & 1 & 2 & 3 & 4 & 5 & 6 & 7 & 8 & 9 \\
\hline \multicolumn{10}{|l|}{ Scientific Research } \\
\hline Worker & 1 & 2 & 3 & 4 & 5 & 6 & 7 & 8 & 9 \\
\hline Physicist & 1 & 2 & 3 & 4 & 5 & 6 & 7 & 8 & 9 \\
\hline Poet & 1 & 2 & 3 & 4 & 5 & 6 & 7 & 8 & 9 \\
\hline Symphony Conductor & 1 & 2 & 3 & 4 & 5 & 6 & 7 & 8 & 9 \\
\hline Musician & 1 & 2 & 3 & 4 & 5 & 6 & 7 & 8 & 9 \\
\hline Novelist & 1 & 2 & 3 & 4 & 5 & 6 & 7 & 8 & 9 \\
\hline Actor/Actress & 1 & 2 & 3 & 4 & 5 & 6 & 7 & 8 & 9 \\
\hline Free-Lance Writer & 1 & 2 & 3 & 4 & 5 & 6 & 7 & 8 & 9 \\
\hline Music Arranger & 1 & 2 & 3 & 4 & 5 & 6 & 7 & 8 & 9 \\
\hline Journalist & 1 & 2 & 3 & 4 & 5 & 6 & 7 & 8 & 9 \\
\hline Artist & 1 & 2 & 3 & 4 & 5 & 6 & 7 & 8 & 9 \\
\hline Singer & 1 & 2 & 3 & 4 & 5 & 6 & 7 & 8 & 9 \\
\hline Composer & 1 & 2 & 3 & 4 & 5 & 6 & 7 & 8 & 9 \\
\hline Sculptor/Sculptress & 1 & 2 & 3 & 4 & 5 & 6 & 7 & 8 & 9 \\
\hline Playwright & 1 & 2 & 3 & 4 & 5 & 6 & 7 & 8 & 9 \\
\hline Cartoonist & 1 & 2 & 3 & 4 & 5 & 6 & 7 & 8 & 9 \\
\hline Sociologist & 1 & 2 & 3 & 4 & 5 & 6 & 7 & 8 & 9 \\
\hline High School Teacher & 1 & 2 & 3 & 4 & 5 & 6 & 7 & 8 & 9 \\
\hline \multicolumn{10}{|l|}{ Juvenile Delinquency } \\
\hline Expert & 1 & 2 & 3 & 4 & 5 & 6 & 7 & 8 & 9 \\
\hline Speech Therapist & 1 & 2 & 3 & 4 & 5 & 6 & 7 & 8 & 9 \\
\hline Marriage Counselor & 1 & 2 & 3 & 4 & 5 & 6 & 7 & 8 & 9 \\
\hline School Principal & 1 & 2 & 3 & 4 & 5 & 6 & 7 & 8 & 9 \\
\hline Physical Therapist & 1 & 2 & 3 & 4 & 5 & 6 & 7 & 8 & 9 \\
\hline
\end{tabular}


Self-efficacy, continued: Confidence in becoming a successful worker

\begin{tabular}{|c|c|c|c|c|c|c|c|c|c|}
\hline \multirow{2}{*}{$\begin{array}{l}\text { Occupation } \\
\text { Clinical Psychologist }\end{array}$} & \multicolumn{7}{|c|}{ Not Very Much } & \multicolumn{2}{|c|}{ Very Much } \\
\hline & 1 & 2 & 3 & 4 & 5 & 6 & 7 & 8 & 9 \\
\hline $\begin{array}{l}\text { Teacher } \\
\text { Director of Welfare }\end{array}$ & 1 & 2 & 3 & 4 & 5 & 6 & 7 & 8 & 9 \\
\hline Agency & 1 & 2 & 3 & 4 & 5 & 6 & 7 & 8 & 9 \\
\hline Youth Camp Director 1 & 1 & 2 & 3 & 4 & 5 & 6 & 7 & 8 & 9 \\
\hline Personal Counselor 1 & 1 & 2 & 3 & 4 & 5 & 6 & 7 & 8 & 9 \\
\hline Social Worker $\quad 1$ & 1 & 2 & 3 & 4 & 5 & 6 & 7 & 8 & 9 \\
\hline Vocational Counselor 1 & 1 & 2 & 3 & 4 & 5 & 6 & 7 & 8 & 9 \\
\hline Speculator & 1 & 2 & 3 & 4 & 5 & 6 & 7 & 8 & 9 \\
\hline Buyer $\quad 1$ & 1 & 2 & 3 & 4 & 5 & 6 & 7 & 8 & 9 \\
\hline $\begin{array}{l}\text { Advertising Executive 1 } \\
\text { Manufacturer's }\end{array}$ & & 2 & 3 & 4 & 5 & 6 & 7 & 8 & 9 \\
\hline $\begin{array}{l}\text { Representative } \\
\text { Life Insurance }\end{array}$ & 1 & 2 & 3 & 4 & 5 & 6 & 7 & 8 & 9 \\
\hline Salesperson & 1 & 2 & 3 & 4 & 5 & 6 & 7 & 8 & 9 \\
\hline Radio-TV Announcer 1 & 1 & 2 & 3 & 4 & 5 & 6 & 7 & 8 & 9 \\
\hline Business Executive 1 & 1 & 2 & 3 & 4 & 5 & 6 & 7 & 8 & 9 \\
\hline Restaurant Manager 1 & 1 & 2 & 3 & 4 & 5 & 6 & 7 & 8 & 9 \\
\hline Master of Ceremonies 1 & 1 & 2 & 3 & 4 & 5 & 6 & 7 & 8 & 9 \\
\hline $\begin{array}{l}\text { Sales Person } \\
\text { Real Estate }\end{array}$ & 1 & 2 & 3 & 4 & 5 & 6 & 7 & 8 & 9 \\
\hline Salesperson & 1 & 2 & 3 & 4 & 5 & 6 & 7 & 8 & 9 \\
\hline $\begin{array}{l}\text { Travel Guide } \\
\text { Department Store }\end{array}$ & 1 & 2 & 3 & 4 & 5 & 6 & 7 & 8 & 9 \\
\hline Manager & 1 & 2 & 3 & 4 & 5 & 6 & 7 & 8 & 9 \\
\hline Sales Manager & 1 & 2 & 3 & 4 & 5 & 6 & 7 & 8 & 9 \\
\hline Bookkeeper & 1 & 2 & 3 & 4 & 5 & 6 & 7 & 8 & 9 \\
\hline Business Teacher & 1 & 2 & 3 & 4 & 5 & 6 & 7 & 8 & 9 \\
\hline $\begin{array}{l}\text { Budget Reviewer } \\
\text { Certified Public }\end{array}$ & 1 & 2 & 3 & 4 & 5 & 6 & 7 & 8 & 9 \\
\hline Accountant & 1 & 2 & 3 & 4 & 5 & 6 & 7 & 8 & 9 \\
\hline Credit Investigator & 1 & 2 & 3 & 4 & 5 & 6 & 7 & 8 & 9 \\
\hline Court Stenographer & 1 & 2 & 3 & 4 & 5 & 6 & 7 & 8 & 9 \\
\hline Bank Teller & 1 & 2 & 3 & 4 & 5 & 6 & 7 & 8 & 9 \\
\hline Tax Expert & 1 & 2 & 3 & 4 & 5 & 6 & 7 & 8 & 9 \\
\hline $\begin{array}{l}\text { Inventory Controller } \\
\text { IBM Equipment }\end{array}$ & 1 & 2 & 3 & 4 & 5 & 6 & 7 & 8 & 9 \\
\hline Operator $\quad 1$ & 1 & 2 & 3 & 4 & 5 & 6 & 7 & 8 & 9 \\
\hline Financial Analyst & 1 & 2 & 3 & 4 & 5 & 6 & 7 & 8 & 9 \\
\hline
\end{tabular}


Self-efficacy, continued: Confidence in becoming a successful worker

\begin{tabular}{llllllllll}
\hline Occupation & \multicolumn{1}{l}{ Not Very Much } & \multicolumn{1}{c}{ Very Much } \\
\hline Cost Estimator & 1 & 2 & 3 & 4 & 5 & 6 & 7 & 8 & 9 \\
Payroll Clerk & 1 & 2 & 3 & 4 & 5 & 6 & 7 & 8 & 9 \\
Bank Examiner & 1 & 2 & 3 & 4 & 5 & 6 & 7 & 8 & 9
\end{tabular}




\begin{abstract}
APPENDIX D
OUTCOME EXPECTATIONS MEASURE

Adapted from Paul Gore and Wade Leuwerke (2000)
\end{abstract}

\title{
OUTCOME EXPECTATIONS
}

Instructions: For each of the occupations listed below indicate rate the degree to which you would GET WHAT YOU WANTED from that occupation on a 9-point scale.

Occupation

Not Very Much

Very Much

$\begin{array}{llllllllll}\text { Airplane Mechanic } & 1 & 2 & 3 & 4 & 5 & 6 & 7 & 8 & 9 \\ \text { Firefighter } & 1 & 2 & 3 & 4 & 5 & 6 & 7 & 8 & 9 \\ \text { Auto Mechanic } & 1 & 2 & 3 & 4 & 5 & 6 & 7 & 8 & 9 \\ \text { Carpenter } & 1 & 2 & 3 & 4 & 5 & 6 & 7 & 8 & 9 \\ \begin{array}{l}\text { Fish and Wildlife } \\ \text { Specialist }\end{array} & 1 & 2 & 3 & 4 & 5 & 6 & 7 & 8 & 9 \\ \text { Tree Surgeon } & 1 & 2 & 3 & 4 & 5 & 6 & 7 & 8 & 9 \\ \text { Truck Driver } & 1 & 2 & 3 & 4 & 5 & 6 & 7 & 8 & 9 \\ \text { Surveyor } & 1 & 2 & 3 & 4 & 5 & 6 & 7 & 8 & 9 \\ \text { Construction } & & & & & & & & & \\ \text { Inspector } & 1 & 2 & 3 & 4 & 5 & 6 & 7 & 8 & 9 \\ \text { Radio Operator } & 1 & 2 & 3 & 4 & 5 & 6 & 7 & 8 & 9 \\ \text { Bus Driver } & 1 & 2 & 3 & 4 & 5 & 6 & 7 & 8 & 9 \\ \text { Locomotive } & & & & & & & & & \\ \text { Engineer } & 1 & 2 & 3 & 4 & 5 & 6 & 7 & 8 & 9 \\ \text { Machinist } & 1 & 2 & 3 & 4 & 5 & 6 & 7 & 8 & 9 \\ \text { Electrician } & 1 & 2 & 3 & 4 & 5 & 6 & 7 & 8 & 9 \\ \text { Meteorologist } & 1 & 2 & 3 & 4 & 5 & 6 & 7 & 8 & 9\end{array}$


Outcome expectations, continued: Get what you wanted

\begin{tabular}{|c|c|c|c|c|c|c|c|c|c|}
\hline \multirow{2}{*}{$\begin{array}{l}\text { Occupation } \\
\text { Biologist }\end{array}$} & \multicolumn{7}{|c|}{ Not Very Much } & \multicolumn{2}{|c|}{ Very Much } \\
\hline & 1 & 2 & 3 & 4 & 5 & 6 & 7 & 8 & 9 \\
\hline Astronomer & 1 & 2 & 3 & 4 & 5 & 6 & 7 & 8 & 9 \\
\hline \multicolumn{10}{|l|}{ Medical Laboratory } \\
\hline Technician & 1 & 2 & 3 & 4 & 5 & 6 & 7 & 8 & 9 \\
\hline Anthropologist & 1 & 2 & 3 & 4 & 5 & 6 & 7 & 8 & 9 \\
\hline Zoologist & 1 & 2 & 3 & 4 & 5 & 6 & 7 & 8 & 9 \\
\hline Chemist & 1 & 2 & 3 & 4 & 5 & 6 & 7 & 8 & 9 \\
\hline \multicolumn{10}{|l|}{ Independent Research } \\
\hline Scientist & 1 & 2 & 3 & 4 & 5 & 6 & 7 & 8 & 9 \\
\hline \multicolumn{10}{|l|}{ Writer of Scientific } \\
\hline Articles & 1 & 2 & 3 & 4 & 5 & 6 & 7 & 8 & 9 \\
\hline \multicolumn{10}{|l|}{ Editor of Scientific } \\
\hline Articles & 1 & 2 & 3 & 4 & 5 & 6 & 7 & 8 & 9 \\
\hline Geologist & 1 & 2 & 3 & 4 & 5 & 6 & 7 & 8 & 9 \\
\hline Botanist & 1 & 2 & 3 & 4 & 5 & 6 & 7 & 8 & 9 \\
\hline \multicolumn{10}{|l|}{ Scientific Research } \\
\hline Worker & 1 & 2 & 3 & 4 & 5 & 6 & 7 & 8 & 9 \\
\hline Physicist & 1 & 2 & 3 & 4 & 5 & 6 & 7 & 8 & 9 \\
\hline Poet & 1 & 2 & 3 & 4 & 5 & 6 & 7 & 8 & 9 \\
\hline Symphony Conductor & 1 & 2 & 3 & 4 & 5 & 6 & 7 & 8 & 9 \\
\hline Musician & 1 & 2 & 3 & 4 & 5 & 6 & 7 & 8 & 9 \\
\hline Novelist & 1 & 2 & 3 & 4 & 5 & 6 & 7 & 8 & 9 \\
\hline Actor/Actress & 1 & 2 & 3 & 4 & 5 & 6 & 7 & 8 & 9 \\
\hline Free-Lance Writer & 1 & 2 & 3 & 4 & 5 & 6 & 7 & 8 & 9 \\
\hline Music Arranger & 1 & 2 & 3 & 4 & 5 & 6 & 7 & 8 & 9 \\
\hline Journalist & 1 & 2 & 3 & 4 & 5 & 6 & 7 & 8 & 9 \\
\hline Artist & 1 & 2 & 3 & 4 & 5 & 6 & 7 & 8 & 9 \\
\hline Singer & 1 & 2 & 3 & 4 & 5 & 6 & 7 & 8 & 9 \\
\hline Composer & 1 & 2 & 3 & 4 & 5 & 6 & 7 & 8 & 9 \\
\hline Sculptor/Sculptress & 1 & 2 & 3 & 4 & 5 & 6 & 7 & 8 & 9 \\
\hline Playwright & 1 & 2 & 3 & 4 & 5 & 6 & 7 & 8 & 9 \\
\hline Cartoonist & 1 & 2 & 3 & 4 & 5 & 6 & 7 & 8 & 9 \\
\hline Sociologist & 1 & 2 & 3 & 4 & 5 & 6 & 7 & 8 & 9 \\
\hline High School Teacher & 1 & 2 & 3 & 4 & 5 & 6 & 7 & 8 & 9 \\
\hline \multicolumn{10}{|l|}{ Juvenile Delinquency } \\
\hline Expert & 1 & 2 & 3 & 4 & 5 & 6 & 7 & 8 & 9 \\
\hline Speech Therapist & 1 & 2 & 3 & 4 & 5 & 6 & 7 & 8 & 9 \\
\hline Marriage Counselor & 1 & 2 & 3 & 4 & 5 & 6 & 7 & 8 & 9 \\
\hline School Principal & 1 & 2 & 3 & 4 & 5 & 6 & 7 & 8 & 9 \\
\hline Physical Therapist & 1 & 2 & 3 & 4 & 5 & 6 & 7 & 8 & 9 \\
\hline
\end{tabular}


Outcome expectations, continued: Get what you wanted

\begin{tabular}{|c|c|c|c|c|c|c|c|c|c|}
\hline \multirow{2}{*}{$\begin{array}{l}\text { Occupation } \\
\text { Clinical Psychologist }\end{array}$} & \multicolumn{7}{|c|}{ Not Very Much } & \multicolumn{2}{|c|}{ Very Much } \\
\hline & 1 & 2 & 3 & 4 & 5 & 6 & 7 & 8 & 9 \\
\hline $\begin{array}{l}\text { Teacher } \\
\text { Director of Welfare }\end{array}$ & 1 & 2 & 3 & 4 & 5 & 6 & 7 & 8 & 9 \\
\hline Agency & 1 & 2 & 3 & 4 & 5 & 6 & 7 & 8 & 9 \\
\hline Youth Camp Director & 1 & 2 & 3 & 4 & 5 & 6 & 7 & 8 & 9 \\
\hline Personal Counselor & 1 & 2 & 3 & 4 & 5 & 6 & 7 & 8 & 9 \\
\hline Social Worker & 1 & 2 & 3 & 4 & 5 & 6 & 7 & 8 & 9 \\
\hline Vocational Counselor & 1 & 2 & 3 & 4 & 5 & 6 & 7 & 8 & 9 \\
\hline Speculator & 1 & 2 & 3 & 4 & 5 & 6 & 7 & 8 & 9 \\
\hline Buyer & 1 & 2 & 3 & 4 & 5 & 6 & 7 & 8 & 9 \\
\hline $\begin{array}{l}\text { Advertising Executive } \\
\text { Manufacturer's }\end{array}$ & & 2 & 3 & 4 & 5 & 6 & 7 & 8 & 9 \\
\hline $\begin{array}{l}\text { Representative } \\
\text { Life Insurance }\end{array}$ & 1 & 2 & 3 & 4 & 5 & 6 & 7 & 8 & 9 \\
\hline Salesperson & 1 & 2 & 3 & 4 & 5 & 6 & 7 & 8 & 9 \\
\hline Radio-TV Announcer & 1 & 2 & 3 & 4 & 5 & 6 & 7 & 8 & 9 \\
\hline Business Executive & 1 & 2 & 3 & 4 & 5 & 6 & 7 & 8 & 9 \\
\hline Restaurant Manager & 1 & 2 & 3 & 4 & 5 & 6 & 7 & 8 & 9 \\
\hline Master of Ceremonies & 1 & 2 & 3 & 4 & 5 & 6 & 7 & 8 & 9 \\
\hline $\begin{array}{l}\text { Sales Person } \\
\text { Real Estate }\end{array}$ & 1 & 2 & 3 & 4 & 5 & 6 & 7 & 8 & 9 \\
\hline Salesperson & 1 & 2 & 3 & 4 & 5 & 6 & 7 & 8 & 9 \\
\hline $\begin{array}{l}\text { Travel Guide } \\
\text { Department Store }\end{array}$ & 1 & 2 & 3 & 4 & 5 & 6 & 7 & 8 & 9 \\
\hline Manager & 1 & 2 & 3 & 4 & 5 & 6 & 7 & 8 & 9 \\
\hline Sales Manager & 1 & 2 & 3 & 4 & 5 & 6 & 7 & 8 & 9 \\
\hline Bookkeeper & 1 & 2 & 3 & 4 & 5 & 6 & 7 & 8 & 9 \\
\hline Business Teacher & 1 & 2 & 3 & 4 & 5 & 6 & 7 & 8 & 9 \\
\hline $\begin{array}{l}\text { Budget Reviewer } \\
\text { Certified Public }\end{array}$ & 1 & 2 & 3 & 4 & 5 & 6 & 7 & 8 & 9 \\
\hline Accountant & 1 & 2 & 3 & 4 & 5 & 6 & 7 & 8 & 9 \\
\hline Credit Investigator & 1 & 2 & 3 & 4 & 5 & 6 & 7 & 8 & 9 \\
\hline Court Stenographer & 1 & 2 & 3 & 4 & 5 & 6 & 7 & 8 & 9 \\
\hline Bank Teller & 1 & 2 & 3 & 4 & 5 & 6 & 7 & 8 & 9 \\
\hline Tax Expert & 1 & 2 & 3 & 4 & 5 & 6 & 7 & 8 & 9 \\
\hline $\begin{array}{l}\text { Inventory Controller } \\
\text { IBM Equipment }\end{array}$ & 1 & 2 & 3 & 4 & 5 & 6 & 7 & 8 & 9 \\
\hline Operator & 1 & 2 & 3 & 4 & 5 & 6 & 7 & 8 & 9 \\
\hline Financial Analyst & 1 & 2 & 3 & 4 & 5 & 6 & 7 & 8 & 9 \\
\hline
\end{tabular}


Outcome expectations, continued: Get what you wanted

\begin{tabular}{lllllllllll}
\hline Occupation & \multicolumn{1}{l}{ Not Very Much } & \multicolumn{1}{c}{ Very Much } \\
\hline Cost Estimator & 1 & 2 & 3 & 4 & 5 & 6 & 7 & 8 & 9 \\
Payroll Clerk & 1 & 2 & 3 & 4 & 5 & 6 & 7 & 8 & 9 \\
Bank Examiner & 1 & 2 & 3 & 4 & 5 & 6 & 7 & 8 & 9
\end{tabular}




\title{
APPENDIX E
}

\author{
VOCATIONAL INTERESTS MEASURE \\ Adapted from Paul Gore and Wade Leuwerke (2000)
}

\section{VOCATIONAL INTERESTS}

Instructions: For each of the occupations listed below indicate HOW MUCH YOU

THINK YOU WOULD LIKE OR DISLIKE THE WORK ACTIVITIES THAT PEOPLE

IN EACHOF THESE OCCUPATIONS PEFORM on a 9-point scale.

Occupation

Not Very Much

Very Much

$\begin{array}{llllllllll}\text { Airplane Mechanic } & 1 & 2 & 3 & 4 & 5 & 6 & 7 & 8 & 9 \\ \text { Firefighter } & 1 & 2 & 3 & 4 & 5 & 6 & 7 & 8 & 9 \\ \text { Auto Mechanic } & 1 & 2 & 3 & 4 & 5 & 6 & 7 & 8 & 9 \\ \text { Carpenter } & 1 & 2 & 3 & 4 & 5 & 6 & 7 & 8 & 9 \\ \begin{array}{l}\text { Fish and Wildlife } \\ \text { Specialist }\end{array} & 1 & 2 & 3 & 4 & 5 & 6 & 7 & 8 & 9 \\ \text { Tree Surgeon } & 1 & 2 & 3 & 4 & 5 & 6 & 7 & 8 & 9 \\ \text { Truck Driver } & 1 & 2 & 3 & 4 & 5 & 6 & 7 & 8 & 9 \\ \text { Surveyor } & 1 & 2 & 3 & 4 & 5 & 6 & 7 & 8 & 9 \\ \text { Construction } & & & & & & & & & \\ \text { Inspector } & 1 & 2 & 3 & 4 & 5 & 6 & 7 & 8 & 9 \\ \text { Radio Operator } & 1 & 2 & 3 & 4 & 5 & 6 & 7 & 8 & 9 \\ \text { Bus Driver } & 1 & 2 & 3 & 4 & 5 & 6 & 7 & 8 & 9 \\ \text { Locomotive } & & & & & & & & & \\ \text { Engineer } & 1 & 2 & 3 & 4 & 5 & 6 & 7 & 8 & 9 \\ \text { Machinist } & 1 & 2 & 3 & 4 & 5 & 6 & 7 & 8 & 9 \\ \text { Electrician } & 1 & 2 & 3 & 4 & 5 & 6 & 7 & 8 & 9 \\ \text { Meteorologist } & 1 & 2 & 3 & 4 & 5 & 6 & 7 & 8 & 9\end{array}$


Vocational interests, continued: Like of dislike the work activities

\begin{tabular}{|c|c|c|c|c|c|c|c|c|c|}
\hline \multirow{2}{*}{$\begin{array}{l}\text { Occupation } \\
\text { Biologist }\end{array}$} & \multicolumn{7}{|c|}{ Not Very Much } & \multicolumn{2}{|c|}{ Very Much } \\
\hline & 1 & 2 & 3 & 4 & 5 & 6 & 7 & 8 & 9 \\
\hline Astronomer & 1 & 2 & 3 & 4 & 5 & 6 & 7 & 8 & 9 \\
\hline \multicolumn{10}{|l|}{ Medical Laboratory } \\
\hline Technician & 1 & 2 & 3 & 4 & 5 & 6 & 7 & 8 & 9 \\
\hline Anthropologist & 1 & 2 & 3 & 4 & 5 & 6 & 7 & 8 & 9 \\
\hline Zoologist & 1 & 2 & 3 & 4 & 5 & 6 & 7 & 8 & 9 \\
\hline Chemist & 1 & 2 & 3 & 4 & 5 & 6 & 7 & 8 & 9 \\
\hline \multicolumn{10}{|l|}{ Independent Research } \\
\hline Scientist & 1 & 2 & 3 & 4 & 5 & 6 & 7 & 8 & 9 \\
\hline \multicolumn{10}{|l|}{ Writer of Scientific } \\
\hline Articles & 1 & 2 & 3 & 4 & 5 & 6 & 7 & 8 & 9 \\
\hline \multicolumn{10}{|l|}{ Editor of Scientific } \\
\hline Articles & 1 & 2 & 3 & 4 & 5 & 6 & 7 & 8 & 9 \\
\hline Geologist & 1 & 2 & 3 & 4 & 5 & 6 & 7 & 8 & 9 \\
\hline Botanist & 1 & 2 & 3 & 4 & 5 & 6 & 7 & 8 & 9 \\
\hline \multicolumn{10}{|l|}{ Scientific Research } \\
\hline Worker & 1 & 2 & 3 & 4 & 5 & 6 & 7 & 8 & 9 \\
\hline Physicist & 1 & 2 & 3 & 4 & 5 & 6 & 7 & 8 & 9 \\
\hline Poet & 1 & 2 & 3 & 4 & 5 & 6 & 7 & 8 & 9 \\
\hline Symphony Conductor & 1 & 2 & 3 & 4 & 5 & 6 & 7 & 8 & 9 \\
\hline Musician & 1 & 2 & 3 & 4 & 5 & 6 & 7 & 8 & 9 \\
\hline Novelist & 1 & 2 & 3 & 4 & 5 & 6 & 7 & 8 & 9 \\
\hline Actor/Actress & 1 & 2 & 3 & 4 & 5 & 6 & 7 & 8 & 9 \\
\hline Free-Lance Writer & 1 & 2 & 3 & 4 & 5 & 6 & 7 & 8 & 9 \\
\hline Music Arranger & 1 & 2 & 3 & 4 & 5 & 6 & 7 & 8 & 9 \\
\hline Journalist & 1 & 2 & 3 & 4 & 5 & 6 & 7 & 8 & 9 \\
\hline Artist & 1 & 2 & 3 & 4 & 5 & 6 & 7 & 8 & 9 \\
\hline Singer & 1 & 2 & 3 & 4 & 5 & 6 & 7 & 8 & 9 \\
\hline Composer & 1 & 2 & 3 & 4 & 5 & 6 & 7 & 8 & 9 \\
\hline Sculptor/Sculptress & 1 & 2 & 3 & 4 & 5 & 6 & 7 & 8 & 9 \\
\hline Playwright & 1 & 2 & 3 & 4 & 5 & 6 & 7 & 8 & 9 \\
\hline Cartoonist & 1 & 2 & 3 & 4 & 5 & 6 & 7 & 8 & 9 \\
\hline Sociologist & 1 & 2 & 3 & 4 & 5 & 6 & 7 & 8 & 9 \\
\hline High School Teacher & 1 & 2 & 3 & 4 & 5 & 6 & 7 & 8 & 9 \\
\hline \multicolumn{10}{|l|}{ Juvenile Delinquency } \\
\hline Expert & 1 & 2 & 3 & 4 & 5 & 6 & 7 & 8 & 9 \\
\hline Speech Therapist & 1 & 2 & 3 & 4 & 5 & 6 & 7 & 8 & 9 \\
\hline Marriage Counselor & 1 & 2 & 3 & 4 & 5 & 6 & 7 & 8 & 9 \\
\hline School Principal & 1 & 2 & 3 & 4 & 5 & 6 & 7 & 8 & 9 \\
\hline
\end{tabular}


Vocational interests, continued: Like or dislike the work activities

\begin{tabular}{|c|c|c|c|c|c|c|c|c|c|}
\hline Occupation & & ery & & & & & & & Much \\
\hline Physical Therapist & 1 & 2 & 3 & 4 & 5 & 6 & 7 & 8 & 9 \\
\hline $\begin{array}{l}\text { Clinical Psychologist } \\
\text { Social Science }\end{array}$ & 1 & 2 & 3 & 4 & 5 & 6 & 7 & 8 & 9 \\
\hline $\begin{array}{l}\text { Teacher } \\
\text { Director of Welfare }\end{array}$ & 1 & 2 & 3 & 4 & 5 & 6 & 7 & 8 & 9 \\
\hline Agency & 1 & 2 & 3 & 4 & 5 & 6 & 7 & 8 & 9 \\
\hline Youth Camp Director & 1 & 2 & 3 & 4 & 5 & 6 & 7 & 8 & 9 \\
\hline Personal Counselor & 1 & 2 & 3 & 4 & 5 & 6 & 7 & 8 & 9 \\
\hline Social Worker & 1 & 2 & 3 & 4 & 5 & 6 & 7 & 8 & 9 \\
\hline Vocational Counselor & 1 & 2 & 3 & 4 & 5 & 6 & 7 & 8 & 9 \\
\hline Speculator & 1 & 2 & 3 & 4 & 5 & 6 & 7 & 8 & 9 \\
\hline Buyer & 1 & 2 & 3 & 4 & 5 & 6 & 7 & 8 & 9 \\
\hline $\begin{array}{l}\text { Advertising Executive } \\
\text { Manufacturer's }\end{array}$ & & 2 & 3 & 4 & 5 & 6 & 7 & 8 & 9 \\
\hline $\begin{array}{l}\text { Representative } \\
\text { Life Insurance }\end{array}$ & 1 & 2 & 3 & 4 & 5 & 6 & 7 & 8 & 9 \\
\hline Salesperson & 1 & 2 & 3 & 4 & 5 & 6 & 7 & 8 & 9 \\
\hline Radio-TV Announcer & 1 & 2 & 3 & 4 & 5 & 6 & 7 & 8 & 9 \\
\hline Business Executive & 1 & 2 & 3 & 4 & 5 & 6 & 7 & 8 & 9 \\
\hline Restaurant Manager & 1 & 2 & 3 & 4 & 5 & 6 & 7 & 8 & 9 \\
\hline Master of Ceremonies & & 2 & 3 & 4 & 5 & 6 & 7 & 8 & 9 \\
\hline $\begin{array}{l}\text { Sales Person } \\
\text { Real Estate }\end{array}$ & 1 & 2 & 3 & 4 & 5 & 6 & 7 & 8 & 9 \\
\hline Salesperson & 1 & 2 & 3 & 4 & 5 & 6 & 7 & 8 & 9 \\
\hline $\begin{array}{l}\text { Travel Guide } \\
\text { Department Store }\end{array}$ & 1 & 2 & 3 & 4 & 5 & 6 & 7 & 8 & 9 \\
\hline Manager & 1 & 2 & 3 & 4 & 5 & 6 & 7 & 8 & 9 \\
\hline Sales Manager & 1 & 2 & 3 & 4 & 5 & 6 & 7 & 8 & 9 \\
\hline Bookkeeper & 1 & 2 & 3 & 4 & 5 & 6 & 7 & 8 & 9 \\
\hline Business Teacher & 1 & 2 & 3 & 4 & 5 & 6 & 7 & 8 & 9 \\
\hline $\begin{array}{l}\text { Budget Reviewer } \\
\text { Certified Public }\end{array}$ & 1 & 2 & 3 & 4 & 5 & 6 & 7 & 8 & 9 \\
\hline Accountant & 1 & 2 & 3 & 4 & 5 & 6 & 7 & 8 & 9 \\
\hline Credit Investigator & 1 & 2 & 3 & 4 & 5 & 6 & 7 & 8 & 9 \\
\hline Court Stenographer & 1 & 2 & 3 & 4 & 5 & 6 & 7 & 8 & 9 \\
\hline Bank Teller & 1 & 2 & 3 & 4 & 5 & 6 & 7 & 8 & 9 \\
\hline Tax Expert & 1 & 2 & 3 & 4 & 5 & 6 & 7 & 8 & 9 \\
\hline $\begin{array}{l}\text { Inventory Controller } \\
\text { IBM Equipment }\end{array}$ & 1 & 2 & 3 & 4 & 5 & 6 & 7 & 8 & 9 \\
\hline Operator & 1 & 2 & 3 & 4 & 5 & 6 & 7 & 8 & 9 \\
\hline
\end{tabular}


Vocational interests, continued: Like of dislike the work activities

\begin{tabular}{llllllllll}
\hline Occupation & \multicolumn{1}{l}{ Not Very Much } & & & & & \multicolumn{2}{c}{ Very Much } \\
\hline Financial Analyst & 1 & 2 & 3 & 4 & 5 & 6 & 7 & 8 & 9 \\
Cost Estimator & 1 & 2 & 3 & 4 & 5 & 6 & 7 & 8 & 9 \\
Payroll Clerk & 1 & 2 & 3 & 4 & 5 & 6 & 7 & 8 & 9 \\
Bank Examiner & 1 & 2 & 3 & 4 & 5 & 6 & 7 & 8 & 9
\end{tabular}




\begin{abstract}
APPENDIX F
CHOICE GOALS MEASURE

Adapted from Paul Gore and Wade Leuwerke (2000)
\end{abstract}

\title{
CHOICE GOALS
}

Instructions: For each of the occupations listed below indicate HOW SERIOUSLY YOU WOULD CONSIDER EACH OCCUPATION AS A POSSIBLE CAREER FOR

YOURSELF on a 9-point scale.

Occupation

Not Very Much

Very Much

$\begin{array}{llllllllll}\text { Airplane Mechanic } & 1 & 2 & 3 & 4 & 5 & 6 & 7 & 8 & 9 \\ \text { Firefighter } & 1 & 2 & 3 & 4 & 5 & 6 & 7 & 8 & 9 \\ \text { Auto Mechanic } & 1 & 2 & 3 & 4 & 5 & 6 & 7 & 8 & 9 \\ \text { Carpenter } & 1 & 2 & 3 & 4 & 5 & 6 & 7 & 8 & 9 \\ \text { Fish and Wildlife } & & & & & & & & & \\ \text { Specialist } & 1 & 2 & 3 & 4 & 5 & 6 & 7 & 8 & 9 \\ \text { Tree Surgeon } & 1 & 2 & 3 & 4 & 5 & 6 & 7 & 8 & 9 \\ \text { Truck Driver } & 1 & 2 & 3 & 4 & 5 & 6 & 7 & 8 & 9 \\ \text { Surveyor } & 1 & 2 & 3 & 4 & 5 & 6 & 7 & 8 & 9 \\ \text { Construction } & & & & & & & & & \\ \text { Inspector } & 1 & 2 & 3 & 4 & 5 & 6 & 7 & 8 & 9 \\ \text { Radio Operator } & 1 & 2 & 3 & 4 & 5 & 6 & 7 & 8 & 9 \\ \text { Bus Driver } & 1 & 2 & 3 & 4 & 5 & 6 & 7 & 8 & 9 \\ \text { Locomotive } & & & & & & & & & \\ \text { Engineer } & 1 & 2 & 3 & 4 & 5 & 6 & 7 & 8 & 9 \\ \text { Machinist } & 1 & 2 & 3 & 4 & 5 & 6 & 7 & 8 & 9 \\ \text { Electrician } & 1 & 2 & 3 & 4 & 5 & 6 & 7 & 8 & 9 \\ \text { Meteorologist } & 1 & 2 & 3 & 4 & 5 & 6 & 7 & 8 & 9\end{array}$


Choice goals, continued: Possible career for yourself

\begin{tabular}{|c|c|c|c|c|c|c|c|c|c|}
\hline \multirow{2}{*}{$\begin{array}{l}\text { Occupation } \\
\text { Biologist }\end{array}$} & \multicolumn{7}{|c|}{ Not Very Much } & \multicolumn{2}{|c|}{ Very Much } \\
\hline & 1 & 2 & 3 & 4 & 5 & 6 & 7 & 8 & 9 \\
\hline Astronomer & 1 & 2 & 3 & 4 & 5 & 6 & 7 & 8 & 9 \\
\hline \multicolumn{10}{|l|}{ Medical Laboratory } \\
\hline Technician & 1 & 2 & 3 & 4 & 5 & 6 & 7 & 8 & 9 \\
\hline Anthropologist & 1 & 2 & 3 & 4 & 5 & 6 & 7 & 8 & 9 \\
\hline Zoologist & 1 & 2 & 3 & 4 & 5 & 6 & 7 & 8 & 9 \\
\hline Chemist & 1 & 2 & 3 & 4 & 5 & 6 & 7 & 8 & 9 \\
\hline \multicolumn{10}{|c|}{ Independent Research } \\
\hline Scientist & 1 & 2 & 3 & 4 & 5 & 6 & 7 & 8 & 9 \\
\hline \multicolumn{10}{|l|}{ Writer of Scientific } \\
\hline Articles & 1 & 2 & 3 & 4 & 5 & 6 & 7 & 8 & 9 \\
\hline \multicolumn{10}{|l|}{ Editor of Scientific } \\
\hline Articles & 1 & 2 & 3 & 4 & 5 & 6 & 7 & 8 & 9 \\
\hline Geologist & 1 & 2 & 3 & 4 & 5 & 6 & 7 & 8 & 9 \\
\hline Botanist & 1 & 2 & 3 & 4 & 5 & 6 & 7 & 8 & 9 \\
\hline \multicolumn{10}{|l|}{ Scientific Research } \\
\hline Worker & 1 & 2 & 3 & 4 & 5 & 6 & 7 & 8 & 9 \\
\hline Physicist & 1 & 2 & 3 & 4 & 5 & 6 & 7 & 8 & 9 \\
\hline Poet & 1 & 2 & 3 & 4 & 5 & 6 & 7 & 8 & 9 \\
\hline Symphony Conductor & 1 & 2 & 3 & 4 & 5 & 6 & 7 & 8 & 9 \\
\hline Musician & 1 & 2 & 3 & 4 & 5 & 6 & 7 & 8 & 9 \\
\hline Novelist & 1 & 2 & 3 & 4 & 5 & 6 & 7 & 8 & 9 \\
\hline Actor/Actress & 1 & 2 & 3 & 4 & 5 & 6 & 7 & 8 & 9 \\
\hline Free-Lance Writer & 1 & 2 & 3 & 4 & 5 & 6 & 7 & 8 & 9 \\
\hline Music Arranger & 1 & 2 & 3 & 4 & 5 & 6 & 7 & 8 & 9 \\
\hline Journalist & 1 & 2 & 3 & 4 & 5 & 6 & 7 & 8 & 9 \\
\hline Artist & 1 & 2 & 3 & 4 & 5 & 6 & 7 & 8 & 9 \\
\hline Singer & 1 & 2 & 3 & 4 & 5 & 6 & 7 & 8 & 9 \\
\hline Composer & 1 & 2 & 3 & 4 & 5 & 6 & 7 & 8 & 9 \\
\hline Sculptor/Sculptress & 1 & 2 & 3 & 4 & 5 & 6 & 7 & 8 & 9 \\
\hline Playwright & 1 & 2 & 3 & 4 & 5 & 6 & 7 & 8 & 9 \\
\hline Cartoonist & 1 & 2 & 3 & 4 & 5 & 6 & 7 & 8 & 9 \\
\hline Sociologist & 1 & 2 & 3 & 4 & 5 & 6 & 7 & 8 & 9 \\
\hline High School Teacher & 1 & 2 & 3 & 4 & 5 & 6 & 7 & 8 & 9 \\
\hline \multicolumn{10}{|l|}{ Juvenile Delinquency } \\
\hline Expert & 1 & 2 & 3 & 4 & 5 & 6 & 7 & 8 & 9 \\
\hline Speech Therapist & 1 & 2 & 3 & 4 & 5 & 6 & 7 & 8 & 9 \\
\hline Marriage Counselor & 1 & 2 & 3 & 4 & 5 & 6 & 7 & 8 & 9 \\
\hline School Principal & 1 & 2 & 3 & 4 & 5 & 6 & 7 & 8 & 9 \\
\hline Physical Therapist & 1 & 2 & 3 & 4 & 5 & 6 & 7 & 8 & 9 \\
\hline
\end{tabular}


Choice goals, continued: Possible career for yourself

\begin{tabular}{|c|c|c|c|c|c|c|c|c|c|}
\hline \multirow{2}{*}{$\begin{array}{l}\text { Occupation } \\
\text { Clinical Psychologist } \\
\text { Social Science }\end{array}$} & \multicolumn{7}{|c|}{ Not Very Much } & \multicolumn{2}{|c|}{ Very Much } \\
\hline & 1 & 2 & 3 & 4 & 5 & 6 & 7 & 8 & 9 \\
\hline $\begin{array}{l}\text { Teacher } \\
\text { Director of Welfare }\end{array}$ & 1 & 2 & 3 & 4 & 5 & 6 & 7 & 8 & 9 \\
\hline Agency & 1 & 2 & 3 & 4 & 5 & 6 & 7 & 8 & 9 \\
\hline Youth Camp Director & 1 & 2 & 3 & 4 & 5 & 6 & 7 & 8 & 9 \\
\hline Personal Counselor & 1 & 2 & 3 & 4 & 5 & 6 & 7 & 8 & 9 \\
\hline Social Worker & 1 & 2 & 3 & 4 & 5 & 6 & 7 & 8 & 9 \\
\hline Vocational Counselor & 1 & 2 & 3 & 4 & 5 & 6 & 7 & 8 & 9 \\
\hline Speculator & 1 & 2 & 3 & 4 & 5 & 6 & 7 & 8 & 9 \\
\hline Buyer & 1 & 2 & 3 & 4 & 5 & 6 & 7 & 8 & 9 \\
\hline $\begin{array}{l}\text { Advertising Executive } \\
\text { Manufacturer's }\end{array}$ & e1 & 2 & 3 & 4 & 5 & 6 & 7 & 8 & 9 \\
\hline $\begin{array}{l}\text { Representative } \\
\text { Life Insurance }\end{array}$ & 1 & 2 & 3 & 4 & 5 & 6 & 7 & 8 & 9 \\
\hline Salesperson & 1 & 2 & 3 & 4 & 5 & 6 & 7 & 8 & 9 \\
\hline Radio-TV Announcer & 1 & 2 & 3 & 4 & 5 & 6 & 7 & 8 & 9 \\
\hline Business Executive & 1 & 2 & 3 & 4 & 5 & 6 & 7 & 8 & 9 \\
\hline Restaurant Manager & 1 & 2 & 3 & 4 & 5 & 6 & 7 & 8 & 9 \\
\hline Master of Ceremonies & & 2 & 3 & 4 & 5 & 6 & 7 & 8 & 9 \\
\hline $\begin{array}{l}\text { Sales Person } \\
\text { Real Estate }\end{array}$ & 1 & 2 & 3 & 4 & 5 & 6 & 7 & 8 & 9 \\
\hline Salesperson & 1 & 2 & 3 & 4 & 5 & 6 & 7 & 8 & 9 \\
\hline $\begin{array}{l}\text { Travel Guide } \\
\text { Department Store }\end{array}$ & 1 & 2 & 3 & 4 & 5 & 6 & 7 & 8 & 9 \\
\hline Manager & 1 & 2 & 3 & 4 & 5 & 6 & 7 & 8 & 9 \\
\hline Sales Manager & 1 & 2 & 3 & 4 & 5 & 6 & 7 & 8 & 9 \\
\hline Bookkeeper & 1 & 2 & 3 & 4 & 5 & 6 & 7 & 8 & 9 \\
\hline Business Teacher & 1 & 2 & 3 & 4 & 5 & 6 & 7 & 8 & 9 \\
\hline $\begin{array}{l}\text { Budget Reviewer } \\
\text { Certified Public }\end{array}$ & 1 & 2 & 3 & 4 & 5 & 6 & 7 & 8 & 9 \\
\hline Accountant & 1 & 2 & 3 & 4 & 5 & 6 & 7 & 8 & 9 \\
\hline Credit Investigator & 1 & 2 & 3 & 4 & 5 & 6 & 7 & 8 & 9 \\
\hline Court Stenographer & 1 & 2 & 3 & 4 & 5 & 6 & 7 & 8 & 9 \\
\hline Bank Teller & 1 & 2 & 3 & 4 & 5 & 6 & 7 & 8 & 9 \\
\hline Tax Expert & 1 & 2 & 3 & 4 & 5 & 6 & 7 & 8 & 9 \\
\hline $\begin{array}{l}\text { Inventory Controller } \\
\text { IBM Equipment }\end{array}$ & 1 & 2 & 3 & 4 & 5 & 6 & 7 & 8 & 9 \\
\hline Operator & 1 & 2 & 3 & 4 & 5 & 6 & 7 & 8 & 9 \\
\hline Financial Analyst & 1 & 2 & 3 & 4 & 5 & 6 & 7 & 8 & 9 \\
\hline
\end{tabular}


Choice goals, continued: Possible career for yourself

\begin{tabular}{llllllllll}
\hline Occupation & \multicolumn{1}{l}{ Not Very Much } & & & & Very Much \\
\hline Cost Estimator & 1 & 2 & 3 & 4 & 5 & 6 & 7 & 8 & 9 \\
Payroll Clerk & 1 & 2 & 3 & 4 & 5 & 6 & 7 & 8 & 9 \\
Bank Examiner & 1 & 2 & 3 & 4 & 5 & 6 & 7 & 8 & 9
\end{tabular}




\section{APPENDIX G}

\section{SCHEDULE OF RACIST EVENTS}

Hope Landrine and Elizabeth Klonoff (1996)

We are interested in your experiences with racism. As you answer the questions below, please think about your ENTIRE LIFE, from when you were a child to the present. For each question, please circle the number that best captures the things that have happened to you. Answer each question TWICE, once for what has happened to you IN THE PAST YEAR, and once for what YOUR ENTIRE LIFE HAS BEEN LIKE. Use these numbers:

Circle $1=$ If this has NEVER happened to you

Circle $2=$ If this has happened ONCE IN A WHILE (less than $10 \%$ of the time)

Circle $3=$ If this has happened SOMETIMES (10\%-25\% of the time)

Circle $4=$ if this has happened A LOT (26\%- $49 \%$ of the time)

Circle $5=$ If this has happened MOST OF THE TIME (50\%-70\% of the time)

Circle $6=$ If this has happened ALMOST ALL OF THE TIME (more than $70 \%$ of the time).

1. How many times have you been treated unfairly by teachers and professors because you are Black?

$\begin{array}{llllllll}\text { How many times in the past year? } & 1 & 2 & 3 & 4 & 5 & 6\end{array}$

How many times in your entire life? $1 \quad 2 \quad \begin{array}{lllll}1 & 2 & 4 & 5 & 6\end{array}$

Not at All Extremely

$\begin{array}{llllllll}\text { How stressful was this for you? } & 1 & 2 & 3 & 4 & 5 & 6\end{array}$

2. How many times have you been treated unfairly by your employers, bosses, and supervisors because you are Black?

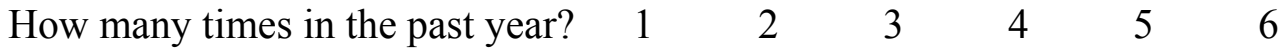
How many times in your entire life? $1 \quad \begin{array}{llllll}1 & 2 & 3 & 4 & 5 & 6\end{array}$

\begin{tabular}{lllllll} 
& \multicolumn{1}{l}{ Not at All } & & \multicolumn{2}{c}{ Extremely } \\
How stressful was this for you? & 1 & 2 & 3 & 4 & 5 & 6
\end{tabular}


3. How many times have you been treated unfairly by your coworkers, fellow students, and colleagues because you are Black?

$\begin{array}{llllllll}\text { How many times in the past year? } & 1 & 2 & 3 & 4 & 5 & 6\end{array}$

How many times in your entire life? $1 \quad \begin{array}{lllllll}1 & 2 & 3 & 4 & 5 & 6\end{array}$ Not at All Extremely

$\begin{array}{llllllll}\text { How stressful was this for you? } & 1 & 2 & 3 & 4 & 5 & 6\end{array}$

4. How many times have you been treated unfairly by people in service jobs (store clerks, waiters, bartenders, bank tellers, and others) because you are Black?

$\begin{array}{llllllll}\text { How many times in the past year? } & 1 & 2 & 3 & 4 & 5 & 6\end{array}$ How many times in your entire life? $1 \quad \begin{array}{llllll}1 & 2 & 3 & 4 & 5 & 6\end{array}$ $\begin{array}{lll} & \text { Not at All Extremely }\end{array}$ $\begin{array}{llllllll}\text { How stressful was this for you? } & 1 & 2 & 3 & 4 & 5 & 6\end{array}$

5 How many times have you been treated unfairly by strangers because you are Black?

$\begin{array}{llllllll}\text { How many times in the past year? } & 1 & 2 & 3 & 4 & 5 & 6\end{array}$ How many times in your entire life? $1 \quad \begin{array}{llllll} & 2 & 3 & 4 & 5 & 6\end{array}$ \begin{tabular}{llllllll} 
& \multicolumn{1}{l}{ Not at All } & & \multicolumn{2}{c}{ Extremely } \\
How stressful was this for you? & 1 & 2 & 3 & 4 & 5 & 6
\end{tabular}

6. How many times have you been treated unfairly by people in helping jobs (doctors, nurses, psychiatrists, case workers, dentists, school counselors, therapists, social workers, and others) because you are Black?

$\begin{array}{llllllll}\text { How many times in the past year? } & 1 & 2 & 3 & 4 & 5 & 6\end{array}$

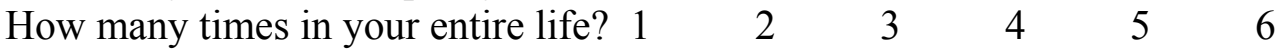

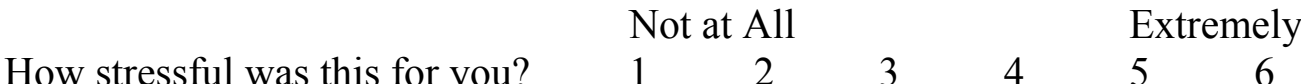

7. How many times have you been treated unfairly by neighbors because you are Black?

$\begin{array}{llllllll}\text { How many times in the past year? } & 1 & 2 & 3 & 4 & 5 & 6\end{array}$ How many times in your entire life? $1 \quad \begin{array}{lllllll} & 2 & 3 & 4 & 5 & 6\end{array}$ \begin{tabular}{lllllll} 
& Not at All & \multicolumn{3}{c}{ Extremely } \\
How stressful was this for you? & 1 & 2 & 3 & 4 & 5 & 6
\end{tabular}

8. How many times have you been treated unfairly by institutions (schools, universities, law firms, the police, the courts, the Department of Social Services, the Unemployment Office, and others) because you are Black? 
$\begin{array}{llllllll}\text { How many times in the past year? } & 1 & 2 & 3 & 4 & 5 & 6\end{array}$

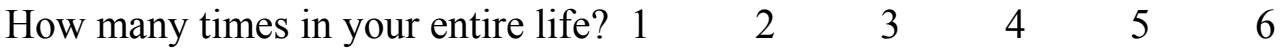
\begin{tabular}{lllllll} 
& \multicolumn{3}{c}{ Not at All } & \multicolumn{3}{c}{ Extremely } \\
How stressful was this for you? & 1 & 2 & 3 & 4 & 5 & 6
\end{tabular}

9. How many times have you been treated unfairly by the people that you thought were your friends because you are Black?

$\begin{array}{lllllllll}\text { How many times in the past year? } & 1 & 2 & 3 & 4 & 5 & 6\end{array}$

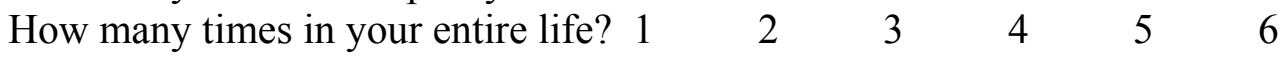
Not at All Extremely $\begin{array}{llllllll}\text { How stressful was this for you? } & 1 & 2 & 3 & 4 & 5 & 6\end{array}$

10. How many times have you been accused or suspected of doing something wrong (such as stealing, cheating, not doing your share of the work, or breaking the law) because you are Black?

$\begin{array}{llllllll}\text { How many times in the past year? } & 1 & 2 & 3 & 4 & 5 & 6\end{array}$

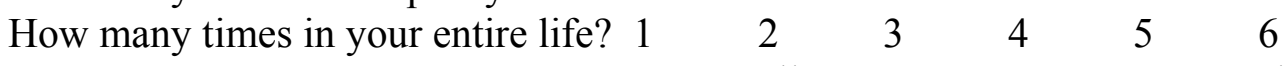
\begin{tabular}{lllllll} 
& \multicolumn{1}{c}{ Not at All } & \multicolumn{3}{c}{ Extremely } \\
How stressful was this for you? & 1 & 2 & 3 & 4 & 5 & 6
\end{tabular}

11. How many times have people misunderstood your intentions and motives because you are Black?

$\begin{array}{llllllll}\text { How many times in the past year? } & 1 & 2 & 3 & 4 & 5 & 6\end{array}$

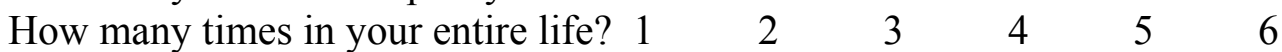
\begin{tabular}{lllllll} 
& \multicolumn{3}{c}{ Not at All } & \multicolumn{3}{c}{ Extremely } \\
How stressful was this for you? & 1 & 2 & 3 & 4 & 5 & 6
\end{tabular}

12. How many times did you want to tell someone off for being racist but didn't say anything?

$\begin{array}{llllllll}\text { How many times in the past year? } & 1 & 2 & 3 & 4 & 5 & 6\end{array}$

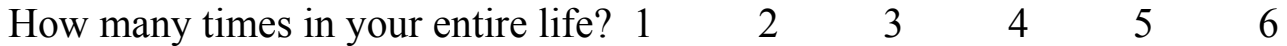
\begin{tabular}{lllllll} 
& Not at All & \multicolumn{3}{c}{ Extremely } \\
How stressful was this for you? & 1 & 2 & 3 & 4 & 5 & 6
\end{tabular}

13. How many times have you been really angry about something racist that was done to you?

$\begin{array}{llllllll}\text { How many times in the past year? } & 1 & 2 & 3 & 4 & 5 & 6\end{array}$

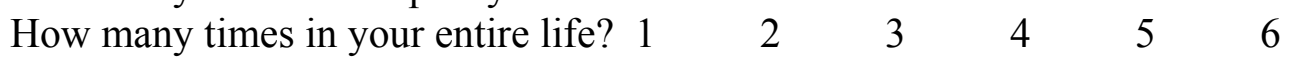
Not at All Extremely $\begin{array}{llllllll}\text { How stressful was this for you? } & 1 & 2 & 3 & 4 & 5 & 6\end{array}$ 
14. How many times were you forced to take drastic steps (such as filing a grievance, filing a lawsuit, quitting your job, moving away, and other actions) to deal with some racist thing that was done to you?

$\begin{array}{llllllll}\text { How many times in the past year? } & 1 & 2 & 3 & 4 & 5 & 6\end{array}$

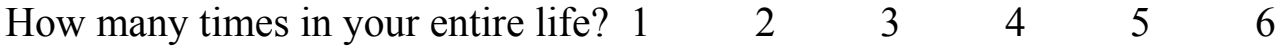
Not at All Extremely $\begin{array}{llllllll}\text { How stressful was this for you? } & 1 & 2 & 3 & 4 & 5 & 6\end{array}$

15. How many times have you been called a racist name like nigger, a coon, jungle bunny or other names?

$\begin{array}{llllllll}\text { How many times in the past year? } & 1 & 2 & 3 & 4 & 5 & 6\end{array}$ How many times in your entire life? $1 \quad \begin{array}{llllll}1 & 2 & 3 & 4 & 5 & 6\end{array}$ Not at All Extremely $\begin{array}{llllllll}\text { How stressful was this for you? } & 1 & 2 & 3 & 4 & 5 & 6\end{array}$

16. How many times have you gotten into an argument or fight about something racist that was done to you or done to somebody else?

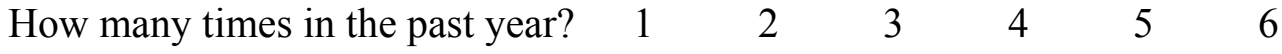
How many times in your entire life? $1 \quad 2 \quad \begin{array}{lllll}1 & 2 & 4 & 5 & 6\end{array}$ \begin{tabular}{llllllll} 
& \multicolumn{3}{l}{ Not at All } & \multicolumn{3}{c}{ Extremely } \\
How stressful was this for you? & 1 & 2 & 3 & 4 & 5 & 6
\end{tabular}

17. How many times have you been made fun of, picked on, pushed, shoved, hit, or threatened with harm because you are Black?

$\begin{array}{llllllll}\text { How many times in the past year? } & 1 & 2 & 3 & 4 & 5 & 6\end{array}$

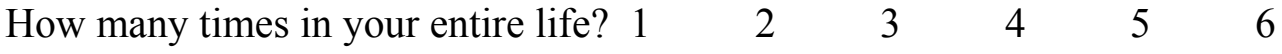
\begin{tabular}{lllllll} 
& Not at All & & \multicolumn{2}{c}{ Extremely } \\
How stressful was this for you? & 1 & 2 & 3 & 4 & 5 & 6
\end{tabular}

18. How different would your life be now if you HAD NOT BEEN treated in a racist and unfair way

In the past year?

\begin{tabular}{|c|c|c|c|c|c|}
\hline $\begin{array}{l}\text { Same } \\
\text { as now } \\
1\end{array}$ & $\begin{array}{l}\text { A little } \\
\text { different } \\
2\end{array}$ & $\begin{array}{l}\text { Different in } \\
\text { a few ways } \\
3\end{array}$ & $\begin{array}{l}\text { Different in } \\
\text { a lot of ways } \\
4\end{array}$ & $\begin{array}{l}\text { Different in } \\
\text { most ways } \\
5\end{array}$ & $\begin{array}{l}\text { Totally } \\
\text { different } \\
6\end{array}$ \\
\hline \multicolumn{6}{|c|}{ In your entire life? } \\
\hline $\begin{array}{l}\text { Same } \\
\text { as now } \\
1\end{array}$ & $\begin{array}{l}\text { A little } \\
\text { different } \\
2\end{array}$ & $\begin{array}{l}\text { Different in } \\
\text { a few ways } \\
3\end{array}$ & $\begin{array}{l}\text { Different in } \\
\text { a lot of ways } \\
4\end{array}$ & $\begin{array}{l}\text { Different in } \\
\text { most ways } \\
5\end{array}$ & $\begin{array}{l}\text { Totally } \\
\text { different } \\
6\end{array}$ \\
\hline
\end{tabular}




\section{APPENDIX H}

TABLE 20. CORRELATIONS AMONG PERFORMANCE ACCOMPLISHMENTS, VICARIOUS LEARNING, VERBAL PERSUASION, EMOTIONAL AROUSAL, AND SELF-EFFICACY FOR ALL SIX RIASEC THEMES

\begin{tabular}{|c|c|c|c|c|c|c|}
\hline & $\begin{array}{l}\text { Realistic } \\
\text { PA }\end{array}$ & $\begin{array}{l}\text { Realistic } \\
\text { VL }\end{array}$ & $\begin{array}{l}\text { Realistic } \\
\text { VP }\end{array}$ & $\begin{array}{l}\text { Realistic } \\
\text { EA }\end{array}$ & $\begin{array}{l}\text { Realistic } \\
\text { SE }\end{array}$ & $\begin{array}{l}\text { Investigative } \\
\text { PA }\end{array}$ \\
\hline Realistic PA & 1 & $.48 * *$ & $.54 * *$ & $.27 * *$ & $.44 * *$ & $.38 * *$ \\
\hline Realistic VL & $.48 * *$ & 1 & $.48 * *$ & $.18^{*}$ & $.20 * *$ & $.35^{* *}$ \\
\hline Realistic VP & $.54 * *$ & $.48^{* *}$ & 1 & .00 & $.32 * *$ & $.33^{* *}$ \\
\hline Realistic EA & $.27 * *$ & $.18^{*}$ & .00 & 1 & $.20 * *$ & $.19 * *$ \\
\hline Realistic SE & $.44 * *$ & $.20 * *$ & $.32 * *$ & $.20 * *$ & 1 & $.19 * *$ \\
\hline Investigative PA & $.38^{* *}$ & $.35^{* *}$ & $.33 * *$ & $.19 * *$ & $.19^{* *}$ & 1 \\
\hline Investigative VL & $.39 * *$ & $.39 * *$ & $.50 * *$ & -.003 & $.23 * *$ & $.50 * *$ \\
\hline Investigative VP & $.37 * *$ & $.37 * *$ & $.56^{* *}$ & .013 & $.18^{* *}$ & $.53 * *$ \\
\hline Investigative EA & .05 & .06 & -.03 & $.50 * *$ & .10 & $.41 * *$ \\
\hline Investigative SE & $.30 * *$ & $.16^{*}$ & $.26^{* *}$ & $.18^{* *}$ & $.67 * *$ & $.30 * *$ \\
\hline Artistic PA & $.31 * *$ & $.27 * *$ & $.29 * *$ & .09 & .13 & $.29 * *$ \\
\hline Artistic VL & $.45 * *$ & $.48^{* *}$ & $.49 * *$ & .01 & $.16^{*}$ & $.31 * *$ \\
\hline Artistic VP & $.25 * *$ & $.36^{* *}$ & $.38^{* *}$ & .10 & .13 & $.33^{* *}$ \\
\hline Artistic EA & .13 & .10 & -.01 & $.38 * *$ & .11 & .12 \\
\hline Artistic SE & $.17^{*}$ & .06 & $.19 * *$ & .08 & $.47 * *$ & .09 \\
\hline Social PA & $.21 * *$ & $.37 * *$ & .03 & $.26 * *$ & -.01 & $.50 * *$ \\
\hline Social VL & $.26^{* *}$ & $.45^{* *}$ & $.21^{* *}$ & .01 & .05 & $.32 * *$ \\
\hline Social VP & $.25 * *$ & $.45^{* *}$ & $.35^{* *}$ & .10 & .05 & $.49 * *$ \\
\hline Social EA & .07 & .10 & .00 & $.37 * *$ & -.01 & $.26^{* *}$ \\
\hline Social SE & $.20^{* *}$ & $.16^{*}$ & .09 & $.17 *$ & $.44 * *$ & $.16^{*}$ \\
\hline Enterprising PA & $.26^{* *}$ & $.38^{* *}$ & $.22 * *$ & .08 & .05 & $.49 *$ \\
\hline Enterprising VL & $.42 * *$ & $.50 * *$ & $.43^{* *}$ & .04 & .06 & $.41 * *$ \\
\hline Enterprising VP & $.23 * *$ & $.31 * *$ & $.42 * *$ & -.01 & .09 & $.41 * *$ \\
\hline Enterprising EA & -.02 & .03 & -.13 & $.40 * *$ & -.02 & $.16^{*}$ \\
\hline Enterprising SE & $.19^{* *}$ & .13 & .11 & .11 & $.47 * *$ & $.19 * *$ \\
\hline Conventional PA & $.31 * *$ & $.42 * *$ & $.21 * *$ & $.16^{*}$ & .09 & $.55^{* *}$ \\
\hline Conventional VL & $.36^{* *}$ & $.50 * *$ & $.35^{* *}$ & .03 & .01 & $.35^{* *}$ \\
\hline Conventional VP & $.34 * *$ & $.45^{* *}$ & $.53 * *$ & -.06 & $.14 *$ & $.44 * *$ \\
\hline Conventional EA & .06 & .12 & -.01 & $.54 * *$ & .13 & $.23 * *$ \\
\hline Conventional SE & $.21 * *$ & .10 & $.20 * *$ & .07 & $.57 * *$ & $.19^{* *}$ \\
\hline
\end{tabular}




\begin{tabular}{|c|c|c|c|c|c|c|}
\hline & $\begin{array}{l}\text { Investigative } \\
\text { VL }\end{array}$ & $\begin{array}{l}\text { Investigative } \\
\text { VP }\end{array}$ & $\begin{array}{l}\text { Investigative } \\
\text { EA }\end{array}$ & $\begin{array}{l}\text { Investigative } \\
\text { SE }\end{array}$ & $\begin{array}{l}\text { Artistic } \\
\text { PA }\end{array}$ & $\begin{array}{l}\text { Artistic } \\
\text { VL }\end{array}$ \\
\hline Realistic PA & $.39 * *$ & $.37 * *$ & .05 & $.30 * *$ & $.31 * *$ & $.45 * *$ \\
\hline Realistic VL & $.39 * *$ & $.37 * *$ & .06 & $.16^{*}$ & $.27 * *$ & $.48^{* *}$ \\
\hline Realistic VP & $.50 * *$ & $.56^{* *}$ & -.03 & $.26 * *$ & $.29 * *$ & $.49 * *$ \\
\hline Realistic EA & -.003 & .01 & $.50 * *$ & $.18^{*}$ & .09 & .01 \\
\hline Realistic SE & $.23 * *$ & $.18^{* *}$ & .10 & $.67^{* *}$ & .13 & $.16^{*}$ \\
\hline Investigative PA & $.50 * *$ & $.53 * *$ & $.41^{* *}$ & $.30^{* *}$ & $.29 * *$ & $.31 * *$ \\
\hline Investigative VL & 1 & $.53 * *$ & .06 & $.36^{* *}$ & $.28 * *$ & $.54 * *$ \\
\hline Investigative VP & $.53^{* *}$ & 1 & $.15^{*}$ & $.30^{* *}$ & $.38^{* *}$ & $.45^{* *}$ \\
\hline Investigative EA & .06 & $.15^{*}$ & 1 & $.21^{* *}$ & -.03 & -.09 \\
\hline Investigative SE & $.36^{* *}$ & $.30^{* *}$ & $.21 * *$ & 1 & $.23 * *$ & $.19^{* *}$ \\
\hline Artistic PA & $.28 * *$ & $.38^{* *}$ & -.03 & $.23^{* *}$ & 1 & $.48^{* *}$ \\
\hline Artistic VL & $.54 * *$ & $.45^{* *}$ & -.09 & $.19^{* *}$ & $.48 * *$ & 1 \\
\hline Artistic VP & $.33^{* *}$ & $.43^{* *}$ & -.04 & $.20 * *$ & $.57 * *$ & $.60 * *$ \\
\hline Artistic EA & -.02 & .09 & $.35^{* *}$ & .07 & $.19^{* *}$ & .03 \\
\hline Artistic SE & .09 & $.15^{*}$ & .00 & $.55^{* *}$ & $.40^{* *}$ & $.28 * *$ \\
\hline Social PA & $.19^{* *}$ & $.22 * *$ & $.23 * *$ & .06 & $.22 * *$ & $.16^{*}$ \\
\hline Social VL & $.40^{* *}$ & $.35^{* *}$ & .06 & .03 & $.22 * *$ & $.40^{* *}$ \\
\hline Social VP & $.47 * *$ & $.51 * *$ & $.17 *$ & .11 & $.21^{* *}$ & $.38^{* *}$ \\
\hline Social EA & .02 & $.19^{* *}$ & $.44 * *$ & .03 & .10 & -.04 \\
\hline Social SE & .13 & .07 & .10 & $.45^{* *}$ & .05 & .07 \\
\hline Enterprising PA & $.33^{* *}$ & $.35^{* *}$ & .00 & .07 & $.36^{* *}$ & $.38 * *$ \\
\hline Enterprising VL & $.54 * *$ & $.47 * *$ & -.05 & .08 & $.39 * *$ & $.58 * *$ \\
\hline Enterprising VP & $.39 * *$ & $.43^{* *}$ & -.003 & .05 & $.28^{* *}$ & $.40 * *$ \\
\hline Enterprising EA & -.11 & .11 & $.44 * *$ & .00 & .05 & -.09 \\
\hline Enterprising SE & $.19^{* *}$ & $.14 *$ & .03 & $.46^{* *}$ & .13 & $.15^{*}$ \\
\hline Conventional PA & $.31 * *$ & $.30^{* *}$ & $.17^{*}$ & .04 & $.25^{* *}$ & $.28 * *$ \\
\hline Conventional VL & $.50 * *$ & $.47 * *$ & -.01 & .05 & $.30 * *$ & $.47 * *$ \\
\hline Conventional VP & $.54 * *$ & $.60 * *$ & -.02 & $.14^{*}$ & $.24 * *$ & $.48^{* *}$ \\
\hline Conventional EA & -.01 & .09 & $.54 * *$ & $.18^{*}$ & .07 & -.04 \\
\hline Conventional SE & $.22 * *$ & .13 & .12 & $.53 * *$ & -.03 & .11 \\
\hline
\end{tabular}




\begin{tabular}{|c|c|c|c|c|c|c|}
\hline & $\begin{array}{l}\text { Artistic } \\
\text { VP }\end{array}$ & $\begin{array}{l}\text { Artistic } \\
\text { EA }\end{array}$ & $\begin{array}{l}\text { Artistic } \\
\text { SE }\end{array}$ & $\begin{array}{l}\text { Social } \\
\text { PA }\end{array}$ & $\begin{array}{l}\text { Social } \\
\text { VL }\end{array}$ & $\begin{array}{l}\text { Social } \\
\text { VP }\end{array}$ \\
\hline Realistic PA & $.25 * *$ & .13 & $.17 *$ & $.21 * *$ & $.26 * *$ & $.25 * *$ \\
\hline Realistic VL & $.36^{* *}$ & .10 & .06 & $.37 * *$ & $.45^{* *}$ & $.45^{* *}$ \\
\hline Realistic VP & $.38^{* *}$ & -.01 & $.19^{* *}$ & .03 & $.21 * *$ & $.35 * *$ \\
\hline Realistic EA & .02 & $.38^{* *}$ & .08 & $.26^{* *}$ & .01 & .09 \\
\hline Realistic SE & .13 & .11 & $.47^{* *}$ & -.01 & .05 & .05 \\
\hline Investigative PA & $.33^{* *}$ & .12 & .09 & $.50 * *$ & $.32 * *$ & $.49 * *$ \\
\hline Investigative VL & $.33 * *$ & -.02 & $.19^{* *}$ & $.19^{* *}$ & $.40^{* * *}$ & $.47 * *$ \\
\hline Investigative VP & $.43^{* *}$ & .09 & $.15^{*}$ & $.22 * *$ & $.35^{* *}$ & $.51^{* *}$ \\
\hline Investigative EA & -.04 & $.35^{* *}$ & .00 & $.23^{* *}$ & .06 & $.17 *$ \\
\hline Investigative SE & $.20 * *$ & .07 & $.55^{* *}$ & .06 & .03 & .11 \\
\hline Artistic PA & $.57 * *$ & $.19^{* *}$ & $.40^{* *}$ & $.22 * *$ & $.22 * *$ & $.21 * *$ \\
\hline Artistic VL & $.60^{* *}$ & .03 & $.28^{* *}$ & $.16^{*}$ & $.40^{* *}$ & $.38 * *$ \\
\hline Artistic VP & 1 & .12 & $.38^{* *}$ & $.21 * *$ & $.32 * *$ & $.42 * *$ \\
\hline Artistic EA & .12 & 1 & $.17^{*}$ & $.21^{* *}$ & $.18^{*}$ & .13 \\
\hline Artistic SE & $.38^{* *}$ & $.17^{*}$ & 1 & -.01 & .05 & .06 \\
\hline Social PA & $.21 * *$ & $.21 * *$ & -.01 & 1 & $.50 * *$ & $.51 * *$ \\
\hline Social VL & $.32 * *$ & $.18^{*}$ & .05 & $.50^{* *}$ & 1 & $.57 * *$ \\
\hline Social VP & $.42 * *$ & .13 & .06 & $.51 * *$ & $.57 * *$ & 1 \\
\hline Social EA & .04 & $.46^{* *}$ & .05 & $.45 * *$ & $.24 * *$ & $.22 * *$ \\
\hline Social SE & .13 & .13 & $.49 * *$ & $.33^{* *}$ & $.28^{* *}$ & $.31 * *$ \\
\hline Enterprising PA & $.46^{* *}$ & $20 * *$ & .09 & $.57 * *$ & $.43 * *$ & $.47 * *$ \\
\hline Enterprising VL & $.47^{* *}$ & .04 & .12 & $.42 * *$ & $.50^{* *}$ & $.44^{* *}$ \\
\hline Enterprising VP & $.47^{* *}$ & .00 & .08 & $.33^{* *}$ & $.37^{* *}$ & $.54 * *$ \\
\hline Enterprising EA & .01 & $.43 * *$ & .03 & $.24^{* *}$ & .04 & .12 \\
\hline Enterprising SE & $.19^{* *}$ & .07 & $.59^{* *}$ & $.20^{* *}$ & $.17^{*}$ & $.19^{* *}$ \\
\hline Conventional PA & $.29 * *$ & .14 & -.01 & $.59^{* *}$ & $.40^{* *}$ & $.45^{* *}$ \\
\hline Conventional VL & $.35^{* *}$ & .04 & .05 & $.38^{* *}$ & $.53^{* *}$ & $.49^{* *}$ \\
\hline Conventional VP & $.46^{* *}$ & -.02 & .09 & $.34 * *$ & $.45^{* *}$ & $.66^{* *}$ \\
\hline Conventional EA & .10 & $.46^{* *}$ & .07 & $.26^{* *}$ & .08 & .13 \\
\hline Conventional SE & .09 & .01 & $.51^{* *}$ & .04 & .06 & .10 \\
\hline
\end{tabular}




\begin{tabular}{|c|c|c|c|c|c|c|}
\hline & $\begin{array}{l}\text { Social } \\
\text { EA }\end{array}$ & $\begin{array}{l}\text { Social } \\
\text { SE }\end{array}$ & $\begin{array}{l}\text { Enterprising } \\
\text { PA }\end{array}$ & $\begin{array}{l}\text { Enterprising } \\
\text { VL }\end{array}$ & $\begin{array}{l}\text { Enterprising } \\
\text { VP }\end{array}$ & $\begin{array}{l}\text { Enterprising } \\
\text { EA }\end{array}$ \\
\hline Realistic PA & .07 & $.20^{* *}$ & $.26^{* *}$ & $.42 * *$ & $.23 * *$ & -.02 \\
\hline Realistic VL & .10 & $.16^{*}$ & $.38^{* *}$ & $.50^{* * *}$ & $.31 * *$ & .03 \\
\hline Realistic VP & .00 & .09 & $.22 * *$ & $.43 * *$ & $.42 * *$ & -.13 \\
\hline Realistic EA & $.37 * *$ & $.17^{*}$ & .08 & .04 & -.01 & $.40 * *$ \\
\hline Realistic SE & -.01 & $.44 * *$ & .05 & .06 & .09 & -.02 \\
\hline Investigative PA & $.26^{* *}$ & $.16^{*}$ & $.49 * *$ & $.41 * *$ & $.41 * *$ & $.16^{*}$ \\
\hline Investigative VL & .02 & .13 & $.33^{* *}$ & $.54 * *$ & $.39 * *$ & -.11 \\
\hline Investigative VP & $.19 * *$ & .07 & $.35^{* *}$ & $.47 * *$ & $.43^{* *}$ & .11 \\
\hline Investigative EA & $.44 * *$ & .10 & .00 & -.05 & -.003 & $.44 * *$ \\
\hline Investigative SE & .03 & $.45 * *$ & .07 & .08 & .05 & .00 \\
\hline Artistic PA & .10 & .05 & $.36^{* *}$ & $.39 * *$ & $.28 * *$ & .05 \\
\hline Artistic VL & -.04 & .07 & $.38^{* *}$ & $.58^{* *}$ & $.40 * *$ & -.09 \\
\hline Artistic VP & .04 & .13 & $.46^{* *}$ & $.47 * *$ & $.47 * *$ & .01 \\
\hline Artistic EA & $.46^{* *}$ & .13 & $.20 * *$ & .04 & .00 & $.43 * *$ \\
\hline Artistic SE & .05 & $.49 * *$ & .09 & .12 & .08 & .03 \\
\hline Social PA & $.45^{* *}$ & $.33 * *$ & $.57 * *$ & $.42 * *$ & $.33 * *$ & $.24 * *$ \\
\hline Social VL & $.24 * *$ & $.28 * *$ & $.43^{* *}$ & $.50 * *$ & $.37 * *$ & .04 \\
\hline Social VP & $.22 * *$ & $.31 * *$ & $.47 * *$ & $.44 * *$ & $.54 * *$ & .12 \\
\hline Social EA & 1 & $.14 *$ & $.29 * *$ & $.17 *$ & .12 & $.59 * *$ \\
\hline Social SE & $.14 *$ & 1 & $.17^{*}$ & $.14 *$ & $.14 *$ & .06 \\
\hline Enterprising PA & $.29 * *$ & $.17^{*}$ & 1 & $.50 * *$ & $.56^{* *}$ & $.24 * *$ \\
\hline Enterprising VL & $.17^{*}$ & $.14 *$ & $.50 * *$ & 1 & $.44 * *$ & -.03 \\
\hline Enterprising VP & .12 & $.14 *$ & $.56^{* *}$ & $.44 * *$ & 1 & .10 \\
\hline Enterprising EA & $.59 * *$ & .06 & $.24 * *$ & -.03 & .10 & 1 \\
\hline Enterprising SE & .11 & $.71 * *$ & $.27 * *$ & $.21 * *$ & $.25^{* *}$ & .08 \\
\hline Conventional PA & $.27 * *$ & $.19^{* *}$ & $.54 * *$ & $.42 * *$ & $.43^{* *}$ & .10 \\
\hline Conventional VL & .13 & .05 & $.40 * *$ & $.68^{* *}$ & $.39 * *$ & .02 \\
\hline Conventional VP & .10 & $.15^{*}$ & $.48^{* *}$ & $.50 * *$ & $.63^{* *}$ & .03 \\
\hline Conventional EA & $.39 * *$ & $.18^{* *}$ & .13 & .03 & -.02 & $.35^{* *}$ \\
\hline Conventional SE & -.02 & $.66^{* *}$ & .03 & .10 & $.15^{*}$ &.-03 \\
\hline
\end{tabular}




\begin{tabular}{|c|c|c|c|c|c|c|}
\hline & $\begin{array}{l}\text { Enterprising } \\
\text { SE }\end{array}$ & $\begin{array}{l}\text { Conventional } \\
\text { PA }\end{array}$ & $\begin{array}{l}\text { Conventional } \\
\text { VL }\end{array}$ & $\begin{array}{l}\text { Conventional } \\
\text { VP }\end{array}$ & $\begin{array}{l}\text { Conventional } \\
\text { EA }\end{array}$ & $\begin{array}{l}\text { Conventional } \\
\text { SE }\end{array}$ \\
\hline Realistic PA & $.19 * *$ & $.31 * *$ & $.36^{* *}$ & $.34 * *$ & .06 & $.21 * *$ \\
\hline Realistic VL & .13 & $.42 * *$ & $.50 * *$ & $.45 * *$ & .12 & .10 \\
\hline Realistic VP & .11 & $.21^{* *}$ & $.35 * *$ & $.53^{* *}$ & -.08 & $.20 * *$ \\
\hline Realistic EA & .11 & $.16^{*}$ & .03 & -.06 & $.54 * *$ & .07 \\
\hline Realistic SE & $.47^{* *}$ & .09 & .01 & $.14^{*}$ & .13 & $.57 * *$ \\
\hline Investigative PA & $.19^{* *}$ & $.55^{* *}$ & $.35 * *$ & $.44^{* *}$ & $.23 * *$ & $.19^{* *}$ \\
\hline Investigative VL & $.19^{* *}$ & $.31^{* *}$ & $.50^{* *}$ & $.54 * *$ & -.01 & $.22 * *$ \\
\hline Investigative VP & $.14^{*}$ & $.30^{* *}$ & $.47 * *$ & $.60^{* *}$ & .09 & .13 \\
\hline Investigative EA & .03 & $.17^{*}$ & -.01 & -.02 & $.54 * *$ & .12 \\
\hline Investigative SE & $.46^{* *}$ & .04 & .05 & $.14^{*}$ & $.18^{*}$ & $.53 * *$ \\
\hline Artistic PA & .13 & $.25^{* *}$ & $.30 * *$ & $.24 * *$ & .07 & -.03 \\
\hline Artistic VL & $.15^{*}$ & $.28^{* *}$ & $.47 * *$ & $.48^{* *}$ & -.04 & .11 \\
\hline Artistic VP & $.19^{* *}$ & $.29 * *$ & $.35 * *$ & $.46^{* *}$ & .10 & .09 \\
\hline Artistic EA & .07 & $.14^{*}$ & .04 & -.02 & $.46^{* *}$ & .01 \\
\hline Artistic SE & $.59 * *$ & -.01 & .05 & .09 & .07 & $.51 * *$ \\
\hline Social PA & $.20^{* *}$ & $.59 * *$ & $.38 * *$ & $.34 * *$ & $.26^{* *}$ & .04 \\
\hline Social VL & $.17^{*}$ & $.40^{* *}$ & $.53^{* *}$ & $.45^{* *}$ & .08 & .06 \\
\hline Social VP & $.19^{* *}$ & $.45^{* *}$ & $.49^{* *}$ & $.66^{* *}$ & .13 & .10 \\
\hline Social EA & .11 & $.27 * *$ & .13 & .10 & $.39 * *$ & -.02 \\
\hline Social SE & $.71 * *$ & $.19^{* *}$ & .05 & $.15 *$ & $.18^{*}$ & $.66^{* *}$ \\
\hline Enterprising PA & $.27 * *$ & $.54 * *$ & $.40 * *$ & $.48^{* *}$ & .13 & .03 \\
\hline Enterprising VL & $.21 * *$ & $.42 * *$ & $.68 * *$ & $.50 * *$ & .03 & .10 \\
\hline Enterprising VP & $.25^{* *}$ & $.43 * *$ & $.39 * *$ & $.63 * *$ & -.02 & $.15^{*}$ \\
\hline Enterprising EA & .08 & .10 & .02 & .03 & $.35 * *$ & -.03 \\
\hline Enterprising SE & 1 & $.15^{*}$ & $.14 *$ & $.23 * *$ & $.14 *$ & $.77 * *$ \\
\hline Conventional PA & $.15^{*}$ & 1 & $.44 * *$ & $.42 * *$ & $.26^{* *}$ & .12 \\
\hline Conventional VL & $.14^{*}$ & $.44 * *$ & 1 & $.59^{* *}$ & .00 & .06 \\
\hline Conventional VP & $.23 * *$ & $.42 * *$ & $.59 * *$ & 1 & -.04 & $.21 * *$ \\
\hline Conventional EA & $.14 *$ & $.26 * *$ & .00 & -.04 & 1 & $.15 *$ \\
\hline Conventional SE & $.77^{* *}$ & .12 & .06 & $.21 * *$ & $.15^{*}$ & 1 \\
\hline
\end{tabular}

Note. $\mathrm{N}=2$ 208. $\mathrm{PA}=$ Performance Accomplishments; $\mathrm{VL}=$ Vicarious Learning; $\mathrm{VP}=$ Verbal Persuasion; EA = Emotional Arousal; SE = Self-Efficacy.

$* \mathrm{p}<.05 .{ }^{* *} \mathrm{p}<.01$ 


\section{APPENDIX I}

TABLE 21. CORRELATIONS AMONG PERFORMANCE ACCOMPLISHMENTS, VICARIOUS LEARNING, VERBAL PERSUASION, EMOTIONAL AROUSAL, AND OUTCOME EXPECTATIONS FOR ALL SIX RIASEC THEMES.

\begin{tabular}{|c|c|c|c|c|c|c|}
\hline & $\begin{array}{l}\text { Realistic } \\
\text { PA }\end{array}$ & $\begin{array}{l}\text { Realistic } \\
\text { VL }\end{array}$ & $\begin{array}{l}\text { Realistic } \\
\text { VP }\end{array}$ & $\begin{array}{l}\text { Realistic } \\
\text { EA }\end{array}$ & $\begin{array}{l}\text { Realistic } \\
\text { OE }\end{array}$ & $\begin{array}{l}\text { Investigative } \\
\text { PA }\end{array}$ \\
\hline Realistic PA & 1 & $.47 * *$ & $.54 * *$ & $.27 * *$ & $.20 * *$ & $.38 * *$ \\
\hline Realistic VL & $.47 * *$ & 1 & $.48 * *$ & $.18^{* *}$ & .01 & $.35^{* *}$ \\
\hline Realistic VP & $.54 * *$ & $.48 * *$ & 1 & .00 & $.26^{* *}$ & $.33 * *$ \\
\hline Realistic EA & $.27 * *$ & $.18^{* *}$ & .00 & 1 & .01 & $19 * *$ \\
\hline Realistic OE & $.20 * *$ & .01 & $.26 * *$ & .01 & 1 & -.05 \\
\hline Investigative PA & $.38^{* *}$ & $.35 * *$ & $.33 * *$ & $.19^{* *}$ & -.05 & 1 \\
\hline Investigative VL & $.39^{* *}$ & $.39 * *$ & $.50 * *$ & -.00 & $.15^{*}$ & $.50 * *$ \\
\hline Investigative VP & $.37 * *$ & $.37 * *$ & $.56^{* *}$ & .01 & .11 & $.53 * *$ \\
\hline Investigative EA & .05 & .06 & -.03 & $.50^{* *}$ & -.05 & $.41 * *$ \\
\hline Investigative $\mathrm{OE}$ & $.17 *$ & .02 & $.22 * *$ & -.01 & $.74 * *$ & .05 \\
\hline Artistic PA & $.31 * *$ & $.27 * *$ & $.29 * *$ & .09 & .05 & $.29 * *$ \\
\hline Artistic VL & $.45 * *$ & $.48 * *$ & $.49 * *$ & .01 & $.15^{*}$ & $.31 * *$ \\
\hline Artistic VP & $.25 * *$ & $.36^{* *}$ & $.38 * *$ & .02 & .03 & $.33 * *$ \\
\hline Artistic EA & .13 & .10 & $\begin{array}{l}-.01 \\
\end{array}$ & $.38 * *$ & -.07 & .12 \\
\hline Artistic OE & .04 & -.01 & .07 & -.07 & $.46 * *$ & -.09 \\
\hline Social PA & $.21^{* *}$ & $.37 * *$ & .03 & $.26^{* *}$ & $-.25 * *$ & $.50 * *$ \\
\hline Social VL & $.26 * *$ & $.45^{* *}$ & $.21 * *$ & .01 & -.02 & $.32 * *$ \\
\hline Social VP & $.25^{* *}$ & $.45^{* *}$ & $.35 * *$ & .09 & -.05 & $.49 * *$ \\
\hline Social EA & .07 & .10 & .00 & $.37 * *$ & $-.17 *$ & $.26 * *$ \\
\hline Social OE & .12 & $.14 *$ & .06 & .02 & $.36^{* *}$ & .04 \\
\hline Enterprising PA & $.26^{* *}$ & $.38^{* *}$ & $.22 * *$ & .08 & -.12 & $.49^{* *}$ \\
\hline Enterprising VL & $.42 * *$ & $.50 * *$ & $.43 * *$ & .04 & -.04 & $.41 * *$ \\
\hline Enterprising VP & $.23^{* *}$ & $.31 * *$ & $.42 * *$ & -.01 & -.03 & $.41 * *$ \\
\hline Enterprising EA & -.02 & .03 & -.13 & $.40 * *$ & $-.19 * *$ & $.16^{*}$ \\
\hline Enterprising OE & $.14 *$ & .05 & $.21 * *$ & -.08 & $.61^{* *}$ & .01 \\
\hline Conventional PA & $.31 * *$ & $.42 * *$ & $.21 * *$ & $.16^{*}$ & $-.17 *$ & $.55 * *$ \\
\hline Conventional VL & $.36^{* *}$ & $.50 * *$ & $.35 * *$ & .03 & -.05 & $.35 * *$ \\
\hline Conventional VP & $.34 * *$ & $.45 * *$ & $.53 * *$ & -.06 & .06 & $.44 * *$ \\
\hline Conventional EA & .06 & .12 & -.08 & $.54 * *$ & -.03 & $.23^{* *}$ \\
\hline Conventional OE & .13 & -.06 & $.22 * *$ & -.05 & $.63^{* *}$ & -.02 \\
\hline
\end{tabular}




\begin{tabular}{|c|c|c|c|c|c|c|}
\hline & $\begin{array}{l}\text { Investigative } \\
\text { VL }\end{array}$ & $\begin{array}{l}\text { Investigative } \\
\text { VP }\end{array}$ & $\begin{array}{l}\text { Investigative } \\
\text { EA }\end{array}$ & $\begin{array}{l}\text { Investigative } \\
\text { OE }\end{array}$ & $\begin{array}{l}\text { Artistic } \\
\text { PA }\end{array}$ & $\begin{array}{l}\text { Artistic } \\
\text { VL }\end{array}$ \\
\hline Realistic PA & $.39 * *$ & $.37 * *$ & .05 & $.17 *$ & $.31 * *$ & $.45 * *$ \\
\hline Realistic VL & $.39 * *$ & $.37 * *$ & .06 & .02 & $.27 * *$ & $.48 * *$ \\
\hline Realistic VP & $.50^{* *}$ & $.56 * *$ & -.03 & $.22 * *$ & $.29 * *$ & $.49 * *$ \\
\hline Realistic EA & -.00 & .01 & $.50 * *$ & -.10 & .09 & .01 \\
\hline Realistic OE & $.15^{*}$ & .11 & -.05 & $.74 * *$ & .05 & $.15^{*}$ \\
\hline Investigative PA & $.50^{* *}$ & $.53 * *$ & $.41 * *$ & .05 & $.29 * *$ & $.31 * *$ \\
\hline Investigative VL & 1 & $.53 * *$ & .06 & $28 * *$ & $28 * *$ & $.54 * *$ \\
\hline Investigative VP & $.53 * *$ & 1 & $.15^{*}$ & $.21 * *$ & $.38^{* *}$ & $.45^{* *}$ \\
\hline Investigative EA & .06 & $.15^{*}$ & 1 & .05 & -.03 & -.09 \\
\hline Investigative $\mathrm{OE}$ & $.28^{* *}$ & $.21 * *$ & .05 & 1 & .12 & $.17^{*}$ \\
\hline Artistic PA & $.28 * *$ & $.38^{* *}$ & -.03 & .12 & 1 & $.48^{* *}$ \\
\hline Artistic VL & $.54 * *$ & $.45^{* *}$ & -.09 & $.17 *$ & $.48 * *$ & 1 \\
\hline Artistic VP & $.33^{* *}$ & $.43^{* *}$ & -.04 & .08 & $.57 * *$ & $.60^{* *}$ \\
\hline Artistic EA & -.02 & .09 & $.35^{* *}$ & -.04 & $.19^{* *}$ & .03 \\
\hline Artistic OE & .07 & .01 & -.10 & $.55^{* *}$ & $.29 * *$ & $.16^{*}$ \\
\hline Social PA & $.19^{* *}$ & $.22 * *$ & $.23 * *$ & $-.17^{*}$ & $.22 * *$ & $.16^{*}$ \\
\hline Social VL & $.40^{* *}$ & $.35^{* *}$ & .06 & .03 & $.22 * *$ & $.40^{* *}$ \\
\hline Social VP & $.47 * *$ & $.51^{* *}$ & $.17^{*}$ & .01 & $.21^{* *}$ & $.38^{* *}$ \\
\hline Social EA & .02 & $.19 * *$ & $.44 * *$ & -.07 & .10 & -.04 \\
\hline Social OE & .09 & -.02 & -.00 & $.43^{* *}$ & -.00 & .04 \\
\hline Enterprising PA & $.33^{* *}$ & $.35^{* *}$ & .00 & -.08 & $.36^{* *}$ & $.38^{* *}$ \\
\hline Enterprising VL & $.54 * *$ & $.47 * *$ & -.05 & -.04 & $.39 * *$ & $.58 * *$ \\
\hline Enterprising VP & $.39 * *$ & $.43^{* *}$ & -.00 & -.08 & $.28 * *$ & $.40^{* *}$ \\
\hline Enterprising EA & -.11 & .11 & $.44 * *$ & -.12 & .05 & -.09 \\
\hline Enterprising OE & $.19^{* *}$ & .07 & $-.14 *$ & $.53 * *$ & .07 & .12 \\
\hline Conventional PA & $.31 * *$ & $.30^{* *}$ & $.17 *$ & $-.17 *$ & $.25^{* *}$ & $.28 * *$ \\
\hline Conventional VL & $.50 * *$ & $.47 * *$ & -.01 & .01 & $.30 * *$ & $.47 * *$ \\
\hline Conventional VP & $.54 * *$ & $.60 * *$ & -.02 & .11 & $.24 * *$ & $.48^{* *}$ \\
\hline Conventional EA & -.01 & .09 & $.54 * *$ & .02 & .07 & -.04 \\
\hline Conventional OE & $.15^{*}$ & .08 & -.07 & $.55^{*}$ & -.09 & .03 \\
\hline
\end{tabular}




\begin{tabular}{|c|c|c|c|c|c|c|}
\hline & $\begin{array}{l}\text { Artistic } \\
\text { VP }\end{array}$ & $\begin{array}{l}\text { Artistic } \\
\text { EA }\end{array}$ & $\begin{array}{l}\text { Artistic } \\
\text { OE }\end{array}$ & $\begin{array}{l}\text { Social } \\
\text { PA }\end{array}$ & $\begin{array}{l}\text { Social } \\
\text { VL }\end{array}$ & $\begin{array}{l}\text { Social } \\
\text { VP }\end{array}$ \\
\hline Realistic PA & $.25 * *$ & .13 & .04 & $.21 * *$ & $.26 * *$ & $.25 * *$ \\
\hline Realistic VL & $.36^{* *}$ & .10 & -.01 & $.37 * *$ & $.45^{* *}$ & $.45^{* *}$ \\
\hline Realistic VP & $.38^{* *}$ & -.01 & .07 & .03 & $.21 * *$ & $.35 * *$ \\
\hline Realistic EA & .02 & $.38 * *$ & -.07 & $.26 * *$ & .01 & .09 \\
\hline Realistic OE & .03 & $\begin{array}{l}-.07 \\
\end{array}$ & $.46^{* *}$ & $-.25 * *$ & -.02 & -.05 \\
\hline Investigative PA & $.33^{* *}$ & .12 & $\begin{array}{l}.09 \\
\end{array}$ & $.50 * *$ & $.32 * *$ & $.49 * *$ \\
\hline Investigative VL & $.33^{* *}$ & -.02 & .07 & $.19^{* *}$ & $.40^{* *}$ & $.47 * *$ \\
\hline Investigative VP & $.43^{* *}$ & .09 & .01 & $.22 * *$ & $.35 * *$ & $.51^{* *}$ \\
\hline Investigative EA & -.04 & $.35^{* *}$ & .10 & $.23 * *$ & .06 & $.17^{*}$ \\
\hline Investigative $\mathrm{OE}$ & .08 & -.04 & $.55^{* *}$ & $-.17^{*}$ & .03 & .01 \\
\hline Artistic PA & $.57 * *$ & $.19^{* *}$ & $.29 * *$ & $.22 * *$ & $.22 * *$ & $.21^{* *}$ \\
\hline Artistic VL & $.60^{* *}$ & .03 & $.16^{*}$ & $.16^{*}$ & $.40 * *$ & $.38 * *$ \\
\hline Artistic VP & 1 & .12 & $.29 * *$ & $.21 * *$ & $.32 * *$ & $.42 * *$ \\
\hline Artistic EA & .12 & 1 & .03 & $.21 * *$ & $.18^{* *}$ & .13 \\
\hline Artistic OE & $.29 * *$ & .03 & 1 & -.09 & .05 & .02 \\
\hline Social PA & $.21^{* *}$ & $.21 * *$ & -.09 & 1 & $.50 * *$ & $.51^{* *}$ \\
\hline Social VL & $.32 * *$ & $.18^{* *}$ & .05 & $.50 * *$ & 1 & $.57 * *$ \\
\hline Social VP & $.42 * *$ & .13 & .02 & $.51 * *$ & $.57 * *$ & 1 \\
\hline Social EA & .04 & $.46^{* *}$ & -.01 & $.45^{* *}$ & $.24 * *$ & $.22 * *$ \\
\hline Social OE & .09 & -.02 & $.52 * *$ & $.17^{*}$ & $.30^{* *}$ & $.25^{* *}$ \\
\hline Enterprising PA & $.46^{* *}$ & $.20 * *$ & .01 & $.57 * *$ & $.43^{* *}$ & $.47 * *$ \\
\hline Enterprising VL & $.47 * *$ & .04 & -.02 & $.42 * *$ & $.50 * *$ & $.44 * *$ \\
\hline Enterprising VP & $.47 * *$ & .00 & -.02 & $.33^{* *}$ & $.37 * *$ & $.54 * *$ \\
\hline Enterprising EA & .01 & $.43 * *$ & -.07 & $.24 * *$ & .04 & .12 \\
\hline Enterprising OE & .11 & $-.16^{*}$ & $.54 * *$ & -.08 & .05 & .06 \\
\hline Conventional PA & $.29 * *$ & $.14^{*}$ & $-.14^{*}$ & $.59 * *$ & $.40^{* *}$ & $.45^{* *}$ \\
\hline Conventional VL & $.35^{* *}$ & .04 & .00 & $.38 * *$ & $.53 * *$ & $.49 * *$ \\
\hline Conventional VP & $.46^{* *}$ & -.02 & .02 & $.34 * *$ & $.45^{* *}$ & $.66^{* *}$ \\
\hline Conventional EA & .10 & $.46^{* *}$ & -.03 & $.26^{* *}$ & .08 & .13 \\
\hline Conventional OE & -.01 & -.13 & $.41 * *$ & $-.22 * *$ & -.06 & .00 \\
\hline
\end{tabular}




\begin{tabular}{|c|c|c|c|c|c|c|}
\hline & $\begin{array}{l}\text { Social } \\
\text { EA }\end{array}$ & $\begin{array}{l}\text { Social } \\
\text { OE }\end{array}$ & $\begin{array}{l}\text { Enterprising } \\
\text { PA }\end{array}$ & $\begin{array}{l}\text { Enterprising } \\
\text { VL }\end{array}$ & $\begin{array}{l}\text { Enterprising } \\
\text { VP }\end{array}$ & $\begin{array}{l}\text { Enterprising } \\
\text { EA }\end{array}$ \\
\hline Realistic PA & .07 & .12 & $.26 * *$ & $.42 * *$ & $.23 * *$ & -.02 \\
\hline Realistic VL & .10 & $.14^{*}$ & $.38 * *$ & $.50 * *$ & $.31 * *$ & .03 \\
\hline Realistic VP & .00 & .06 & $.22 * *$ & $.43 * *$ & $.42 * *$ & -.13 \\
\hline Realistic EA & $.37 * *$ & .02 & .08 & .04 & -.01 & $.40 * *$ \\
\hline Realistic OE & $-.17 *$ & $.37 * *$ & -.12 & -.04 & -.03 & $-.19 * *$ \\
\hline Investigative PA & $.26^{* *}$ & .04 & $.49 * *$ & $.41 * *$ & $.41 * *$ & $.16^{*}$ \\
\hline Investigative VL & .02 & .09 & $.33 * *$ & $.54 * *$ & $.39 * *$ & -.11 \\
\hline Investigative VP & $.19^{* *}$ & -.02 & $.35^{* *}$ & $.47 * *$ & $.43 * *$ & .11 \\
\hline Investigative EA & $.44 * *$ & -.00 & .00 & -.05 & -.00 & $.44 * *$ \\
\hline Investigative $\mathrm{OE}$ & -.07 & $.43 * *$ & -.08 & -.04 & -.08 & -.12 \\
\hline Artistic PA & .10 & -.00 & $.36^{* *}$ & $.39^{* *}$ & $.28 * *$ & .05 \\
\hline Artistic VL & -.04 & .04 & $.38^{* *}$ & $.58 * *$ & $.40 * *$ & -.09 \\
\hline Artistic VP & .04 & .09 & $.46^{* *}$ & $.47 * *$ & $.47 * *$ & .01 \\
\hline Artistic EA & $.46^{* *}$ & -.02 & $.20 * *$ & .04 & .00 & $.43 * *$ \\
\hline Artistic OE & -.01 & $.52 * *$ & .01 & -.02 & -.02 & -.07 \\
\hline Social PA & $.45^{* *}$ & $.17 *$ & $.57 * *$ & $.42 * *$ & $.33 * *$ & $.24 * *$ \\
\hline Social VL & $.24 * *$ & $.30^{* *}$ & $.43 * *$ & $.50 * *$ & $.37 * *$ & .04 \\
\hline Social VP & $.22 * *$ & $.25^{* *}$ & $.47 * *$ & $.44 * *$ & $.54 * *$ & .12 \\
\hline Social EA & 1 & .01 & $.29 * *$ & $.17^{*}$ & .12 & $.59 * *$ \\
\hline Social OE & .01 & 1 & .08 & .06 & .08 & -.04 \\
\hline Enterprising PA & $.29 * *$ & .08 & 1 & $.50^{* *}$ & $.56 * *$ & $.24 * *$ \\
\hline Enterprising VL & $.17^{*}$ & .06 & $.50^{* *}$ & 1 & $.44 * *$ & -.03 \\
\hline Enterprising VP & .12 & .08 & $.56^{* *}$ & $.44 * *$ & 1 & .10 \\
\hline Enterprising EA & $.59 * *$ & -.04 & $.24 * *$ & $\begin{array}{l}-.03 \\
\end{array}$ & .10 & 1 \\
\hline Enterprising OE & $\begin{array}{l}-.07 \\
\end{array}$ & $.54 * *$ & .04 & .11 & $.20 * *$ & -.178 \\
\hline Conventional PA & $.27 * *$ & .09 & $.54 * *$ & $.42 * *$ & $.43 * *$ & .10 \\
\hline Conventional VL & .13 & .07 & $.40^{* *}$ & $.68^{* *}$ & $.39 * *$ & .02 \\
\hline Conventional VP & .10 & .12 & $.48^{* *}$ & $.50 * *$ & $.63^{* *}$ & .03 \\
\hline Conventional EA & $.39 * *$ & .03 & .13 & .03 & -.02 & $.35^{* *}$ \\
\hline Conventional OE & $-.15^{*}$ & $.44 * *$ & -.13 & .00 & .07 & -.20 \\
\hline
\end{tabular}




\begin{tabular}{|c|c|c|c|c|c|c|}
\hline & $\begin{array}{l}\text { Enterprising } \\
\text { OE }\end{array}$ & $\begin{array}{l}\text { Conventional } \\
\text { PA }\end{array}$ & $\begin{array}{l}\text { Conventional } \\
\text { VL }\end{array}$ & $\begin{array}{l}\text { Conventional } \\
\text { VP }\end{array}$ & $\begin{array}{l}\text { Conventional } \\
\text { EA }\end{array}$ & $\begin{array}{l}\text { Conventional } \\
\text { OE }\end{array}$ \\
\hline Realistic PA & .148 & $.31 * *$ & $.36^{* * *}$ & $.34 * *$ & .06 & .13 \\
\hline Realistic VL & .05 & $.42 * *$ & $.50^{* *}$ & $.45^{* *}$ & .12 & -.06 \\
\hline Realistic VP & $.21 * *$ & $.21 * *$ & $.35^{* *}$ & $.53^{* *}$ & -.08 & $.22 * *$ \\
\hline Realistic EA & $\begin{array}{l}-.08 \\
\end{array}$ & $.16^{*}$ & .03 & -.06 & $.54 * *$ & -.05 \\
\hline Realistic OE & $.61^{* *}$ & $-.17 *$ & -.05 & .06 & $\begin{array}{l}-.03 \\
\end{array}$ & $.63^{* *}$ \\
\hline Investigative PA & .01 & $.55^{* *}$ & $.35^{* *}$ & $.44 * *$ & $.23 * *$ & -.02 \\
\hline Investigative VL & $.19 * *$ & $.31 * *$ & $.50 * *$ & $.54 * *$ & -.01 & $.15^{*}$ \\
\hline Investigative VP & .07 & $.30 * *$ & $.47 * *$ & $.60^{* *}$ & .09 & .08 \\
\hline Investigative EA & $-.14 *$ & $.17 *$ & -.01 & -.02 & $.54 * *$ & -.07 \\
\hline Investigative $\mathrm{OE}$ & $.53^{* *}$ & $-.17^{*}$ & .01 & .11 & .02 & $.55^{* *}$ \\
\hline Artistic PA & .07 & $.25 * *$ & $.30^{* *}$ & $.24 * *$ & .07 & $\begin{array}{l}-.09 \\
\end{array}$ \\
\hline Artistic VL & .12 & $.28 * *$ & $.47 * *$ & $.48^{* *}$ & -.04 & .03 \\
\hline Artistic VP & .11 & $.29 * *$ & $.35^{* *}$ & $.46^{* *}$ & .10 & -.01 \\
\hline Artistic EA & $-.16^{*}$ & $.14 *$ & .04 & $\begin{array}{l}-.02 \\
\end{array}$ & $.46^{* *}$ & -.13 \\
\hline Artistic OE & $.54 * *$ & $-.14^{*}$ & .00 & .02 & -.03 & $.41 * *$ \\
\hline Social PA & -.08 & $.59 * *$ & $.38^{* *}$ & $.34 * *$ & $.26^{* *}$ & $-.22 * *$ \\
\hline Social VL & .05 & $.40^{* *}$ & $.53 * *$ & $.45^{* *}$ & .08 & -.06 \\
\hline Social VP & .06 & $.45^{* *}$ & $.49 * *$ & $.66^{* *}$ & .13 & .00 \\
\hline Social EA & -.07 & $.27 * *$ & .13 & .10 & $.39 * *$ & $-.15^{*}$ \\
\hline Social OE & $.54 * *$ & .09 & .07 & .12 & .03 & $.44 * *$ \\
\hline Enterprising PA & .04 & $.54 * *$ & $.40 * *$ & $.48^{* *}$ & .13 & -.13 \\
\hline Enterprising VL & .11 & $.42 * *$ & $.68^{* *}$ & $.50^{* *}$ & .03 & .00 \\
\hline Enterprising VP & $.20 * *$ & $.43^{* *}$ & $.39 * *$ & $.63^{* *}$ & -.02 & .07 \\
\hline Enterprising EA & $-.17 *$ & .10 & .02 & .03 & $.35^{* *}$ & $-.20 * *$ \\
\hline Enterprising OE & 1 & -.04 & .10 & $.18^{* *}$ & -.11 & $.81 * *$ \\
\hline Conventional PA & -.04 & 1 & $.44 *$ & $.42 * *$ & $.26 * *$ & -.13 \\
\hline Conventional VL & .10 & $.44 * *$ & 1 & $.59 * *$ & .00 & -.00 \\
\hline Conventional VP & $.18^{* *}$ & $.42 * *$ & $.59 * *$ & 1 & -.04 & .09 \\
\hline Conventional EA & -.11 & $.26 * *$ & .00 & -.04 & 1 & -.06 \\
\hline Conventional OE & $.81 * *$ & -.13 & -.00 & .09 & -.06 & 1 \\
\hline
\end{tabular}

Note. $\mathrm{N}=2$ 208. $\mathrm{PA}=$ Performance Accomplishments; $\mathrm{VL}=$ Vicarious Learning; $\mathrm{VP}=$ Verbal Persuasion; $\mathrm{EA}=$ Emotional Arousal; $\mathrm{OE}=$ Outcome Expectations.

$* \mathrm{p}<.05 . * * \mathrm{p}<.01$. 
APPENDIX J

\section{IRB APPROVAL LETTERS}

This appendix includes two IRB approval letters. The first letter included is the IRB approval letter from the University of Akron. The second letter included is the IRB approval letter from The Ohio State University. Both letters indicate that this study qualified for exemption from continuing IRB review and presented minimal risk to the research subjects. In addition, both letters indicate that this research was also exempt from documentation of informed consent. 


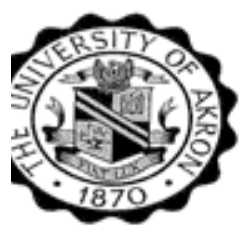

Office of Research Services and Sponsored Programs

Akron, $\mathrm{OH}$ 44325-2102.

330i $972-7666$ Ottice

(330) $972-6281$ Fax

March 6, 2006

Josephine Dickinson, M.A.

489 Barwetl St.

Akron, Ohío 44303

Ms. Dickinson:

The University of Akron's Institutional Review Board for the Protection of Human Subjects (IRB) completed a review of the protocol entitled "An Examination of the Applicability of Social Cognitive Career Theory for African American College Students". The IRB application number assigned to this project is 20060307.

The protocol was reviewed on March 3, 2006 and qualified for exemption from continuing IRB review. The protocol represents minimal risk to subjects and matches the following federal category for exemption?

(2) Research imvolving the use of educational tests (cognitive, diognostic, optitude, achievement), survey procedures, interview procedures or abservation of public behavior, unless: (i) information is recorded in such a manner that subjects can be identified, directly or through identifiers linked to subjects; AND (ii) any disclosure of responses outside the research could reasonably place the subjects at risk of civil or criminal liability or be damaging to subjects' financial standing, employability or reputation

Enclosed is a copy of the informed consent document, which the IRB has approved for your use in this research. In addition, your request for a waiver of documentation of informed consent, as permitted under 45 CFR $46.117(\mathrm{c})$, is also approved.

Annual contimuation applications are not required for exempt projects. If you make any changes or modifications to the study's design or procedures that either increase the risk to subjects or include activities that do not fall within one of the categories exempted from the regulations, please contact the IRB first, to discuss whether or not a request for change must be submitted. Any such changes or modifications must be reviewed and approved by the IRB prior to their implementation.

Please retain this letter for your fles. If the research is being conducted for a master's thesis or doctoral dissertation, the student must file a copy of this letter with the thesis or dissertation.

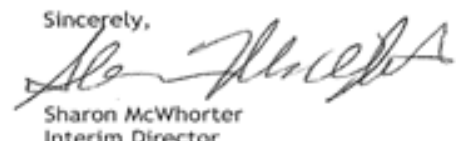

Interim Director

\section{Cc: David Tokar, Advisor \\ Chair}

Phil Allen, IRB Chair 


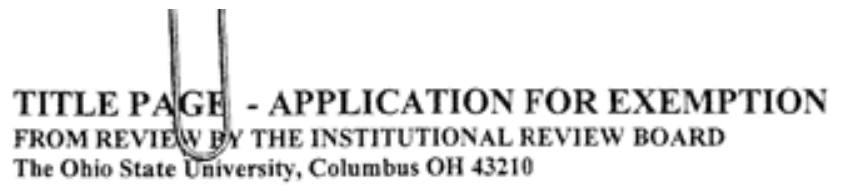

REL'D MAR 14 ZUUb FROM REVIEWW BY THE INSTITUTIONAL REVIEW BOARD The Ohio State University, Columbus OH 4321

For office use only

PROTOCOL NUMBER: 200600203

\begin{tabular}{|c|c|c|}
\hline -Principal Investigator & Name: Nancy Betz, Ph.D. & Phone: $292-4166$ \\
\hline \multirow{3}{*}{$\begin{array}{l}\text { University Title: } \\
\text { X Professor } \\
\square \text { Associate Professor } \\
\square \text { Assistant Professor } \\
\text { Instructor } \\
\text { (May require prior approval.) }\end{array}$} & Department or College: Psychology & \multirow[t]{2}{*}{ E-mail: betz.3@osu.edu } \\
\hline & $\begin{array}{l}\text { Campus Address (room, building, street address): } \\
\text { O60 Psychology } \\
1835 \text { Neil Avenue } \\
\text { Columbus, OH } 43210\end{array}$ & \\
\hline & Signature: & $688-3984$ \\
\hline \multirow{3}{*}{$\begin{array}{l}\text { C } 0 \text {-Investigator } \\
\text { University Status: } \\
\square \text { Faculty } \\
\text { X Staff } \\
\square \text { Graduate Student } \\
\square \text { Undergraduate Student } \\
\square \text { Other. Please specify. }\end{array}$} & Name: Josephine Dickinson, M.A. & Phone: $292-5766$ \\
\hline & $\begin{array}{l}\text { Campus Address (room, building, street address) or } \\
\text { Mailing Address: } \\
\text { Counseling and Consultation Service } \\
\text { Younkin Success Center- } 4^{\text {th }} \text { Floor } \\
1640 \text { Neil Avenue } \\
\text { Columbus, OH } 43210-4333\end{array}$ & $\begin{array}{l}\text { E-mail: } \\
\text { dickinson.52@osu.edu }\end{array}$ \\
\hline & 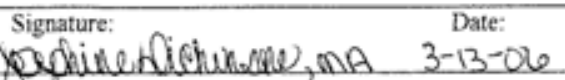 & Fax: $\quad 688-3440$ \\
\hline - $\mathrm{C}_{0}$-Investigator & Name: & Phone: \\
\hline \multirow{2}{*}{$\begin{array}{l}\text { University Status: } \\
\square \text { Faculty } \\
\text { Staff } \\
\text { Graduate Student } \\
\text { Undergraduate Student } \\
\square \text { Other. Please specify. }\end{array}$} & $\begin{array}{l}\text { Campus Address (room, building, street address) or } \\
\text { Mailing Address: }\end{array}$ & E-mail: \\
\hline & Signature: & Fax: \\
\hline
\end{tabular}

\begin{tabular}{|l|l|}
\hline Protocol Title & $\begin{array}{l}\text { An Examination of the Applicability of Social Cognitive Career Theory for African } \\
\text { American College Students. }\end{array}$
\end{tabular}

\begin{tabular}{|l|l|}
\hline Source of Funding & N/A \\
\hline For Office Use Omly \\
\hline Approved.
\end{tabular}

